\title{
BAIXO PESO AO NASCER E A POLUIÇÃO DO AR NO MUNICÍPIO DE SÃO PAULO
}

\author{
Dissertação apresentada à Faculdade de \\ Medicina da Universidade de São Paulo para \\ obtenção do título de Mestre em Ciência. \\ Área de Concentração: Medicina Preventiva. \\ Orientador: Prof. Dr. Nelson Gouveia.
}


Dissertação apresentada à Faculdade de Medicina da Universidade de São Paulo para obtenção do título de Mestre em Ciência.

Área de Concentração: Medicina Preventiva.

Orientador: Prof. Dr. Nelson Gouveia. 
Dedico este trabalho às pessoas que mais amo:

Ao meu pai, Prof. Edson, que com seu exemplo de caráter e integridade foi meu primeiro e mais importante professor.

À minha mãe, Cidinha, pelo amor e dedicação, pelo exemplo de autenticidade e também pela formação humanística, ensinando-me respeitar e valorizar as pessoas.

Aos meus irmãos, Luciano e Juliano, pelo carinho e pelas saudosas lembranças dos inocentes anos de infância e adolescência.

À minha tia Cidinha e meus primos, Félix e Valtinho, pelo amor e amizade sempre presentes.

Ao meu marido, João José, pelo amor dedicado e pelo companheirismo sempre presente nestes sete anos de convivência. Sempre demonstrou solidariedade e afeto nos momentos difíceis e compartilhou com satisfação os de alegria. SNosso amor nos presenteou com nosso querido filho.

Ao meu filho, João José, minha maior riqueza, minha preciosidade, meu encanto. 


\section{AGRADECIMENTOS}

Completar este trabalho tem sido uma experiência rica e inesquecivel. Mais do que adquirir novos conhecimentos que irão melhorar meu desempenho como professora, eu pude contar com a colaboração de pessoas importantes, algumas velhas conhecidas e outras que vim a conhecer durante este período. Sem elas, provavelmente, este momento não chegaria.

Ao meu querido pai, meu melhor amigo e maior incentivador. Homem de visão sempre à frente do seu tempo, dotado de inteligência impar. Agradeço as oportunidades, orientação, confiança e amor. A ele meu amor eterno.

À querida Profa. Dra. Ana Maria Tsanaclis, meu exemplo de médica e pesquisadora, com conhecimentos múltiplos e profundos em diversas áreas. Soma-se a esta profissional exemplar uma figura humana, sensivel, amiga e companheira. Foi quem me encaminhou ao Departamento de Medicina Preventiva, apresentando-me ao Dr. José Eluf $\mathcal{N}$ eto, com quem pude realizar a disciplina pela qual é responsável, como aluna especial. $\mathcal{N a ̃ o}$ bastasse essa ajuda, foi minha colega e amiga, alguém que me acolheu com muito carinho num lugar por mim antes desconhecido. $\mathcal{A}$ ela meu eterno agradecimento e amizade.

Agradeço imensamente o Prof. Dr. NNelson Gouveia, excelente profissional, com muito conhecimento, sensivel e um grande amigo. Pessoa de fundamental importância por tudo aquilo que pude aprender, tanto em relação à estatística, quanto na elaboração da 
dissertação. Sinto-me presenteada por ter tido tão brilhante orientador e espero ter feito jus à sua dedicação. Ao amigo Nelson minha eterna gratidão.

A Prof. Maria Elisa Moreira, profissional exemplar, uma figura humana impar, amiga e sensivel. Agradeço pela maneira carinhosa e acolhedora com que me recebeu no momento que eu precisa de uma orientação profissional. Acreditou em meu potencial $e$ influenciou diretamente a minha carreira profissional. $\mathcal{A}$ amiga Maria Elisa minha eterna gratidão e amizade.

$\mathcal{N}$ o início desta jornada tive grandes dificuldades em lidar com os programas estatísticos e com banco de dados imensos. Foi nesse momento que tive a sorte de contar com a ajuda do Prof. Dr. Luiz Fernando Costa Nascimento, excelente médico e pesquisador, que gentilmente me ensinou a trabalhar com o computador e com a epidemiologia, mas mais do que isso, ele foi e continua sendo um grande amigo.

Ao Prof. Dr. Paulo Hilário Nascimento Saldiva, importante pesquisador, com profundos conhecimentos, generoso ao compartilhá-los com aqueles que o procuram. Fui recebida por ele como se já nos conhecêssemos de longa data. Ao me apresentar, mostrou-se muito receptivo, respondendo prontamente a minha dúvida quanto ao meu trabalho de dissertação. Como senão 6astasse, convidou-me para ir ao Laboratório de Poluição Atmosférica Experimental para conhecer uma das pesquisas que estava sendo desenvolvida e que poderia contribuir nos meus resultados. Ao Prof. Saldiva meus sinceros agradecimentos. 
Um especial agradecimento aos Professores José Eluf Neto, Hillegonda Maria Dutilh Novaes e Maria Regina Afves Cardoso, membros da banca de qualificação, por terem feito sugestões fundamentais para a melhoria desta dissertação. 


\section{SUMÁRIO}

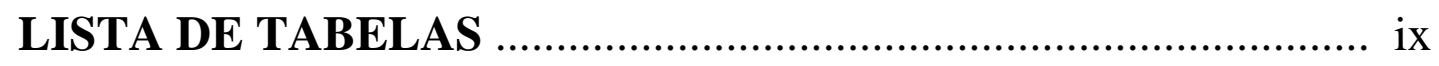

LISTA DE QUADROS ......................................................... xii

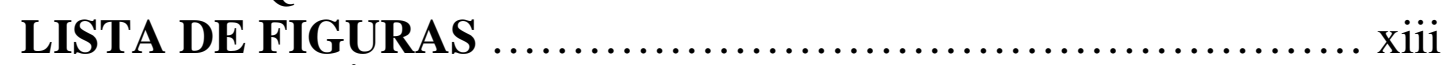

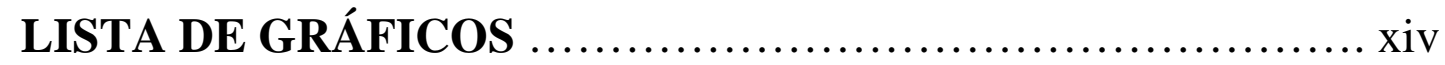

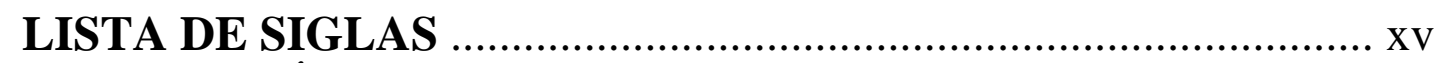

LISTA DE SÍMBOLOS .......................................................... xvi

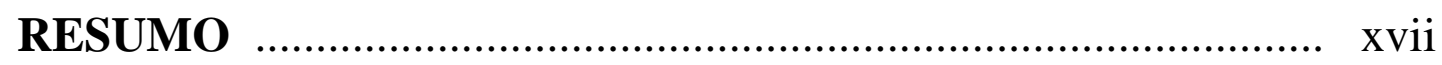

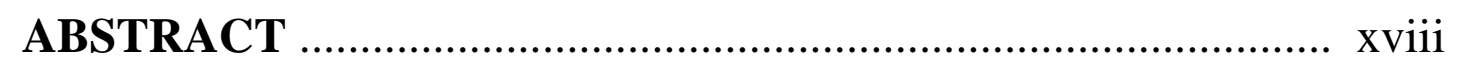

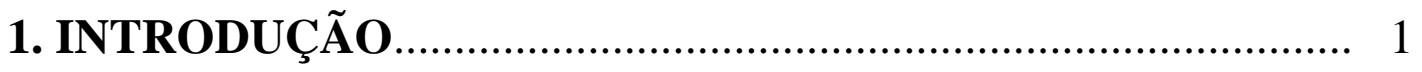

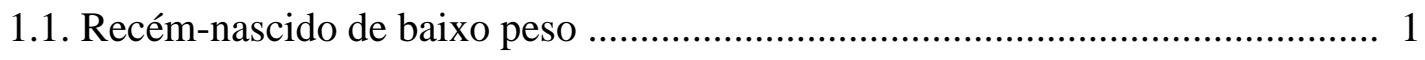

1.1.1. Conceito e classificação do RNBP ................................................. 6

1.1.2. RNBP nos países desenvolvidos e em desenvolvimento ................ 9

1.1.3. Sistema de Informação Sobre os Nascidos Vivos (SINASC) ............. 11

1.1.4.. Determinantes do peso ao nascer ........................................................ 14

1.2. Poluição atmosférica ...……………………………………………………....19

1.2.1. Poluição do ar e saúde ...…………………………………………... 23

1.2.2. Poluição do ar e RNBP ................................................................ 26

1.3. Poluição atmosférica e o crescimento urbano .................................................... 28

1.3.1. A cidade de São Paulo: sua história, seu crescimento industrial ........ 29

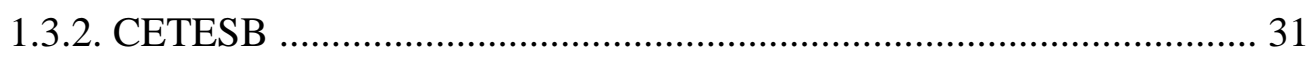

1.3.3. Índices de Qualidade do Ar .................................................................. 32

1.3.4. Clima e características sazonais da poluição do ar no município de São Paulo

1.4. Justificativa ................................................................................................ 35 
3. METODOLOGIA _......................................................................

3.1. Local e População de estudo .................................................................. 38

3.1.1. Critérios de inclusão do RN e definição de BPN ............................ 38

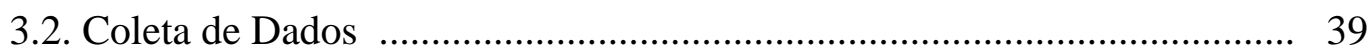

3.2.1. Nascidos Vivos .............................................................................. 40

3.2.2. Poluição do Ar ........................................................................................ 43

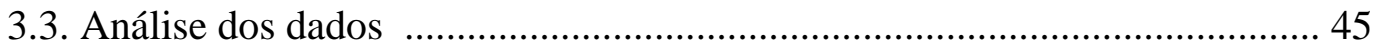

3.3.1. Análise Descritiva ............................................................................... 45

3.3.2. Análises Univariada e Multivariada ...................................................... 46

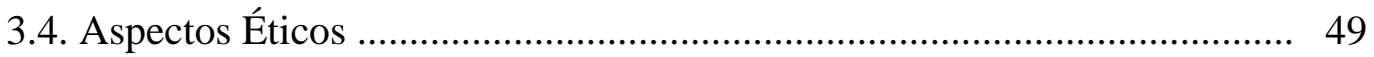

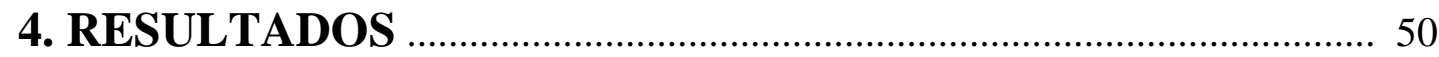

4.1. Descrição ……………………………………………………………………. 50

4.2. Análise Univariada ...…………………………………………………..... 58

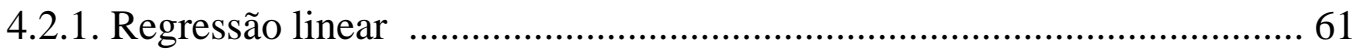

4.2.2. Regressão logística .................................................................................. 62

4.3. Análise Multivariada ....................................................................................... 64

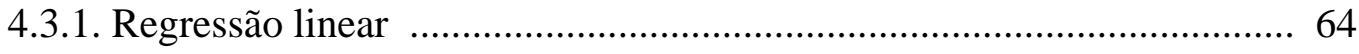

4.3.2. Regressão logística ............................................................................. 65

4.3.3. Modelo com múltiplos poluentes ........................................................ 67

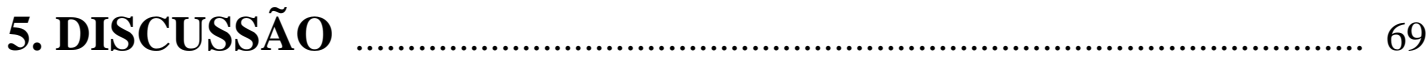

5.1. Estudos Epidemiológicos sobre baixo peso ao nascer e poluição do ar ............ 73

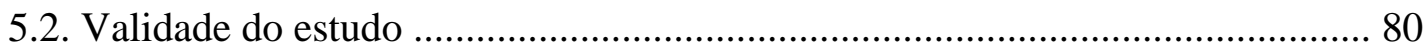


5.2.1. Erro aleatório 80

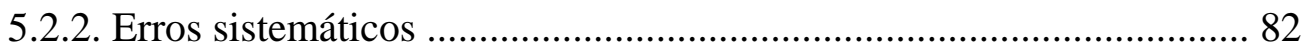

5.2.2.1. Viés de informação ..........................................................82

5.2.2.2. Viés de seleção ............................................................. 86

5.2.2.3. Situação de confusão (confundimento) .............................. 87

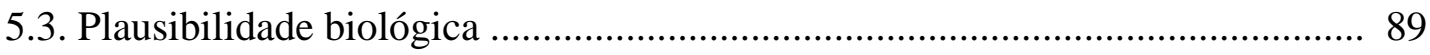

5.4. Medidas adotadas para o controle da poluição do ar em São Paulo ................. 93

5.5. Implicações da poluição do ar e do BPN para a saúde pública ....................... 94

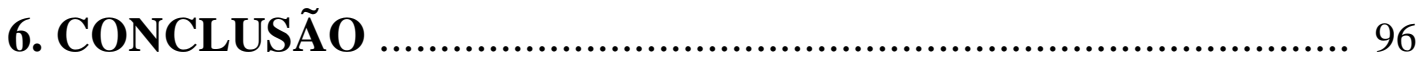

7. REFERÊNCIAS BIBLIOGRÁFICAS .......................................... 97

8. BIBLIOGRAFIA CONSULTADA ........................................... 108

9. ANEXO 


\section{LISTA DE TABELAS}

TABELA 1 - PREVALÊNCIA E OR COM RESPECTIVOS INTERVALOS DE CONFIANÇA (IC 95\%) DE BAIXO PESO AO NASCER (<2500G), DOS NASCIDOS VIVOS NO MUNICÍPIO DE SÃO PAULO DE MÃES RESIDENTES NESTA CIDADE NO PERÍODO ENTRE 1998 E 2000, SEGUNDO VARIÁVEIS RELATIVAS À MÃE, RECÉM-NASCIDO, GESTAÇÃO E PARTO.

TABELA 2 - ANÁLISE DESCRITIVA DO PESO AO NASCER DO RN E IDADE MATERNA NO MUNICÍPIO DE SÃO PAULO ENTRE 1998 E 2000 (N=595.559).

TABELA 3 - DISTRIBUIÇÃO DOS NASCIDOS VIVOS NO MUNICÍPIO DE SÃO PAULO DE MÃES RESIDENTES NESTA CIDADE NO PERÍODO DE 2 ANOS (1999 E 2000), SEGUNDO MALFORMAÇÃO CONGÊNITA E ESTADO CIVIL

TABELA 4 - ANÁLISE DESCRITIVA DOS NÍVEIS DIÁRIOS DE POLUIÇÃO DO AR NO MUNICÍPIO DE SÃO PAULO ENTRE 1998 E 2000.

TABELA 5 - VALORES DAS CONCENTRAÇÕES DOS POLUENTES DO AR DE ACORDO COM O ÍNDICE DA QUALIDADE DO AR

TABELA 6 - DISTRIBUIÇÃO DA MÉDIA DO PESO AO NASCER E DA MÉDIA DOS POLUENTES DO AR, COM SEUS RESPECTIVOS DESVIOS-PADRÕES (DP), DE ACORDO COM OS MESES DO ANO CORRESPONDENTES ÀS ESTAÇÕES DO ANO.

TABELA 7 - PREVALÊNCIA E OR COM RESPECTIVOS INTERVALOS DE CONFIANÇA (IC 95\%) DE BAIXO PESO AO NASCER (<2500G), DOS NASCIDOS VIVOS A TERMO E NÃO GEMELARES NO MUNICÍPIO DE SÃO PAULO (EXCLUINDO REGIÕES MAIS PERIFÉRICAS) DE MÃES RESIDENTES NESTA CIDADE NO PERÍODO ENTRE 1998 E 2000, SEGUNDO VARIÁVEIS RELATIVAS À MÃE, RECÉM-NASCIDO, GESTAÇÃO E PARTO.

TABELA 8 - VARIAÇÃO DO PESO AO NASCER PARA CADA $1 \mu \mathrm{g} / \mathrm{m}^{3}$ DE AUMENTO NA EXPOSIÇÃO MÉDIA MATERNA AOS POLUENTES DO AR (EXCETO CO PARA O QUAL É USADA A MEDIDA DE 1ppm) EM CADA TRIMESTRE DA GESTAÇÃO, NO MUNICÍPIO DE SÃO PAULO ENTRE 1998 E 2000 (ANÁLISE LINEAR UNIVARIADA).

TABELA 9 - ODDS RATIO (OR), INTERVALOS DE CONFIANÇA (IC 95\%) PARA BAIXO PESO AO NASCER DE ACORDO COM OS QUARTIS DE CONCENTRAÇÃO DOS POLUENTES ATMOSFÉRICOS EM CADA TRIMESTRE GESTACIONAL, NO MUNICÍPIO DE SÃO PAULO ENTRE 1998 E 2000 (ANÁLISE LOGÍSTICA UNIVARIADA) 
TABELA 10 - COEFICIENTES DE REGRESSÃO COM SEUS RESPECTIVOS DESVIOS-PADRÕES (DP) E INTERVALOS DE CONFIANÇA DE 95\%, SEGUNDO AS MÉDIAS TRIMESTRAIS DA CONCENTRAÇẤO DOS POLUENTES ATMOSFÉRICOS CORRESPONDENTES AOS TRIMESTRES GESTACIONAIS (REGRESSÃO LINEAR MÚLTIPLA)

TABELA 11 - ODDS RATIO (OR), INTERVALOS DE CONFIANÇA (IC 95\%) PARA BAIXO PESO AO NASCER DE ACORDO COM OS QUARTIS DE CONCENTRAÇÃO DOS POLUENTES ATMOSFÉRICOS EM CADA TRIMESTRE GESTACIONAL, NO MUNICÍPIO DE SÃO PAULO ENTRE 1998 E 2000 (REGRESSÃO LOGÍSTICA MÚLTIPLA). 


\section{LISTA DE QUADROS}

QUADRO 1 - PADRÕES DE QUALIDADE DO AR ADOTADOS PELO BRASIL, ESTADOS UNIDOS E ORGANIZAÇÃO MUNDIAL DE SAÚDE.......... 34

QUADRO 2 - LOCALIZAÇÃO DAS ESTAÇÕES MONITORAS DO MUNICÍPIO DE SÃO PAULO DE ACORDO COM OS POLUENTES QUE MEDEM.. 


\section{LISTA DE FIGURAS}

FIGURA 1 - CURVA DE CRESCIMENTO INTRA-UTERINO

FIGURA 2 - MAPA DA REGIÃO METROPOLITANA DE SÃO PAULO COM AS ESTAÇÕES MONITORAS..

FIGURA 3 - MAPA DO MUNICÍPIO DE SÃO PAULO COM AS ESTAÇÕES MONITORAS E OS DISTRITOS INCLUÍDOS NO ESTUDO. 


\section{LISTA DE GRÁFICOS}

GRÁFICO 1 - MÉDIA DIÁRIA DO PESO DO RN DE MÃES RESIDENTES NO MUNICÍPIO DE SÃO PAULO NO PERÍODO ENTRE $1998 \mathrm{E}$ 2000.

GRÁFICO 2 - MÉDIAS DIÁRIAS DE PM ${ }_{10}\left(\mu \mathrm{g} / \mathrm{m}^{3}\right)$ NO MUNICÍPIO DE SÃO PAULO ENTRE 1998 E 2000

GRÁFICO 3 - MÉDIAS DIÁRIAS DE $\mathrm{NO}_{2}\left(\mu \mathrm{g} / \mathrm{m}^{3}\right)$ NO MUNICÍPIO DE SÃO PAULO ENTRE 1998 E 2000 55

GRÁFICO 4 - MÉDIAS DIÁRIAS DE SO ${ }_{2}\left(\mu \mathrm{g} / \mathrm{m}^{3}\right)$ NO MUNICÍPIO DE SÃO PAULO ENTRE 1998 E 2000 56

GRÁFICO 5 - MÉDIAS DIÁRIAS DE CO (ppm) NO MUNICÍPIO DE SÃO PAULO ENTRE 1998 E 2000. 56

GRÁFICO 6 - MÉDIAS DIÁRIAS DE $\mathrm{O}_{3}\left(\mu \mathrm{g} / \mathrm{m}^{3}\right)$ NO MUNICÍPIO DE SÃO PAULO ENTRE 1998 e 2000. 


\section{LISTA DE SIGLAS}

$\begin{array}{ll}\text { ACTH } & \text { - adrenocorticotrofina } \\ \text { BPN } & \text { - Baixo Peso ao Nascer } \\ \text { CETESB } & \text { - Companhia de Tecnologia de Saneamento Ambiental } \\ \text { CAPPESQ } & \text { - Comissão de Ética para Análise de Projetos de Pesquisa } \\ \text { CONAMA } & \text { - Conselho Nacional do Meio Ambiente } \\ \text { DN } & \text { - Declaração de Nascido Vivo } \\ \text { DP } & \text { - Desvio-Padrão } \\ \text { EPA } & \text { - Environmental Protection Agency } \\ \text { FIBGE } & \text { - Fundação Instituto Brasileiro de Geografia e Estatística } \\ \text { HAP } & \text { - Hidrocarbono Aromático Policíclico } \\ \text { HLC } & \text { - Hormônio Liberador de Corticotrofina } \\ \text { IBGE } & \text { - Instituto Brasileiro de Geografia e Estatística } \\ \text { IC } & \text { - Intervalo de Confiança } \\ \text { IMC } & \text { - Índice de Massa Corporal } \\ \text { OMS } & \text { - Organização Mundial da Saúde } \\ \text { OR } & \text { - Odds ratio } \\ \text { PIG } & \text { - Pequeno para Idade Gestacional } \\ \text { PROCONVE } & \text { - Programa de Controle da Poluição do ar por Veículos } \\ & \text { Automotores } \\ \text { PTS } & \text { - Partículas Totais em Suspensão } \\ \text { RCIU } & \text { - Retardado de Crescimento Intra-Uterino } \\ \text { RMSP } & \text { - Região Metropolitana de São Paulo } \\ \text { RN } & \text { - Recém-Nascido } \\ \text { RNBP } & \text { - Recém-Nascido Baixo Peso } \\ \text { RNs } & \text { - Recém-Nascidos } \\ \text { SEADE } & \text { - Sistema Estadual de Análise de Dados } \\ \text { SINASC } & \text { - Sistema de Informação Sobre os Nascidos Vivos }\end{array}$




\section{LISTA DE SÍMBOLOS}

$\% \quad$ - Por cento

CO - Monóxido de Carbono

NOx - Óxidos de Nitrogênios

NO2 - Dióxido de Nitrogênio

O3 - Ozônio

PM10 - Material Particulado

SO2 - Dióxido de Enxofre 
RESUMO

\section{MEDEIROS, A.P.P. Baixo peso ao nascer e a poluição do ar no município de São}

Paulo. São Paulo, 2004.

O peso ao nascer é um fator importante na determinação da morbi-mortalidade neonatal e da mortalidade pós-neonatal, sendo assim de grande importância para a saúde pública, dada a freqüência com que o mesmo ocorre. A Organização Mundial de Saúde considera o baixo peso ao nascer (BPN) como o fator isolado mais importante na sobrevivência infantil. Inúmeros fatores de risco têm sido descritos como associados à ocorrência de BPN, por exemplo, o tabagismo materno e o baixo nível sócioeconômico. Mais recentemente, a poluição do ar tem sido investigada como possível determinante do BPN. A distribuição do peso ao nascer na cidade de São Paulo (média 3.160g com 8,9\% de BPN) é inferior àquela esperada quando se têm ótimas condições de crescimento fetal (média de 3.400-3.500g com 4-5\% de BPN). Esta distribuição tem se mantido estável nos últimos 22 anos, apesar da evolução favorável do estado nutricional das gestantes, da assistência pré-natal e do hábito de fumar durante a gestação. No entanto, são altos os índices de poluição atmosférica em São Paulo, fator que pode estar afetando o desenvolvimento intra-uterino das crianças que aqui nascem. Este estudo foi realizado com a intenção de avaliar uma possível associação do baixo peso ao nascer e a poluição do ar no município de São Paulo. Para tanto foram analisados todos os nascimentos de mães residentes neste município nos anos de 1998 a 2000. As informações sobre esses nascidos vivos foram obtidas do SINASC (Sistema de Informação sobre Nascidos Vivos) através de seu instrumento, a Declaração de Nascido Vivo (DN). Os dados de poluição do ar foram obtidos junto à Companhia de Tecnologia de Saneamento Ambiental (CETESB) que forneceu os registros diários das concentrações de dióxido de enxofre (SO2), partículas em suspensão (PM10), monóxido de carbono (CO), ozônio (O3) e dióxido de nitrogênio (NO2). O efeito da exposição materna à poluição do ar, em cada trimestre da gestação sobre a incidência de recémnascidos de baixo peso foi examinado através de modelos de regressão linear e logística. A exposição materna ao PM10, CO, NO2 e SO2 durante o $1^{\circ}$ trimestre de gestação mostrou associação estatisticamente significante com a diminuição no peso do recémnascido. Para um aumento na exposição média materna, durante o $1^{\circ}$ trimestre de gestação, de $1 \mathrm{ppm}$ de $\mathrm{CO}$, observou-se uma diminuição no peso de nascimento de $11,9 \mathrm{~g}$. 


\begin{abstract}
MEDEIROS APP. Low birth weight and air pollution in the city of São Paulo. São Paulo, 2004.
\end{abstract}

The birth weight is an important factor of the morbi-mortality neonatal determination and of the mortality neonatal, and then of big importance to public health, due frequency that it occurs. Therefore, the Health World Organization considers the low birth weight (LBW) the most important isolated factor in childhood survival. A lot of risk factors have been described as associated to LBW occurrence, for example, the mother smoker and low social-economic level(nível sócio-econômico). Recently, the air pollution has been investigated as possible LBW determinant. The distribution of birth weight in the city of São Paulo (average 3.160g with $8.9 \%$ of LBW) is inferior to that one expected when having good conditions of fetal growth (average between 3400-3500g with 4-5\% of LBW). This distribution has been kept stable for the last 22 years, despite of favorable evolution of the nutritional state of the pregnants, pre-birth assistance and the habit of smoking during the pregnancy. However, the indices of atmospheric pollution are high in São Paulo, this factor can be affecting the development intra-uterine of the children that are born here. Considering the factor that the LBW prevalence in the city of São Paulo city has stayed stable for the last twenty years, that is, a high prevalence, and the fact of São Paulo has high rates of air pollution, it's possible to suppose that the air pollution can be affecting the intra-uterine development of childhood are born. Therefore, it claims to realize a study to value a possible association of LBW and the air pollution in the city of São Paulo. All the births of mothers living in this city between 19982000 were analysed. The information about these born-alive was obtained from Sistema de Informação sobre Nascidos Vivos (SINASC) through of yours instrument, the Declaração de Nascido Vivo (DN). The information about air pollution was obtained from Compahia de Tecnologia de Saneamento Ambiental (CETESB), that supplied the daily registers of sulphur dioxide (SO2), particulate matter (PM10), carbon monoxide (CO), ozone (O3) and nitrogen dioxide (NO2). The effect of mother exposure to air pollution, each pregnancy trimester about the LBW prevalence was made on linear and logistic models. The maternal exposure to $\mathrm{PM}_{10}$, $\mathrm{CO}, \mathrm{NO}_{2}$ and $\mathrm{SO}_{2}$ during the first trimester of pregnancy showed association statistically significant with the decrease in the weight of the new-born child. For an increasing in the maternal average exposure, during the first trimester of pregnancy, in $1 \mathrm{ppm}$ of CO, was observed a decrease of $11.9 \mathrm{~g}$ in the weight born. 


\section{INTRODUÇÃO}

\subsection{Recém-nascido baixo peso}

A saúde do recém-nascido $(\mathrm{RN})$ pode ser analisada sob diversas formas, entre elas o peso ao nascer. Uma criança com baixo peso ao nascer (BPN), ou seja, pesando menos que $2500 \mathrm{~g}$, já inicia sua vida em desvantagem, pois esta condição exerce grande influência sobre o seu estado de saúde e sua chance de sobrevivência (MONTEIRO et al, 2000). O peso ao nascer é um fator importante na determinação da morbi-mortalidade neonatal (até 27 dias de vida) e da mortalidade pós-neonatal (entre 28 dias e 11 meses de vida), sendo assim de grande importância para a saúde pública, dada a freqüência com que o mesmo ocorre (COSTA; GOTLIEB, 1998).

Embora a mortalidade infantil tenha declinado substancialmente, tanto nos países desenvolvidos como nos países em desenvolvimento, este declínio não foi devido a redução das crianças nascidas com baixo peso (KRAMER, 2003), mas às melhorias do cuidado pré-natal, da assistência hospitalar e da puericultura. No entanto, esse declínio tem sido mais lento nos países em desenvolvimento do que nos países desenvolvidos. Essa redução da mortalidade infantil foi observada para todos os nascidos vivos, incluindo os de peso normal. Por outro lado, os nascimentos prematuros aumentaram em ambos os grupos de países, devido principalmente, a maior freqüência das intervenções obstétricas, motivadas em reduzir o risco de natimortos, de mortalidade materna e de morbidade da criança, o que contribui para o aumento do número de recém-nascidos com baixo peso (JOSEPH et al, 2002). Além disso, nos países desenvolvidos o aumento de partos múltiplos (atribuído aos 
tratamentos hormonais e à assistência de tecnologia de reprodução para infertilidade) é também responsável pela maior freqüência de nascimentos prematuros e conseqüentemente de crianças com BPN. Nos países em desenvolvimento, além do aumento de partos prematuros, há também uma grande freqüência de recém-nascido pequeno para idade gestacional resultante do crescimento fetal intra-uterino retardado. Dessa forma, apesar da queda da mortalidade infantil, o baixo peso ao nascer cresce em importância, seja em decorrência do aumento da freqüência de prematuros ou de pequenos para idade gestacional.

O BPN é o maior determinante da mortalidade infantil. Quanto menor o peso ao nascer, maior o risco de mortalidade no primeiro ano de vida, sendo o BPN responsável por dois terços de todas as mortes neonatais (MARIOTONI; FILHO, 2000). Já a mortalidade pós-neonatal não é tão estreitamente relacionada com o peso ao nascer. Por exemplo, um estudo realizado por NETO e BARROS (2000), mostrou que a magnitude da associação do baixo peso ao nascer com a mortalidade é mais acentuada no período neonatal, embora persista uma associação de menor magnitude com a mortalidade pós-neonatal.

Vários estudos brasileiros têm detalhado os riscos relativos de mortalidade infantil associada ao BPN, entre eles, Bailey et al (1990) e Menezes et al (1996). Supondo-se um risco relativo de 9,0 para mortalidade infantil em recém-nascidos com menos de $2500 \mathrm{~g}$ comparados com os de peso normal, uma redução de $8,5 \%$ para $7,0 \%$ na prevalência do BPN preveniria 7,1\% de todas as mortes infantis (VICTORA, 2001). 
No Brasil, a mortalidade infantil vem declinando nas últimas décadas, mas esse declínio tem sido mais lento do que para a maioria dos países americanos (VICTORA, 2001). Dependendo da região brasileira, grandes diferenças ainda são encontradas. Por exemplo, no Nordeste o coeficiente de mortalidade infantil foi quase três vezes mais alto do que o observado no Sul e Sudeste no período entre 1995 a 1997. Além disso, as maiores causas de mortes infantis registradas no Brasil foram as afecções originadas no período perinatal, (período entre $22^{\mathrm{a}}$ semana de gravidez e $7^{\mathrm{o}}$ dia de vida), sendo responsáveis por $46,5 \%$ da mortalidade infantil entre 1985 a 1987 e por 56,8\% no período entre 1995 a 1997 (VICTORA, 2001). Dentre as causas perinatais estão o $\mathrm{BPN}$, prematuridade, a síndrome de sofrimento respiratório, hipóxia ou anóxia e outros problemas respiratórios. Segundo o Ministério da Saúde (1998), o BPN e prematuridade foram responsáveis por $13,0 \%$ da mortalidade por causas perinatais em 1985.

A contribuição do BPN para a morbidade na infância não é tão evidente como para a mortalidade infantil. Mesmo assim, a literatura científica aponta uma série de problemas de saúde para o recém-nascido com baixo peso. Entre os problemas imediatos que podem acometer o recém-nascido estão o sofrimento respiratório, hipoglicemia, hipocalcemia e hipermagnesemia. Se o baixo peso for em decorrência de um crescimento intra-uterino retardado, a criança estará sujeita a problemas como síndrome da angústia respiratória idiopática, hiperbilirrubinemia, hipoglicemia e hemorragia pulmonar. Este recém-nascido também terá maior risco às infecções e às malformações congênitas. Quando a prematuridade for a responsável pelo ganho de peso inadequado dos recém-nascidos, as patologias mais importantes serão a 
dificuldade respiratória (atelectasia, pneumonia, síndrome da membrana hialina), asfixia neonatal, enterocolite necrotizante, hemorragia cerebral entre outros (LUZ, 1997). Somando-se a isto, as técnicas de cuidados intensivos usados para aumentar a sobrevivência dos RNs não estão livres de risco e podem resultar em complicações (BITTAR et al, 2002).

Os indivíduos que sofrem um inadequado crescimento intra-uterino poderão ter repercussões ao longo da vida. Os problemas vão além do aumento da mortalidade e morbidade neonatal, pois na infância poderão apresentar déficit no desenvolvimento neurológico e cognitivo, como a dificuldade na linguagem e no aprendizado. Na vida adulta os riscos serão maiores para o surgimento de hipertensão arterial sistêmica, hipercolesterolemia, doença cardiovascular, doença pulmonar obstrutiva, diabetes e insuficiência renal (KEIRSE, 2000).

Frente a um problema que pode ter repercussões tanto a curto como a longo prazo, a Organização Mundial da Saúde (OMS) tem como meta incentivar a diminuição de nascimentos com menos de $2500 \mathrm{~g}$, o que conseqüentemente favorecerá a diminuição da mortalidade infantil bem como de morbidades (MARIOTONI; FILHO, 2000).

A ocorrência de BPN varia entre países, podendo indicar o nível de saúde de uma população por estar muito associado às condições sócio-econômicas. Assim, na Índia, segundo dados da OMS, a freqüência de recém-nascidos com baixo peso era de $30 \%$, enquanto que dados do Banco Mundial referem, para Alemanha unificada e Canadá, em 1992, respectivamente, 5,7\% e 6\% (NASCIMENTO; GOTLIEB, 2001). 
Nos Estados Unidos a freqüência de BPN aumentou de 6,8\% em 1985 (DIVISION OF NUTRITION, 1994) para 7,5\% em 1997 (GUYER et al, 1998). No entanto, quando são analisadas apenas as gestações únicas, este aumento é substancialmente menor. Com relação às mães brancas, observou-se uma freqüência de recém-nascidos com BPN de 6,3\% em 1996 que pode ser atribuído ao aumento dos nascimentos múltiplos. Para mães negras esta freqüência foi de 13,0\% em 1996, sendo que este maior risco observado possa ser em decorrência da alta prevalência de nascimentos pré-termo nesta população (17,4\% dos recém-nascidos negros e 9,8\% dos brancos).

No Brasil a freqüência de BPN vem aumentando em algumas cidades nos últimos anos. Em Pelotas houve um aumento de 9\% em 1982 para 9,8\% em 1993 (HORTA et al, 1996), já em Ribeirão Preto foi de 7,2\% em 1978-9 para 10,6\% em 1994 (BARBIERI et al, 2000). Os fatores associados a este aumento não são completamente conhecidos (SILVA et al, 2001a). No estudo realizado em Ribeirão Preto por Barbieri et al (2000) foi constatado em 1994 um aumento da freqüência do BPN para ambos os tipos de parto, mas sendo mais acentuado para os partos operatórios. No entanto, no município de São Paulo, a prevalência de BPN não se alterou de forma significativa nas últimas décadas e em 1995 era de 9,2\%, ou seja, não houve aumento, mas a prevalência não é baixa (ALMEIDA et al, 2002). A cidade pode ter atingido o seu limite, um patamar estável de ocorrência do BPN. Isto pode ser em decorrência de inúmeros fatores. Apesar da redução da mortalidade infantil e das melhorias de saneamento e de saúde que vem ocorrendo, outros fatores podem estar contribuindo para manter uma alta prevalência de crianças com baixo peso, por 
exemplo, o tratamento da fertilidade, o aumento da freqüência das cesáreas e dos partos pré-termos, além de outros possíveis fatores.

\subsubsection{Conceito e classificação do recém-nascido com baixo peso}

Uma criança pode apresentar baixo peso ao nascer devido a menor duração da gestação ou ao retardo de crescimento intra-uterino, sendo considerada respectivamente, prematura e pequena para idade gestacional (HORTA et al, 1996). Antigamente, por volta de 1940, todas as crianças nascidas com peso inferior a $2500 \mathrm{~g}$ eram consideradas prematuras (BITTAR et al, 2002). O valor de referência, 2500g, foi baseado no trabalho de um pediatra finlandês que havia demonstrado que crianças com menos de 2500 g não tinham bons prognósticos em relação aquelas pesando acima desse valor (YLLPÖ, 1920 apud KEIRSE, 2000). Ao definir prematuridade dessa forma, pouco se pensou no fato de que partos gemelares podem apresentar grandes diferenças no peso, mas sua idade gestacional é a mesma (KEIRSE, 2000). Atualmente sabe-se que peso ao nascer e idade gestacional são fatores importantes mas distintos. Assim, de acordo com a Organização Mundial da Saúde (1961) a denominação prétermo é atribuída ao recém-nascido com menos de 37 semanas completas (menos de 259 dias) de gestação, enquanto que baixo peso ao nascer é para os que nascem com menos de $2500 \mathrm{~g}$ (até $2499 \mathrm{~g}$ inclusive), mas independente da duração da gestação (BITTAR et al, 2002). 
A existência do retardado de crescimento intra-uterino (RCIU) foi demonstrada por Warkany et al (1961), e posteriormente por Gruenwald (1963). Entretanto, as curvas de crescimento fetal passaram a ter importância com os estudos de Lubchenco et al (1967). Definiu-se assim que o pequeno para idade gestacional (PIG) é aquele cujo peso de nascimento está abaixo do percentil 10 para sua idade gestacional, tendo como referência a curva de crescimento intra-uterino (LUBCHENCO et al, 1972). Deve-se lembrar que há a possibilidade das duas condições estarem associadas, ou seja, ser prematuro e pequeno para idade gestacional (HORTA et al, 1996). Dessa forma, o recém-nascido baixo peso (RNBP) pode ser de termo e apresentar um retardo do crescimento intra-uterino, ser prematuro podendo ter ou não um crescimento normal ou até ser um pós-termo pequeno (BITTAR et al, 2002).

Este tipo de classificação pode ser melhor compreendida ao se analisar a curva de crescimento intra-uterino (FIGURA 1). Nela está apresentada a relação entre peso ao nascer em gramas segundo a idade gestacional em semanas, a partir de 24 semanas de gestação. Categoriza as crianças de acordo com os seguintes percentis: abaixo de 10 (pequena para idade gestacional), entre 10 e 90 (apropriada para idade gestacional) e acima de 90 (grande para idade gestacional) (BATTAGLIA; LUBCHENCO, 1967). Autores como MARGOTTO (1995) e SATANDER et al (1992) mostram que a utilização dos dados da curva de LUBCHENCO et al (1972) pode levar a uma subestimação das freqüências de BPN porque foi realizada quando não se conheciam fatores que alteram o crescimento fetal, como por exemplo a hipertensão materna, hábito de fumar e o baixo nível sócio-econômico (ALMEIDA; JORGE, 1998). Assim, 
ao classificar o recém-nascido utilizando-se esta curva, há risco de subdiagnosticar o pequeno para idade gestacional.

Os recém-nascidos considerados como PIG dependem da curva de crescimento intra-uterino usada como referência, pois esta curva apresenta resultados distintos, dependendo das características da população e das possíveis exclusões realizadas nas amostras do estudo que a padronizou.

Existem curvas de crescimento com dados da população brasileira (BRENELLI, 1992; MARGOTTO, 1995), cujos valores de referência, entre idade gestacional e peso ao nascer, iniciam em 29 semanas de idade gestacional. Esta curva fornece maior comparabilidade quanto à composição da população, porém seriam excluídos os recém-nascidos de menor idade gestacional que podem apresentar retardo de crescimento intra-uterino, e conseqüentemente podendo subestimar a importância desse fator de risco de mortalidade neonatal.

Dessa forma, a utilização da curva de crescimento intra-uterino de LUBCHENCO et al (1972) como referência, permite a identificação do PIG a partir de 24 semanas de gestação, e parece ser a mais adequada para estudar a influência do retardo de crescimento intra-uterino sobre a mortalidade neonatal. Independente das crianças serem classificadas como de BPN, prematuras ou PIG, todas são mais vulneráveis às intercorrências a partir do seu nascimento. 
FIGURA 1 - CURVA DE CRESCIMENTO INTRA-UTERINO

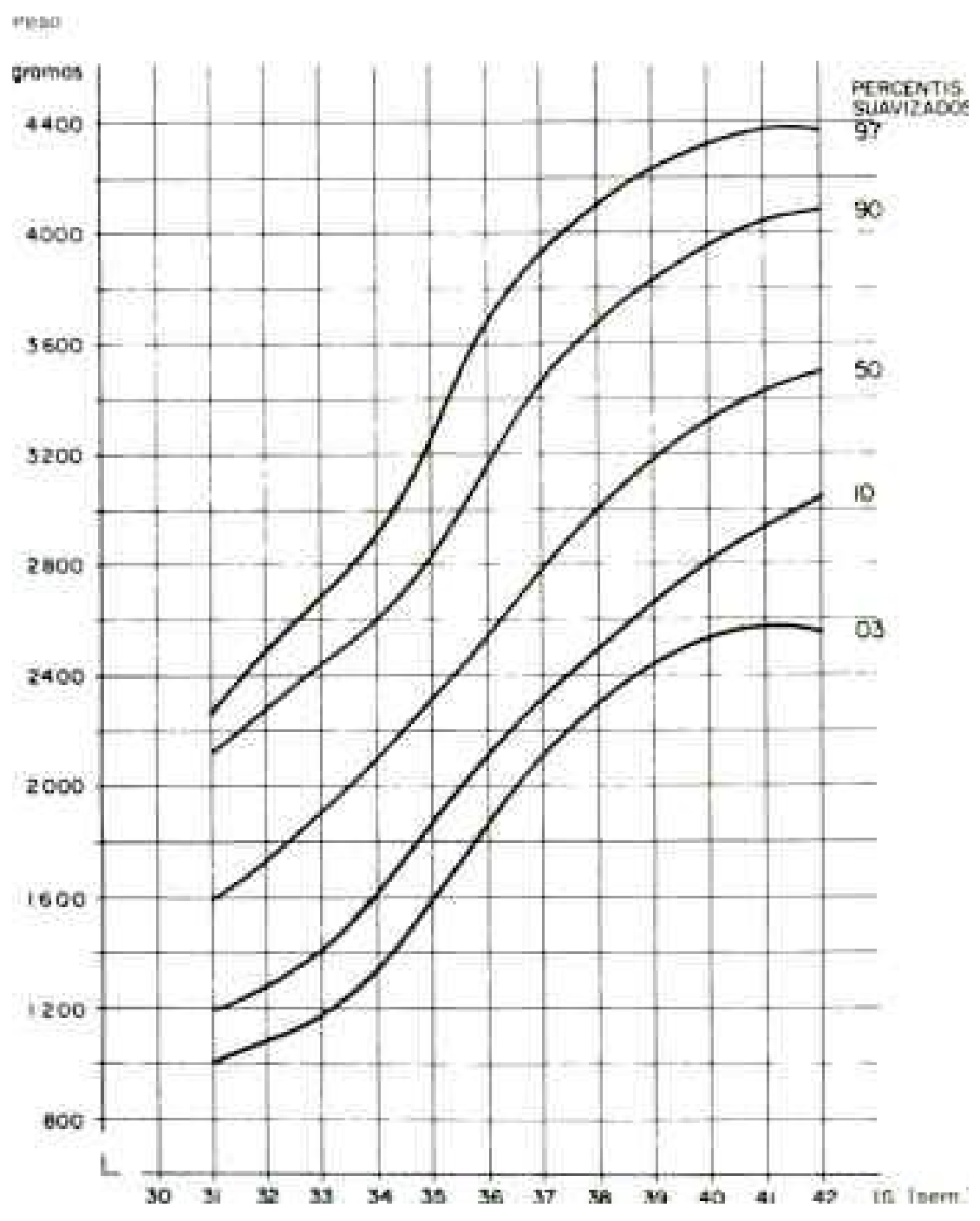

\subsubsection{Recém-nascido com baixo peso nos países desenvolvidos e em desenvolvimento}

Dependendo da situação sócio-econômica de um país, os fatores determinantes do recém-nascido com baixo peso variam, e conseqüentemente sua classificação será 
influenciada, por exemplo, destacando-se mais a presença de prematuros num determinado país do que em outro.

Enquanto a prematuridade está mais presente nos países desenvolvidos, onde os determinantes específicos são as anormalidades placentárias e a incompetência do colo uterino, o retardo de crescimento intra-uterino aparece mais nos países em desenvolvimento devido a uma série de fatores, onde se destaca o consumo calórico insuficiente durante a gravidez (HORTA et al, 1996).

Nos últimos anos tem sido demonstrado que a prevalência do BPN tem diminuído em muitas partes do mundo devido às melhorias dos cuidados à saúde e dos padrões de vida da população (CHIKE-OBI et al, 1996). No entanto, como anteriormente referido, esta prevalência vem aumentando em algumas cidades do Brasil, como por exemplo Pelotas e Ribeirão Preto.

Nos países desenvolvidos, onde é menor a desigualdade social e o sistema de informação de peso ao nascer é confiável, como na Suécia e Noruega, a média do peso dos recém-nascidos é $3500 \mathrm{~g}$ e o número dos que nascem com menos de $2500 \mathrm{~g}$ (baixo peso ao nascer), não ultrapassa 5\% (UNICEF, 1998). De modo geral, nos países desenvolvidos a freqüência de BPN encontra-se entre 4\% e 6\% (MONTEIRO; BENICIO; ORTIZ, 2000). Já nos países em desenvolvimento o peso ao nascer mostra-se diferente, ou seja, há uma maior prevalência de crianças que nascem com menos de 2500g. No Brasil, um inquérito realizado pelo Instituto Brasileiro de Geografia e Estatística (IBGE) em 1989 estimou em 10,2\% a prevalência do baixo peso ao nascer (MONTEIRO et al, 2000). Segundo o DATASUS no ano de 2000 a 
freqüência de BPN era de 7,6\% no Brasil, variando de 6,2\% na região norte a 8,5\% na região sudeste. No entanto, é necessária uma atenção especial para valores subestimados nas regiões norte e nordeste devido às falhas na cobertura do Sistema de Informação Sobre os Nascidos Vivos (SINASC) (NOVAES et al, 2003).

Mais especificamente sobre nascimentos com retardo de crescimento intrauterino, no Brasil, um estudo realizado na cidade de Pelotas por BARROS et al (1992) identificou que numa coorte de 5914 nascidos vivos, 9,0\% e 6,3\% foram classificados como pequenos para idade gestacional e pré-termos respectivamente.

Em relação à prematuridade, em alguns países desenvolvidos, a incidência de prematuros é de $6 \%$, como na França e Estados Unidos (LEONE et al, 1999). Já nos países em desenvolvimento, como o Brasil, no ano de 2000, de acordo com o DATASUS, havia uma proporção de prematuros de $6,7 \%$ enquanto no município de São Paulo essa proporção era de 7,4\%.

\subsubsection{Sistema de Informação Sobre os Nascidos Vivos (SINASC)}

A cidade de São Paulo conta com estimativas confiáveis sobre a distribuição do peso dos recém-nascidos desde 1976, quando foi realizado um estudo a partir de uma amostra probabilística nas maternidades (MONTEIRO et al, 2000). Em 1990 foi implantado pelo Ministério da Saúde o Sistema de Informação Sobre os Nascidos Vivos (SINASC), mas esta implantação ocorreu de forma gradativa nas diferentes áreas do país (COSTA; GOTLIEB, 1998). No estado de São Paulo as informações 
deste sistema tornaram-se disponíveis a partir de 1993 (MONTEIRO et al, 2000). Assim, a cidade de São Paulo tem uma fonte muito importante de dados sobre a distribuição do peso ao nascer e sua evolução. Estudos epidemiológicos estão se utilizando deste sistema, o qual possibilita um fácil acesso a um grande número de informações.

Para se realizar um estudo numa cidade como São Paulo, onde se concentra uma grande massa populacional, a disponibilidade de fonte de dados secundários é uma das formas de se conseguir incluir um grande número de pessoas, num longo período de tempo, em um trabalho.

De posse das informações obtidas de uma amostra probabilística e do SINASC, pôde-se obter um perfil dos nascidos vivos num período 22 anos. Em 1998 o peso ao nascer em São Paulo tinha uma média de $3160 \mathrm{~g}$ e $8,9 \%$ de nascimentos tinham peso < 2500g, sendo que entre 1976 e 1998 pouco foi alterada essa distribuição (MONTEIRO et al, 2000). Dessa forma, encontra-se uma menor média para o peso e uma maior proporção de BPN, valores diferentes ao esperado quando se tem ótimas condições de crescimento fetal, ou seja, média do peso ao nascer em torno de $3400-3500 \mathrm{~g}$ e cerca de $4-5 \%$ dos nascimentos com menos de $2500 \mathrm{~g}$.

A chamada Declaração de Nascido Vivo (DN) é o instrumento utilizado pelo SINASC, que tem como finalidade fornecer uma melhor cobertura dos nascidos vivos e o de obter um perfil dos nascimentos, segundo variáveis relativas à mãe, à gravidez, ao recém-nascido e ao parto (JORGE et al, 1993). Praticamente todas as variáveis presentes na DN são auto-explicativas, com exceção de uma referente ao recém- 
nascido, o Índice de Apgar, o qual merece ser definido. Este índice é utilizado para identificar crianças que podem vir a apresentar complicações isquêmicas ou hipóxicas (GOSHI; ZUCCOLOTTO, 1986). Sua aplicação é logo após o nascimento, no $1^{\circ}$ e $5^{\circ}$ minutos, sendo avaliados freqüência cardíaca, esforço respiratório, tônus muscular, resposta ao cateter introduzido nas narinas e a cor; assim são fornecidas notas entre zero e dois, obtendo-se uma nota final em que o recém-nascido é classificado em melhores condições (índice entre 8-10), moderadamente deprimido (índice entre 5-7) e intensamente deprimido (índice de 4 ou menos) (KOOPS ; BATTAGLIA, 1986).

A DN contempla uma variedade de informações registradas logo após o nascimento das crianças nascidas no ambiente hospitalar. Já os dados contidos no Registro Civil, nem sempre irão refletir a realidade, pois pode haver falha na cobertura total dos nascidos vivos. Com isso, a qualidade dos indicadores que se utilizam do número de nascidos vivos pode ficar comprometida. O principal problema é o subregistro de nascimento, ou seja, os responsáveis pela criança não vão ao cartório registrá-la. A nível nacional quem opera tais informações é a Fundação Instituto Brasileiro de Geografia e Estatística (FIBGE) (JORGE et al, 1993).

Os dados referentes aos nascidos vivos, em países como os Estados Unidos, Suécia, Cuba e Itália, são baseados em uma declaração ou certificado de nascimento que é emitido no serviço onde ocorreu o parto. As vantagens deste tipo de documento é que são preenchidos pelo próprio serviço e o processo das informações é descentralizado, permitindo assim uma certa autonomia na utilização dos dados e facilidade de acesso (JORGE et al, 1993). 
Com o SINASC, o problema com o subregistro diminui, pois as declarações de nascido vivo são preenchidas no hospital logo após o nascimento. Os dados gerados por este sistema representam a totalidade dos nascidos vivos hospitalares (estimado em $80 \%$ no país), além dos domiciliares que receberam atendimento imediato no hospital (JORGE et al, 1993).

Um estudo realizado em cinco municípios do Estado de São Paulo mostrou elevados índices de concordância entre as informações registradas nas declarações e as informações colhidas diretamente nos hospitais (JORGE et al, 1993). Já em estudo realizado no município de São Luis, Maranhão, para verificar a concordância entre as informações presentes na DN e aquelas obtidas por inquérito, observou-se concordância ruim para a variável duração da gestação (SILVA et al, 2001b). De qualquer forma, as fontes secundárias em geral merecem certa cautela ao serem utilizadas. A implantação deste Sistema de Informação sobre Nascidos Vivos no Brasil representa um importante passo na descentralização e transparência dos dados de interesse à pesquisa, sua utilização deve ser estimulada e o aperfeiçoamento de suas informações deve ser sempre buscado.

\subsubsection{Determinantes do peso ao nascer}

O interesse de se conhecer melhor os determinantes do peso ao nascer, fez com que diversos trabalhos fossem realizados neste sentido. 
Estudos epidemiológicos estão dando atenção especial quanto às causas que levam a um menor peso do recém-nascido e muitos fatores estão sendo identificados como determinantes do peso ao nascer (HORTA et al, 1996). As condições de saúde do $\mathrm{RN}$ bem como o seu peso ao nascimento são determinados pelas condições biológicas, sociais e ambientais às quais a mulher está exposta durante a gestação. O que caracteriza o final do crescimento intra-uterino é o peso do $\mathrm{RN}$ no momento do parto, o qual sofre influências dos fatores maternos, placentários e fetais, bem como os ambientais. Dentre os principais fatores que influem no peso ao nascer estão: peso e estatura maternos e paternos, sexo do RN, idade materna, condições sócio-econômicas, cuidados pré-natais, tabagismo materno, escolaridade materna, nascimentos múltiplos, paridade, história obstétrica anterior e morbidade materna durante a gestação (COSTA; GOTLIEB, 1998; MONTEIRO et al, 2000; NASCIMENTO; GOTLIEB, 2001).

Os fatores genéticos têm uma participação de aproximadamente $37 \%$ sobre o peso do recém-nascido, sendo $20 \%$ dependente do genótipo materno, $15 \%$ do genótipo fetal e $2 \%$ do sexo fetal (BITTAR et al, 2002). A contribuição paterna sobre o peso caracteriza-se pela transmissão do cromossomo $\mathrm{Y}$, ficando o feto masculino $150 \mathrm{~g}$ a $200 \mathrm{~g}$ mais pesado que o feminino, o que provavelmente se deva à participação de hormônios masculinos.

A idade materna inferior a 20 anos ou superior a 34 anos constitui em importante fator de risco para o BPN, bem como ser primípara ou multípara. BARROS et al, (1992) e VERCELLINI et al (1993) mostram existir uma associação entre 
gestante em idade mais avançada (35 anos e mais) e o baixo peso ao nascer, principalmente entre os pré-termos, devendo-se provavelmente pela presença de diabete e pressão alta durante a gestação.

A gestação que ocorre na adolescência (menos de 20 anos de idade) apresenta uma associação com os recém-nascidos de BPN e pré-termo mais evidente do que com os PIGs. Marques et al. (1992) indicam que esse efeito provavelmente se deva a um menor número de consultas pré-natais, dificultando o controle de afecções como préeclampsia, infecções urinárias e outras doenças, principalmente, as sexualmente transmissíveis. Somando-se a isso estão o tempo que a adolescente leva para tomar consciência da gestação, a existência de conflitos com a família e com o companheiro. Também é importante salientar que a gestação na adolescência é muito mais freqüente nas camadas de menor nível de renda (GERONIMUS; KOREMAN, 1993).

A condição sócio-econômica da mãe é uma variável importante não apenas pela sua associação com os desfechos da gravidez, mas também com a sobrevivência da criança no primeiro ano de vida (VICTORA et al, 1992). O nível de instrução constitui-se em uma das variáveis mais relevantes neste aspecto, considerada de mais fácil obtenção do que, por exemplo, o nível de renda. Em um estudo, abordando nível de instrução materna, encontrou-se uma associação estatisticamente significante entre menor escolaridade e ocorrência de baixo peso ao nascer (HAIDAR; OLIVEIRA; NASCIMENTO, 2001).

Ao se estudar a relação entre o tipo de parto e BPN, tem-se verificado uma grande influência de fatores sócio-econômicos. Observa-se que a freqüência de BPN 
no parto vaginal e operatório esta relacionada com o nível social da mãe e conseqüentemente com o seu grau de escolaridade. Em estudo realizado por Barbieri et al (2000) foi constatado que a freqüência de recém-nascidos com menos de $2500 \mathrm{~g}$ em 1978-79 foi maior para partos vaginais $(7,8 \%)$ do que para cesárea $(5,9 \%)$. Já em 1994 houve um aumento destes valores para ambos os tipos de parto, mas sendo mais acentuado para os partos operatórios, que foi para 11,3\%, enquanto o parto normal foi para $10,0 \%$. A conclusão deste trabalho foi que a associação encontrada entre cesariana e BPN tende a encobrir as diferenças sócio-econômicas na probabilidade do BPN, pois durante a análise dos partos vaginais isoladamente, as diferenças sócioeconômicas reapareciam. Mães com menor escolaridade tinham maior risco de ter um filho com baixo peso.

Em 2001, um trabalho realizado por SILVA et al verificou que BPN estava associado à cesárea, e dentre os maiores riscos para ocorrência desta estavam o alto grau de instrução materna, ser atendida pelo mesmo médico durante o pré-natal e o nascimento, ter um adequado pré-natal e o local de ocorrência do parto operatório ser um hospital privado.

Uma revisão da literatura brasileira mostrou que uma em cada quatro gestantes é fumante (MENEZES; VICTORA, 1999). O principal efeito do fumo é sobre o retardo do crescimento intra-uterino e não sobre a prematuridade, responsável pela mortalidade da maioria dos recém-nascidos de baixo peso. Entre os componentes presente na fumaça do tabaco está o monóxido de carbono, o qual tem a capacidade de ligar-se à hemoglobina mais facilmente que o oxigênio, privando o sangue da sua 
capacidade de transporte de oxigênio (NETO, 1990). Dessa forma, o CO é um possível responsável pelo efeito da diminuição do peso fetal.

Segundo BRENELLI e MARTINS (1992), verifica-se maior proporção de BPN nas gestações múltiplas em relação às únicas. Quanto a paridade, a associação com o BPN apresenta-se numa curva em forma de "U", verificando-se uma maior prevalência de crianças pesando menos de $2500 \mathrm{~g}$ ao nascer entre primíparas e multíparas (BARROS et al, 1992). No entanto, esta associação desaparece quando o peso é ajustado pela classe sócio-econômica da família.

Além de todos esses fatores envolvidos no desenvolvimento do recém-nascido com baixo peso, a duração da gestação e a velocidade do crescimento fetal são dois processos fundamentais, distintos e determinantes do BPN.

Uma recente revisão mostrou que as principais causas de partos prematuros são infecções genitais, partos múltiplos, hipertensão materna, baixo índice de massa corporal (IMC) pré-gestacional, disfunções uterinas e trabalho materno pesado. Enquanto que as principais causas do retardo de crescimento intra-uterino incluem: baixo consumo de calorias durante a gestação (anteriormente citado), fatores étnicos, baixo índice de massa corporal (IMC) pré-gestacional, baixa estatura materna e tabagismo (KRAMER, 2003). Dessa forma, o BPN é uma combinação de vários problemas diferentes e que requerem intervenções distintas.

Pode-se dizer que o crescimento e o desenvolvimento da criança ocorrem em diferentes ambientes, que são o organismo materno, a moradia da criança e a região onde esta se situa (SCHVARTSMAN, 1999). Uma preocupação voltada ao meio 
ambiente tem se estabelecido como uma das prioridades de saúde pública, já que a qualidade do espaço onde vivem as pessoas pode interferir no estado de saúde destas, mesmo antes de nascerem. Dentre os fatores ambientais destaca-se a poluição atmosférica como um possível determinante do baixo peso ao nascer. $\mathrm{O}$ ar poluído talvez não seja o agente externo mais danoso contra o feto, mas sua importância deriva de sua permanente presença em determinados locais, atingindo um grande número de pessoas ao mesmo tempo.

\subsection{Poluição atmosférica}

Desde os anos 30, do século passado, existe uma preocupação de se investigar os efeitos deletérios causados pela poluição atmosférica. Alguns episódios de alta concentração de poluentes atmosféricos ocorreram no Vale Meuse, na Bélgica em 1930; em Donora, na Pensilvânia; Estados Unidos em 1948 e em Londres na Inglaterra em 1952 (FIRKET, 1931; CIOCCO, 1961; ABERCROMBIE, 1953).

Várias semelhanças existiram entre esses grandes episódios. Neles as características climáticas e topográficas eram favoráveis à formação de neblinas, aconteceram durante períodos de grande inversão térmica, houve aumento marcado do $\mathrm{n}^{\mathrm{o}}$ de mortes e de doentes devido à súbita elevação dos níveis de poluição do ar e as populações mais vulneráveis, como crianças e idosos, foram as mais atingidas.

Somente após o episódio ocorrido em Londres, Inglaterra, no inverno de 1952/53, foi que a preocupação com os malefícios da poluição atmosférica ganhou maior dimensão, pois nessa época foram constatados os níveis mais altos de poluição 
do ar ocorridos naquele país e que trouxeram graves repercussões para a sociedade. Nesse mesmo período foi verificado um aumento do número de mortes, mais de cinco vezes o esperado, devido principalmente a problemas respiratórios e cardiovasculares (MINISTRY OF HEALTH, 1954 apud GOUVEIA et al, 2003). Além disso, ocorreu um aumento do número de internações hospitalares, refletindo assim a elevação da morbidade (ABERCROMBRIE,1953).

Após esse episódio medidas preventivas foram adotadas no sentido de controlar os níveis dos poluentes em diversos centros urbanos, principalmente em países da América do Norte e Europa.

Em 1970 a Environmental Protection Agency (EPA) foi encarregada de estabelecer critérios de qualidade do ar para os poluentes. Foram regulamentados o material particulado, ozônio, dióxido de enxofre, dióxido de nitrogênio, monóxido de carbono e chumbo. Atualmente, constam na lista da EPA, 189 poluentes para regulamentação (BASCON, 1996). Desde 1975 a Organização Mundial da Saúde (OMS) mantém um programa de apoio técnico aos países em desenvolvimento, para que implantem programas de monitorização de poluentes atmosféricos (WHO, 1997).

Admite-se que cinco poluentes são responsáveis por quase 98\% da poluição, em termos genéricos e universais: monóxido de carbono, óxidos de enxofre, hidrocarbonetos, material particulado e óxidos de nitrogênio.

Como são vários os poluentes atmosféricos, a OMS sugere a classificação destes em clássicos (monóxido de carbono, dióxido de enxofre, material particulado, dióxido de nitrogênio e ozônio) e não clássicos (os demais). 
O monóxido de carbono (CO) é um gás derivado da combustão incompleta dos combustíveis que contém carbono, como a gasolina, o gás de cozinha, a madeira, entre outros. O CO tem uma afinidade 220 vezes maior com a hemoglobina do que o oxigênio (ELSOM, 1987). Quando este poluente está em altas concentrações no ambiente, a hemoglobina fica saturada e leva à hipóxia dos tecidos. Ao competir também com o $\mathrm{O}_{2}$ pela mioglobina, a hipóxia atingirá os músculos cardíacos e esqueléticos. Segundo SHEPS et al (1990), pacientes com doenças cardiovasculares, principalmente as isquêmicas do coração, são susceptíveis à exposição ao CO. No sistema nervoso, um aumento dos níveis de carboxihemoglobina pode levar a uma diminuição sensitiva e motora cerebral (BASCON, 1996). Outro efeito da exposição ao CO é aquele que ocorre sobre a gestação e o concepto. No entanto, não são muitos os estudos disponíveis avaliando a exposição de seres humanos ao CO ambiental durante a gestação. ALDERMAN et al (1987) mostrou haver um risco significativamente maior de recém-nascido com BPN quando da exposição materna ao CO. Vale a pena lembrar que um dos componentes da fumaça do tabaco é o $\mathrm{CO}$, o qual como já referido anteriormente pode ser responsável pelo efeito de diminuição do peso fetal associado ao tabagismo materno.

$\mathrm{O}$ dióxido de enxofre $\left(\mathrm{SO}_{2}\right)$ é um contaminante natural dos combustíveis fósseis. Alguns ácidos derivados do processo de oxidação do $\mathrm{SO}_{2}$, estão associados às morbidades respiratórias (DOCKERY et al, 1996).

$\mathrm{O}$ material particulado está muito correlacionado $\operatorname{com~} \mathrm{SO}_{2}$, já que são originários das mesmas fontes fixas (indústrias) ou móveis (veículos movidos a óleo diesel). Quanto à dimensão, há evidências que indicam ser o material particulado fino, 
conhecido como $\mathrm{PM}_{10}$ (abaixo de $10 \mu \mathrm{m}$ ), o principal responsável por danos pulmonares (SCHWARTZ et al, 1996). Doenças cardio-respiratórias e mortalidade total em diferentes localidades também mostraram-se associadas ao $\mathrm{PM}_{10}$ (DOCKERY et al, 1993; SCHWARTZ et al, 1996).

Os óxidos de nitrogênios (NOx) são gerados durante o processo de combustão em altas temperaturas, onde o oxigênio reage com o nitrogênio. Entre os óxidos de nitrogênio formados está o dióxido de nitrogênio $\left(\mathrm{NO}_{2}\right)$, que tem um importante papel na formação do ozônio $\left(\mathrm{O}_{3}\right)(\mathrm{WHO}, 1997)$. Os veículos automotores são os grandes responsáveis por sua emissão (CETESB, 2000). O $\mathrm{NO}_{2}$ é também um contaminante intra-domiciliar, sendo o gás de cozinha a principal fonte de emissão. O aumento da sensibilidade à asma e à bronquite, e ainda, queda da resistência às infecções respiratórias constituem efeitos do $\mathrm{NO}_{2}$ (CETESB, 2000).

O ozônio é um gás que se forma secundariamente, através de uma reação fotoquímica, ou seja, na presença da radiação solar sobre os óxidos de nitrogênio e hidrocarbonetos. Este ozônio localizado na troposfera (camada da atmosfera presente entre a superfície da Terra e a altura de 15-20 Km, constituindo o ar que respiramos) é proveniente de fontes estacionárias e móveis, é danoso à saúde, agindo principalmente no sistema respiratório. Encontra-se em altas concentrações tanto nos meses mais quentes, devido à elevada intensidade da radiação solar, como nos meses mais frios, devido ao período de inversões térmicas, onde seus precursores estão em altas concentrações (BRAGA,1998). Já o $\mathrm{O}_{3}$ localizado na estratosfera exerce um efeito protetor à saúde, protegendo os seres vivos dos raios ultra-violetas. 
Em resumo, quanto às fontes e os efeitos sobre a saúde, pode-se dizer que os poluentes denominados clássicos são emitidos por diversas fontes, que podem ou não ser estacionárias, e são encontrados em sua maioria nos centros urbanos. Os automóveis constituem os principais focos de emissão de monóxido de carbono, óxidos de nitrogênio e hidrocarbonetos, podendo também emitir partículas. Já as fontes estacionárias são responsáveis pelas emissões de enxofre e material particulado. Quanto ao ozônio, este é um poluente secundário resultante de uma reação fotoquímica entre hidrocarbonetos e óxidos de nitrogênio (BASCON, 1996; WHO, 1997). No que diz respeito às ações sobre a saúde, os poluentes dióxido de nitrogênio $\left(\mathrm{NO}_{2}\right)$, dióxido de enxofre $\left(\mathrm{SO}_{2}\right)$, material particulado $\left(\mathrm{PM}_{10}\right)$ e ozônio $\left(\mathrm{O}_{3}\right)$ têm efeito direto na árvore respiratória (causando inflamações e queda da imunidade) e com isso favorecem o aparecimento de infecções, já o monóxido de carbono atua na competição pela hemoglobina do sangue com o oxigênio $\left(\mathrm{O}_{2}\right)$.

\subsubsection{Poluição do ar e saúde}

Vem sendo observado um aumento dos níveis de poluição atmosférica nas cidades, sendo na maioria dos países os veículos automotores os principais responsáveis. A preocupação com essa situação mobilizou muitos pesquisadores de diversos países a investigarem os efeitos nocivos da poluição atmosférica à saúde.

Por exemplo, na Europa, uma revisão de vários estudos foi realizada na República Tcheca, verificando-se um efeito das partículas finas e do hidrocarbono aromático policíclico (HAP) sobre a saúde humana (SRÁM et al, 1996). A exposição 
individual a esses poluentes foi correlacionada com a excreção de metabólitos do HAP na urina, traços de metais no sangue e DNA adducts nas células brancas do sangue. Problemas respiratórios e neurotoxicidade em crianças em idade escolar, e ainda, alteração transitória na qualidade do sêmen (motilidade, morfologia, integridade nuclear), também estiveram associados aos poluentes.

As pessoas mais vulneráveis, como por exemplo, as crianças, podem ter grave comprometimento de sua saúde evoluindo para morte em muitos casos. Nos Estados Unidos foi identificada uma associação entre o $\mathrm{PM}_{10}$, mortalidade pós-neonatal, mortalidade por causas respiratórias em crianças com peso normal ao nascer e com a Síndrome da morte súbita na infância (WOODRUFF et al, 1997).

As pesquisas mostram que a população adulta também tem um maior risco de morrer ou de adoecer em decorrência da exposição aos poluentes atmosféricos. Em Detroit, verificou-se associação entre total de mortes e partículas totais em suspensão (PTS) (SCHWARTZ, 1991); e na Philadelphia um maior risco para problemas cardiovasculares em relação às PTS, e do total de mortes com PTS e $\mathrm{SO}_{2}$ (SCHWARTZ; DOCKERY, 1992). E ainda, em Utah foi constatado risco entre a exposição ao PM10 e total de mortes. (POPE et al, 1992). Um aumento na sua concentração de $100 \mu \mathrm{g} / \mathrm{m} 3$ foi associado com aumento estimado da freqüência de mortalidade diária em $16 \%$ A associação entre mortalidade e PM10 foi principalmente por doenças respiratórias.

No Brasil, alguns trabalhos também identificaram a poluição atmosférica como um dos fatores que comprometem a saúde. Assim como nos países desenvolvidos, os estudos realizados nos países em desenvolvimento encontraram associação entre 
alguns poluentes do ar e a ocorrência de mortes e de doenças, bem como o acometimento das faixas etárias mais vulneráveis da população. Estudos mostram uma associação positiva entre mortalidade e morbidade por problemas respiratórios em crianças. Já entre os idosos, a poluição atmosférica tem sido associada a aumentos de morbidade e de mortalidade, tanto por doenças respiratórias quanto por doenças cardiovasculares.

Com relação aos trabalhos sobre mortalidade, na cidade do Rio de Janeiro foi constatada associação entre PM e mortes por pneumonia em menores de 1 ano de idade (PENNA, 1991). Segundo SALDIVA et al (1994), mortes respiratórias em menores de 5 anos de idade foram associadas com os óxidos de nitrogênio $\left(\mathrm{NO}\right.$ e $\left.\mathrm{NO}_{2}\right)$ na cidade de São Paulo, mostrando que a poluição do ar nesta região tem alcançado níveis altos o suficiente para causar efeitos adversos a saúde na população exposta. A poluição atmosférica também pode afetar a criança mesmo antes dela nascer. Em trabalho de doutorado concluído em 1999 verificou-se que mortes fetais estiveram associadas ao $\mathrm{NO}_{2}$ (PEREIRA, 1999). Entre os idosos, um aumento de 3-4\% nas mortes diárias por todas as causas e por doenças cardiovasculares esteve associado a um aumento de material particulado fino e dióxido de enxofre (GOUVEIA; FLETCHER, 2000a).

Quanto as morbidades, alguns estudos investigaram a exposição aos poluentes nas crianças e nos idosos. BRAGA et al (1999) identificaram que a poluição do ar $\left(\mathrm{PM}_{10}, \mathrm{O}_{3}\right.$ e $\left.\mathrm{CO}\right)$ estava associada às admissões pediátricas hospitalares em São Paulo. Em outro trabalho, também foi constatada uma associação entre admissões hospitalares por doenças respiratórias em crianças e $\mathrm{O}_{3}$ (GOUVEIA; FLETCHER, 
2000b). Ao se avaliar as condições sociais da população da cidade de São Paulo, foi encontrada uma maior prevalência de sintomas respiratórios em crianças mais expostas ao $\mathrm{SO}_{2}$ e partículas totais em suspensão, e que as condições sócio-econômicas agravavam o problema (SOBRAL,1989). Em Cubatão, uma cidade com grande número de indústrias, foi analisado o efeito dos poluentes sobre a função respiratória em crianças em idade escolar, sendo demonstrada uma associação negativa do PM10 em relação à função pulmonar (SPEKTOR, 1991).

Na população idosa, um estudo ecológico de séries temporais foi desenvolvido, observando-se um aumento do número de atendimento por pneumonia e gripe em idosos (MARTINS et al, 2002). Em atendimento num centro de emergência no município de São Paulo observou-se relação entre poluentes atmosféricos e doença cardíaca isquêmica, como angina e infarto agudo do miocárdio (LIN et al, 2003).

\subsubsection{Poluição do ar e RNBP}

Apesar da relação direta ar-pulmão que muitas vezes se faz, a literatura tem demonstrado que os efeitos adversos à saúde relacionados à poluição do ar não se restringem apenas ao aparelho respiratório.

Além da mortalidade e morbidade por problemas respiratórios em crianças, mais recentemente, alguns estudos vêm apontando a poluição do ar como possível determinante do baixo peso ao nascer e da prematuridade. Alguns trabalhos foram publicados a esse respeito em diversos países. 
$\mathrm{Na}$ Ásia, estudo realizado na China, observou-se que as partículas totais em suspensão (PTS) e o $\mathrm{SO}_{2}$ contribuíram para um maior risco de BPN (WANG et al, 1997), e em Seul, na Coréia do Sul, a exposição no $1^{0}$ trimestre de gestação aos poluentes $\mathrm{CO}, \mathrm{NO}_{2}, \mathrm{SO}_{2}$ e partículas totais em suspensão foi fator de risco para o $\mathrm{BPN}$ (HA et al, 2001).

Nos Estados Unidos, mais especificamente na região nordeste, a exposição ambiental ao $\mathrm{CO}, \mathrm{PM}_{10}$ e ao $\mathrm{SO}_{2}$ aumentou o risco para $\mathrm{BPN}$ nos recém-nascidos a termo (MAISONET et al, 2001), e no sul da Califórnia constatou-se que a exposição ao monóxido de carbono $(\mathrm{CO})$ no último trimestre de gravidez está associada com o baixo peso ao nascer (RITZ; YU, 1999). Na Geórgia, ROGERS et al (2000) constataram uma associação entre muito baixo peso ao nascer $(<1500 \mathrm{~g})$ e exposição materna a altos níveis de PTS e $\mathrm{SO}_{2}$.

$\mathrm{Na}$ Europa, outros trabalhos abordando esta mesma temática foram também realizados. Na República Tcheca, região central da Europa, uma associação foi identificada entre BPN e prematuridade e a exposição materna no $1^{\circ}$ trimestre às concentrações de $\mathrm{SO}_{2}$ e das PTS (BOBAK, 2000). Um outro trabalho na República Tcheca também foi desenvolvido, encontrando uma associação entre o baixo peso ao nascer e a poluição do ar em estudo ecológico espacial (BOBAK; LEON, 1999). Ainda na República Tcheca, mais especificamente, na região norte da Boêmia, o risco para o retardo de crescimento intra-uterino aumentou conforme o aumento da concentração do $\mathrm{PM}_{10}$ e do $\mathrm{PM}_{2,5}$ durante o $1^{\circ}$ trimestre de gestação (DEJMEK et al, 1999).

No Brasil, a cidade de São Paulo tem estudos recentes que trouxeram indicações de que o peso ao nascer sofre redução quando as gestantes são expostas a 
níveis elevados de $\mathrm{CO}$ e $\mathrm{PM}_{10}$ no $1^{\circ}$ trimestre de gestação (GOUVEIA; BREMMER; NOVAES, 2004) e que o aumento da concentração do $\mathrm{PM}_{10}$ contribui para a ocorrência de prematuridade (GOUVEIA; MEDEIROS, 2003).

\subsection{Poluição atmosférica e o crescimento urbano}

O crescimento urbano trouxe como uma de suas conseqüências negativas o aumento progressivo da poluição atmosférica, que atinge uma proporção considerável de pessoas.

A poluição do ar tem aumentado mundialmente, provocando degradação ambiental e efeitos adversos nas populações, motivando assim, maior empenho e investimento internacional para diminuir estes agravos. Embora a carga de exposição aos poluentes atmosféricos seja uma característica inevitável nas regiões urbanas em todos os países, ela atinge em maior grau os países em desenvolvimento, onde os níveis de emissão são significativamente maiores e as fontes industriais e veiculares coexistem (GOUVEIA, 1997). Para agravar a situação, muitos destes países possuem grande desigualdade social, onde parcela importante da população está mais vulnerável a sofrer os efeitos adversos da poluição.

No Brasil, apesar dos níveis atuais de poluição atmosférica serem considerados moderados, existe uma grande diferença entre municípios e regiões, em função do desenvolvimento urbano, das atividades econômicas e das características físicas e climáticas, o que gera preocupação a respeito dos efeitos à saúde da população exposta em determinadas áreas. 


\subsubsection{A cidade de São Paulo: sua história, seu crescimento industrial.}

A colonização de São Paulo começou em 1532, mas até o século XIX a economia era baseada na agropecuária de subsistência (ALMANAQUE ABRIL, 2003). Após este período surgiu a cultura cafeeira e a construção de ferrovias que promoveram seu crescimento (SCARLATO, 1996). O crescimento industrial foi favorecido, havendo grande concentração de investimentos das multinacionais norteamericanas e européias e intensas correntes migratórias internas. A partir deste momento inicia-se a construção de rodovias facilitando $\mathrm{o}$ deslocamento da industrialização para outros municípios (SOBRAL,1996), e conseqüentemente surge o investimento nos veículos automotores como meio de transporte.

Atualmente, São Paulo é uma das cidades mais poluídas do mundo e a maior parte desta poluição é devido ao grande número de veículos automotores circulantes (SALDIVA et al, 1994). No ano 2000 a população do município de São Paulo encontrava-se em 10.434.252 habitantes numa área de $1.524 \mathrm{Km}^{2}$ com uma frota de veículos de 4.013.286 (ALMANAQUE ABRIL, 2003).

A cidade de São Paulo tem também um papel de liderança econômica no Brasil (SOBRAL, 1996). Sessenta por cento das sedes das empresas multinacionais instaladas no país encontram-se na região metropolitana de São Paulo. No entanto, a cidade vem perdendo participação na produção industrial brasileira. Isto se deve em parte ao deslocamento de algumas instalações industriais para a periferia e para outros municípios, por causarem transtornos à população ou por estarem em busca de áreas 
mais amplas e baratas. Esse processo, aparentemente benéfico para o meio ambiente da cidade, traz uma queda da produção industrial na região, que somado à recessão econômica e à concentração de renda, tem criado uma população empobrecida na cidade.

Apesar das melhorias das condições de moradia e do saneamento básico, a população ainda sofre com os aspectos sócio-econômicos de uma sociedade concentradora de renda. Dentre os distritos que concentram grande parcela da população excluída estão: Jardim Ângela, Grajaú, Cidade Tiradentes, Itaim Paulista e Lajeado (IZIQUE, 2003). A exclusão não deve ser confundida com pobreza, embora a pobreza seja uma forma de exclusão (SPOSATI, 2000). Os pobres tornam-se mais pobres porque são excluídos dos meios através dos quais suas condições poderiam melhorar. A exclusão social diz respeito à forma de distribuição dos acessos.

O crescimento e a urbanização do município de São Paulo trouxeram como uma de suas conseqüências a poluição atmosférica. O baixo poder de dispersão dos poluentes devido as características atmosféricas e topográficas do local agrava ainda mais a qualidade do ar. Para se ter um perfil da característica do ar que a população daquele local está exposta foram criadas estações de monitoramento do ar. A cidade possui hoje uma rede de monitoramento da qualidade do ar distribuída pelo município o que tem permitido a medição dos poluentes atmosféricos. 


\subsubsection{CETESB}

O Estado de São Paulo, através da Companhia de Tecnologia de Saneamento Ambiental (CETESB), mantém, desde a década de 70, redes de monitoramento da qualidade do ar. A CETESB fornece informações e cuidados preventivos referentes à poluição que coloque em risco a qualidade do ar, água, e solo. Em relação à qualidade do ar, o programa de físcalização abrange indústrias e veículos automotores. Atualmente o município de São Paulo possui 14 estações de monitoramento da qualidade do ar. Uma parte da cidade não tem cobertura dessas estações, pois a implantação da rede de monitoramento pela CETESB foi direcionada para se ter o perfil da poluição do ar nas regiões mais centrais da cidade (FIGURA 2). Mas de qualquer forma, pode-se constatar que cada região do município possui no mínimo duas estações monitoras.

FIGURA 2 - MAPA DA REGIÃO METROPOLITANA DE SÃO PAULO COM AS ESTAÇÕES MONITORAS.

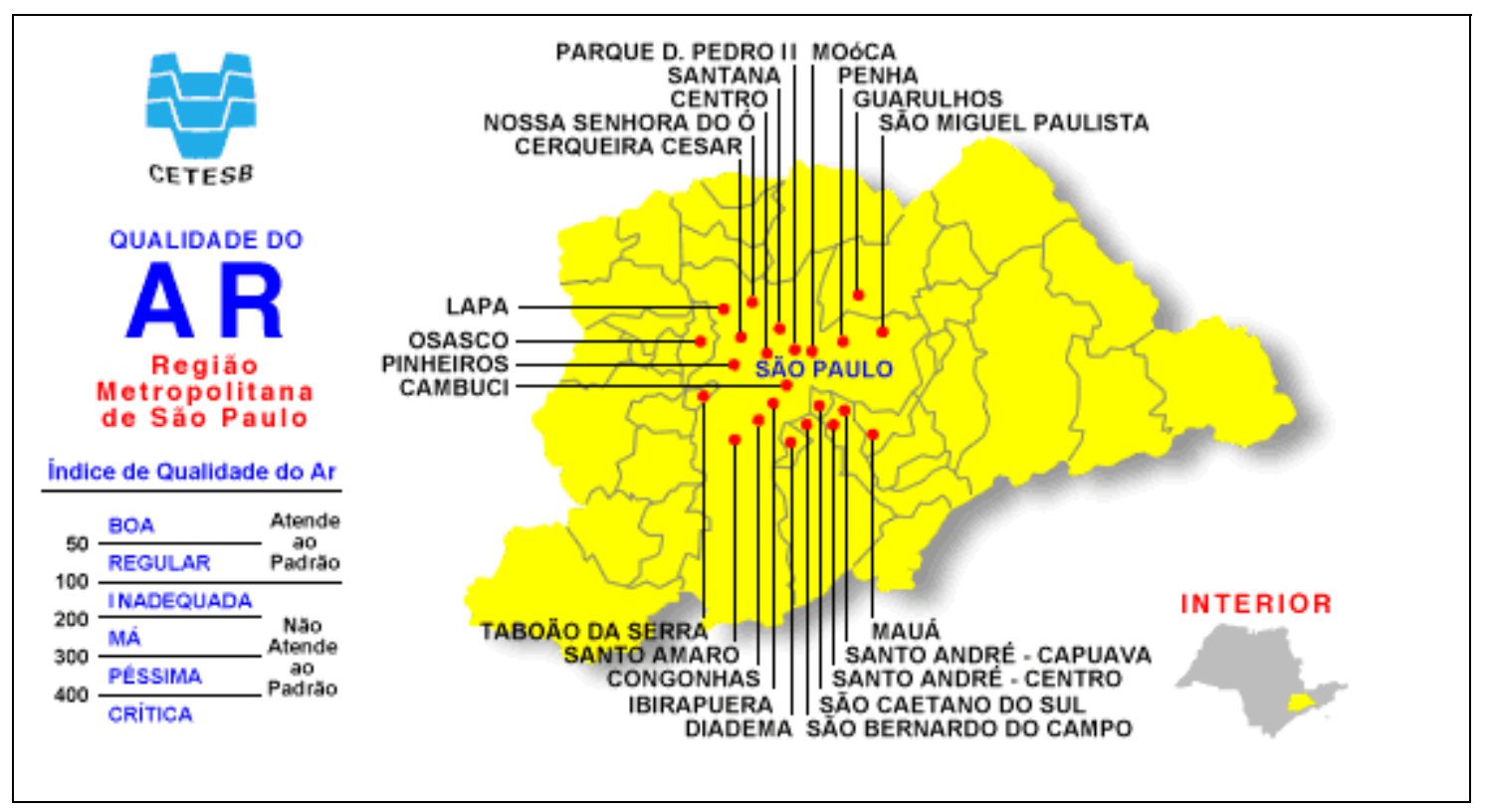

Fonte: CETESB 
A Região Metropolitana de São Paulo (RMSP) merece uma atenção especial devido ao grande comprometimento da qualidade do ar nesta região. De acordo com a CETESB as emissões dos veículos automotores leves e pesados são a principal fonte de poluição atmosférica da região, ficando em segundo plano as emissões provenientes das indústrias.

\subsection{3. Índices de Qualidade do Ar}

Os dados da qualidade do ar, obtidos pela CETESB em suas estações de monitoramento, são divulgados diariamente para a imprensa. Para simplificar o processo de divulgação dos dados é utilizado o índice de qualidade do ar.

Em 1976, o Estado de São Paulo regulamentou alguns padrões de qualidade do ar, que foram ampliados em 1990 a nível nacional, e transformados em resolução do CONAMA (Conselho Nacional do Meio Ambiente). Os poluentes regulamentados foram: partículas totais em suspensão, fumaça, partículas inaláveis, dióxido de enxofre, monóxido de carbono, ozônio e dióxido de nitrogênio. No QUADRO 1 estão os valores dos padrões de qualidade do ar estabelecidos no Brasil, Estados Unidos e da Organização Mundial da Saúde (CETESB, 1992). Os valores são iguais, com exceção do $\mathrm{SO}_{2}$ que apresenta padrão nacional acima daquele dos Estados Unidos, provavelmente pelo fato deste último ter atingido um controle mais satisfatório e ter investido em um padrão mais rigoroso. 


\subsubsection{Clima e características sazonais da poluição do ar no município de}

\section{São Paulo.}

Juntamente com a forte presença industrial e a grande frota de veículos na cidade, a localização geográfica também tem sido um fator que colabora para uma maior concentração de poluentes.

A RMSP localiza-se numa área rebaixada do Planalto Atlântico, um local de muitas colinas que variam de 650 a $1.200 \mathrm{~m}$. A localização da cidade de São Paulo sofre influências tanto da circulação terra-mar quanto do aquecimento continental e geralmente apresenta valores intermediários referentes às variáveis meteorológicas.

Quanto às características sazonais e climáticas, o período compreendido entre maio a setembro é seco, ou seja, com poucas chuvas, e as condições meteorológicas não são favoráveis à dispersão dos poluentes e ocasionam com maior freqüência episódios de ultrapassagem do valor padrão, com exceção do ozônio (CETESB, 1999). Já o período entre os meses de outubro e abril, compreende a estação chuvosa, o que permite amenizar as condições da poluição do ar. 
QUADRO 1 - PADRÕES DE QUALIDADE DO AR ADOTADOS PELO BRASIL, ESTADOS UNIDOS E ORGANIZAÇÃO MUNDIAL DE SAÚDE.

\begin{tabular}{|c|c|c|c|c|c|c|}
\hline \multirow[t]{2}{*}{ Poluente } & \multicolumn{2}{|c|}{$\begin{array}{c}\text { Padrão } \\
\text { Nacional }\end{array}$} & \multicolumn{2}{|c|}{ Padrão EUA } & \multicolumn{2}{|c|}{$\begin{array}{c}\text { Padrão } \\
\text { OMS }\end{array}$} \\
\hline & T.A. & P.P. & T.A. & P.P. & T.A. & P.P. \\
\hline $\begin{array}{l}\text { Partículas } \\
\text { inaláveis }\end{array}$ & $\begin{array}{l}24 \mathrm{~h}(1) \\
\text { MAA }\end{array}$ & $\begin{array}{l}150 \\
50\end{array}$ & $\begin{array}{l}24 \mathrm{~h} \\
\text { MAA }\end{array}$ & $\begin{array}{l}150 \\
50\end{array}$ & - & - \\
\hline $\mathrm{SO}_{2}$ & $\begin{array}{l}24 \mathrm{~h}(1) \\
\text { MAA }\end{array}$ & $\begin{array}{l}365 \\
80\end{array}$ & $\begin{array}{l}24 \mathrm{~h} \\
\text { MMA }\end{array}$ & $\begin{array}{l}150 \\
50\end{array}$ & $\begin{array}{l}24 \mathrm{~h} \\
\text { MMA }\end{array}$ & $\begin{array}{l}100- \\
150 \\
40- \\
90\end{array}$ \\
\hline CO & $\begin{array}{l}1 \mathrm{~h}(1) \\
8 \mathrm{~h}(1)\end{array}$ & $\begin{array}{l}40.000 \\
(35 \mathrm{ppm}) \\
10.000 \\
(9 \mathrm{ppm})\end{array}$ & $\begin{array}{l}1 \mathrm{~h} \\
8 \mathrm{~h}\end{array}$ & $\begin{array}{l}40.000 \\
(35 \mathrm{ppm}) \\
10.000 \\
(9 \mathrm{ppm})\end{array}$ & - & - \\
\hline $\mathbf{O}_{3}$ & $1 \mathrm{~h}(1)$ & 160 & $1 \mathrm{~h}$ & $\begin{array}{l}235 \\
(0,12 \mathrm{ppm})\end{array}$ & $1 \mathrm{~h}$ & $\begin{array}{l}100- \\
200\end{array}$ \\
\hline $\mathrm{NO}_{2}$ & $\begin{array}{l}\text { 1h(1) } \\
\text { MMA }\end{array}$ & $\begin{array}{l}320 \\
100\end{array}$ & MMA & 100 & $1 \mathrm{~h}$ & $\begin{array}{l}190- \\
320\end{array}$ \\
\hline
\end{tabular}

Fonte: CETESB (1992)

NOTA: T.A.= tempo de amostragem P.P.= padrão primário $(\mu \mathrm{m} / \mathrm{m} 3)$

(1) Não deve ser excedido mais do que uma vez ao ano

MAA $=$ Média aritmética anual

$\mathrm{NE}=$ Não estabelecido

O fenômeno da inversão térmica pode ser identificado quando a massa de ar quente dificulta a dispersão dos poluentes para as camadas superiores da troposfera agravando o quadro da qualidade do ar na região (BRAGA, 1998).

\subsection{Justificativa}

A importância do baixo peso ao nascer para a saúde pública é determinada não apenas pelos riscos subseqüentes de mortalidade e morbidade, mas também pela freqüência com que o mesmo ocorre. O peso ao nascer pode refletir a qualidade de 
vida a que a população é submetida. As maiores prevalências de baixo peso ao nascer são observadas nos países em desenvolvimento, como uma conseqüência das piores condições de vida existentes nestes locais.

A população de São Paulo está exposta a grandes concentrações de poluição atmosférica e a prevalência de crianças com baixo peso ao nascer tem se mantido alta nos últimos 22 anos, apesar das melhorias de saneamento e de assistência à saúde. Pode-se então supor que a poluição esteja afetando o desenvolvimento intra-uterino das crianças que aqui nascem.

Entre os inúmeros fatores de risco estudados, vários já foram bem investigados, mas pouca atenção foi dada à poluição do ar, que apenas recentemente tem sido implicada como fator de risco para o BPN. Dentre os poluentes, é importante salientar que o monóxido de carbono pode estar contribuindo para esta situação. Conforme já mencionado ao se referir sobre o tabagismo materno, o $\mathrm{CO}$ é um componente que pode ser originado do fumo e é um dos possíveis responsáveis pelo efeito de diminuição do peso fetal, devido às dificuldades no transporte de oxigênio. Há a possibilidade do $\mathrm{CO}$, gerado principalmente por fontes móveis, estar agindo de forma similar a esta. Quanto aos demais poluentes, estes poderão também estar interferindo, talvez de forma indireta, através de seus efeitos sobre o aparelho respiratório da gestante, causando inflamações, queda da imunidade, infecções e conseqüentemente alguma deficiência no suprimento sanguíneo para o feto.

A poluição do ar talvez não seja o fator mais danoso contra a gravidez e o feto, mas sua importância deriva de sua capacidade em atingir um grande número de pessoas ao mesmo tempo, ou seja, não é um fator de risco apenas individual. 
Dessa forma este estudo se propõe a investigar o efeito da poluição atmosférica sobre a criança, antes mesmo do seu nascimento, através das medidas de exposição materna aos poluentes durante os trimestres de gestação. 


\section{OBJETIVO}

- Avaliar o efeito da poluição do ar na cidade de São Paulo sobre o peso ao nascer, de acordo com a exposição materna nos trimestres de gestação. 


\section{METODOLOGIA}

\subsection{Local e População de estudo}

Para examinar o efeito dos níveis de poluição do ar sobre o peso ao nascer do recém-nascido, foram analisados todos os nascimentos de mães residentes no município de São Paulo nos anos de 1998, 1999 e 2000 que tiveram sua ficha de declaração de nascido vivo preenchida.

\subsubsection{Critérios de inclusão do RN e definição de BPN}

Para a inclusão dos RNs neste trabalho foram considerados alguns critérios referentes as suas características:

- $\quad$ ser a termo, isto é, com idade gestacional entre 37-41 semanas

- $\quad$ não gemelares (gestações únicas)

- nascidos em ambiente hospitalar

- pesando entre 1.000 e $5.500 \mathrm{~g}$

Considerar apenas as gestações a termo e únicas permite eliminar a contribuição da prematuridade e da gemelaridade no peso ao nascer, já que estes recém-nascidos apresentam em sua maioria peso abaixo de $2.500 \mathrm{~g}$. Também não foram incluídos os que nasceram com idade gestacional acima de 41 semanas. Fatores os mais diversos poderiam estar contribuindo para o nascimento de pós-termos, sendo a poluição do ar menos importante nesse aspecto. Cabe lembrar que, como a declaração de nascido 
vivo apresenta informações pré-determinadas (intervalos) a respeito da duração da gestação, torna-se inviável a utilização do percentil 10 como referência para considerar o pequeno para idade gestacional. O motivo pelo qual foram incluídos apenas os nascimentos hospitalares foi a fidedignidade do valor do peso ao nascer obtido neste ambiente, pois se garante que a criança foi pesada logo após o nascimento. A restrição do peso nestes valores $(1.000$ a $5.500 \mathrm{~g})$ foi para excluir aquelas crianças com peso ao nascer mais extremos, provavelmente, frutos de gestações de alto risco onde a contribuição da poluição do ar no peso ao nascimento seria de menor importância.

Foram considerados como RNs com baixo peso neste estudo, aqueles que nasceram com peso inferior a $2500 \mathrm{~g}$ e com idade gestacional entre 37 e 41 semanas.

\subsection{Coleta de dados}

As informações utilizadas neste estudo foram provenientes de fontes secundárias. Trabalhou-se com dois bancos de dados oriundos das seguintes Instituições:

- Fundação SEADE (Sistema Estadual de Análise de Dados), responsável pela organização e gerenciamento dos dados referentes aos nascidos vivos obtidos do SINASC no Estado de São Paulo.

- CETESB (Companhia de Tecnologia de Saneamento Ambiental), responsável pelos dados das concentrações dos poluentes. 


\subsubsection{Nascidos Vivos}

Os dados que chegam à Fundação SEADE referentes aos nascidos vivos são obtidas do SINASC, através de seu instrumento, a DN (ANEXO 1). Neste documento há informações quanto as características relativas ao recém-nascido, à gestação, ao parto e à mãe, que são:

\section{$\underline{\text { Características maternas }}$}

- idade

- estado civil (incluiu-se na categoria "casada" a união consensual e na "separada" a solteira e a viúva)

- escolaridade

- ocupação

- paridade

- local de residência (distrito da cidade de São Paulo)

\section{Características da gestação e do parto:}

- duração da gestação em semanas

- tipo de gravidez ( única ou múltipla)

- tipo de parto ( normal ou cesárea)

- $\quad n^{o}$ de consultas de pré-natal

$\underline{\text { Características do recém-nascido }}$

- data de nascimento 
$-\operatorname{sexo}$

- Índice de Apgar

- raça

- peso ao nascer

- presença de malformação congênita

A declaração de nascido vivo é preenchida na maternidade onde a criança nasceu. Aquelas que não nasceram em ambiente hospitalar, mas receberam atendimento imediato neste local também têm suas declarações devidamente preenchidas. As que nasceram em suas residências e não tiveram atendimento imediato num ambiente hospitalar têm este documento preenchido no Cartório de Registro Civil. O documento é emitido em três vias. A primeira fica com a maternidade para ser fornecida à Secretaria Estadual de Saúde, a segunda e terceira vias vão para a família, sendo que a segunda deve ser entregue ao Cartório no ato do registro de nascimento e a terceira deve ser entregue na primeira consulta na Unidade de Saúde (JORGE et al, 1993). O processamento da informação pode ser feito a nível distrital, municipal, regional ou estadual, permitindo um fácil acesso. No estado de São Paulo a segunda via, que foi para o Cartório, é encaminhada à Fundação Seade, onde são computadas as declarações das crianças nascidas e registradas naquele ano e ainda daquelas nascidas no ano anterior e registradas no presente ano (a cobertura estimada pelo Seade para a cidade de São Paulo é superior a 95\%) (MONTEIRO et al, 2000). 
A Fundação SEADE forneceu informações das DNs ano a ano do período entre 1998 e 2000, sendo o ano de 2000 incompleto, devido ao prazo dado de 1 ano para se registrar as crianças após o nascimento. Com isso, informações atualizadas do ano 2000 foram entregues num segundo momento. O banco de dados continha apenas os RNs vivos de mães residentes no município de São Paulo. De posse dos dados, foi realizada uma verificação das codificações fornecidas às variáveis e foram constatadas diferenças de um ano para outro. Tais diferenças foram corrigidas ao se fazer uma nova codificação, única para todos os anos. Por exemplo, a variável escolaridade no ano de 1998 estava categorizada em: nenhuma, $1^{\circ}$ grau incompleto, $1^{\circ}$ grau completo, $2^{\circ}$ grau e superior. Já em 1999 e 2000 a categorização era nenhuma, 1 a 3 anos, 4 a 7 anos, 8 a 11 anos e 12 anos ou mais. Com a codificação única, as categorias referentes à escolaridade materna ficou: nenhuma, $1^{\circ}$ grau incompleto, $1^{\circ}$ grau completo e $2^{\circ}$ grau e $3^{\circ}$ grau.

Após trabalhar com os dados brutos de todo o município, o cenário da pesquisa envolveu apenas parte do município, ou seja, foram excluídos os distritos mais periféricos (FIGURA 3). O objetivo da pesquisa não era comparar as regiões do município, mas sim de concentrar as regiões mais próximas das estações de monitoramento da qualidade do ar. Permaneceu no estudo apenas a região mais central da cidade, pelo fato das estações monitoras da qualidade do ar estarem mais concentradas neste espaço. 
FIGURA 3 - MAPA DO MUNICÍPIO DE SÃO PAULO COM AS ESTAÇÕES MONITORAS E OS DISTRITOS INCLUÍDOS NO ESTUDO.

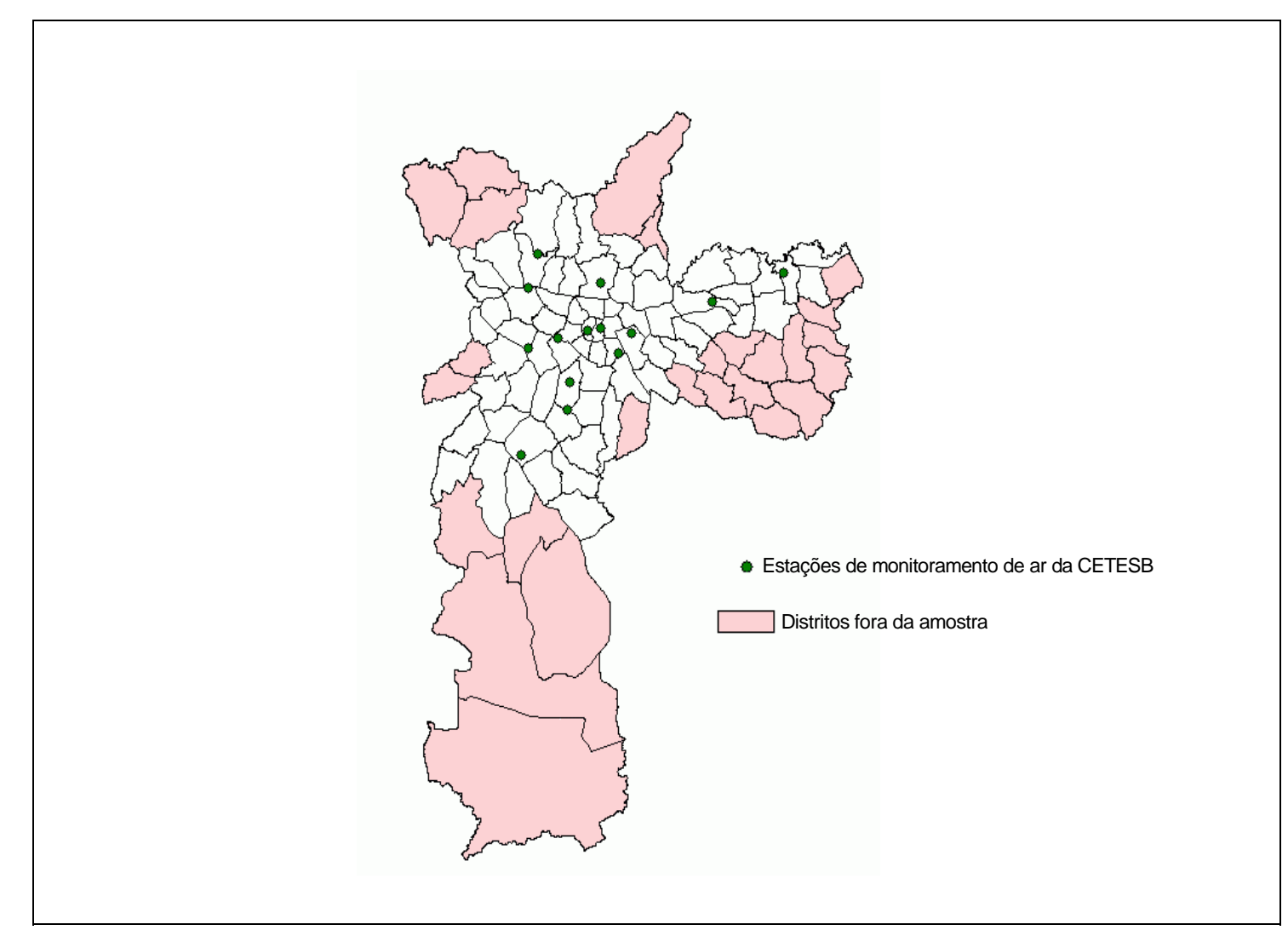

\subsubsection{Poluição do ar}

Para este trabalho a CETESB forneceu os registros diários das concentrações de dióxido de enxofre $\left(\mathrm{SO}_{2}\right)$, partículas em suspensão $\left(\mathrm{PM}_{10}\right)$, monóxido de carbono (CO), ozônio $\left(\mathrm{O}_{3}\right)$ e dióxido de nitrogênio $\left(\mathrm{NO}_{2}\right)$. Foram consideradas todas as estações monitoras do município. Das 14 estações que monitoram o ar em São Paulo, nem todas fornecem medidas de todos os poluentes. As informações referentes às concentrações de $\mathrm{PM}_{10}$ e $\mathrm{SO}_{2}$ foram obtidas por 14 e 6 estações de monitoramento 
respectivamente, enquanto que o $\mathrm{O}_{3}$ foi disponível em 6 e o $\mathrm{NO}_{2}$ e $\mathrm{CO}$ em 7 estações de monitoramento (QUADRO 2).

QUADRO 2 - LOCALIZAÇÃO DAS ESTAÇÕES MONITORAS DO MUNICÍPIO DE SÃO PAULO DE ACORDO COM OS POLUENTES QUE MEDEM.

\begin{tabular}{|c|c|c|c|c|c|}
\hline $\begin{array}{l}\text { LOCALIZAÇÃO } \\
\text { DAS } \\
\text { ESTAÇÕES }\end{array}$ & $\mathbf{P M}_{10}$ & $\mathrm{SO}_{2}$ & $\mathrm{CO}$ & $\mathrm{NO}_{2}$ & $\mathbf{O}_{3}$ \\
\hline P. D. Pedro II & $\mathrm{X}$ & $\mathrm{X}$ & $\mathrm{X}$ & $\mathrm{X}$ & $\mathrm{X}$ \\
\hline Santana & $\bar{X}$ & & & & $\mathrm{X}$ \\
\hline Moóca & $X$ & & & & $X$ \\
\hline Cambuci & $\mathrm{X}$ & & & & \\
\hline Ibirapuera & $\mathrm{X}$ & $\mathrm{X}$ & $\mathrm{X}$ & $\mathrm{X}$ & $\mathrm{X}$ \\
\hline N. S. do Ó & $\mathrm{X}$ & & & & \\
\hline Congonhas & $\mathrm{X}$ & $\mathrm{X}$ & $\bar{X}$ & $\mathrm{X}$ & \\
\hline Lapa & $\mathrm{X}$ & & $\mathrm{X}$ & $X$ & \\
\hline Cerqueira César & $\mathrm{X}$ & $\mathrm{X}$ & $X$ & $\mathrm{X}$ & \\
\hline Penha & $\mathrm{X}$ & & & & \\
\hline Centro & $\mathrm{X}$ & $\bar{X}$ & $\bar{X}$ & $\mathrm{X}$ & \\
\hline Sto. Amaro & $\mathrm{X}$ & & $\mathrm{X}$ & & \\
\hline S. M. Paulista & $\mathrm{X}$ & & & & $\mathrm{X}$ \\
\hline Pinheiros & $\mathrm{X}$ & $\mathrm{X}$ & & $\mathrm{X}$ & $\mathrm{X}$ \\
\hline
\end{tabular}

Fonte: CETESB

Os cinco poluentes $\left(\mathrm{O}_{3}, \mathrm{PM}_{10}, \mathrm{NO}_{2}, \mathrm{CO}\right.$ e $\left.\mathrm{SO}_{2}\right)$ foram analisados separadamente. A partir das médias diárias de $\mathrm{PM}_{10}$ e $\mathrm{SO}_{2}$, máxima média móvel diária de 8 horas do $\mathrm{CO}$, máxima horária diária do $\mathrm{O}_{3}$ e $\mathrm{NO}_{2}$, foram calculadas as médias trimestrais da concentração de cada poluente nos respectivos trimestres de gestação. Cada poluente também foi analisado através da recodificação em quartis, sendo a média da concentração trimestral dividida em quatro intervalos : 0 a 25\%; 26 a 50\%; 51 a $75 \%$ e 76 a $100 \%$. 
A data de nascimento foi a referência para se obter a média da concentração do poluente nos respectivos trimestres de gestação. Por exemplo: uma criança que nasceu com idade gestacional entre 37 e 41 semanas no dia 30 de novembro de 2000, foi considerada como tendo 39 semanas neste dia, e a partir desta data calculou-se a média de concentração do poluente dos 9 meses que antecederam o nascimento, ou seja, o período compreendido entre março a novembro de 2000. Dessa forma, obteve-se a média da concentração do poluente no $1^{\circ}$ (março a maio), $2^{\circ}$ (junho a agosto) e $3^{\circ}$ (setembro a novembro) trimestres de gestação para aquela criança. A partir dessa média da concentração trimestral, calculou-se também os quartis.

Dessa forma a exposição materna durante a gestação pôde ser medida tanto de forma contínua, através das médias das concentrações dos poluentes nos trimestres, como de forma categórica, de acordo com os quartis.

\subsection{Análise dos dados}

\subsubsection{Análise Descritiva}

Primeiramente foi realizada uma análise descritiva, através de gráficos e tabelas de freqüência simples do banco de dados dos nascimentos e dos poluentes. Esta análise examinou primeiro todos os nascidos vivos de mães residentes nesta cidade no período de três anos (1998 a 2000). Em seguida foram retirados os nascimentos de mães residentes nos distritos mais periféricos e aqueles que não atendiam os critérios de inclusão anteriormente citados. 
Foram criadas novas variáveis a partir da recodificação daquelas já existentes no banco de dados. Por exemplo, número de filhos mortos que era uma variável contínua, passou a ser dicotômica, ou seja, sem filhos mortos ou um e mais filhos mortos. Neste caso, considerou-se a ocorrência de pelo menos um filho morto como sendo um possível fator de confusão e de risco para o BPN. Após este procedimento, foram excluídas todas as variáveis que não seriam trabalhadas.

- raça: por possuir muitos dados ignorados.

- apgar no $1^{\mathrm{o}}$ e $5^{\mathrm{o}}$ minutos: devido à falta de fidedignidade do preenchimento desta variável (JORGE et al, 1993; SILVA et al, 2001).

- idade gestacional: todos os RNs do estudo são a termo.

- tipo de gravidez: todas as gestações do estudo foram não gemelares.

- distritos de residência: todos os distritos mais centrais foram considerados em conjunto neste estudo

- código de ocupação da mãe: apenas o ano 2000 continha esta informação.

- código de anomalia e sua identificação: o ano de 1998 não continha estas variáveis, além do que havia muitos dados ignorados nos outros anos.

- estado civil da mãe: pela ausência desta informação no ano de 1998.

- n no de abortos: para os anos de 1999 e 2000 não havia esta informação.

\subsubsection{Análises Univariada e Multivariada}

Para examinar a associação entre exposição materna à poluição do ar e o BPN utilizou-se de regressão linear (univariada e multivariada) e logística (univariada e 
multivariada). Na regressão linear, a variável desfecho, peso ao nascer em gramas, foi analisada de forma contínua, enquanto que na regressão logística, o peso ao nascer foi dicotomizado (peso $<2500 \mathrm{~g}$ e peso $>=2500 \mathrm{~g}$ ). Dessa forma, a escala de medida da variável peso ao nascer foi contínua ou discreta, dependendo do tipo de regressão.

Com relação à exposição materna aos poluentes, na regressão linear foram consideradas as médias trimestrais da concentração de cada poluente nos respectivos trimestres de gestação, enquanto que na regressão logística, essas médias foram recodificadas em quartis.

A análise univariada linear e logística examinou, primeiramente, a relação do peso ou do BPN com a exposição materna aos diversos poluentes com o objetivo de estimar o efeito bruto, ou seja, sem ajustes, dessa exposição no peso da criança. Além disso, o modelo logístico univariado foi utilizado para verificar a relação do desfecho com cada variável presente na $\mathrm{DN}$, de maneira a identificar possíveis fatores de confusão. Neste caso, a análise estatística baseou-se no cálculo do OR para se estimar o risco de recém-nascido com $\mathrm{BPN}$ associado a cada variável. Em todas as análises foram construídos intervalos de $95 \%$ de confiança e adotado nível de significância de $5 \%(\alpha=5 \%)$.

A partir dos resultados deste modelo logístico univariado, foram selecionadas as variáveis para os modelos multivariados, com a finalidade de se fazer o controle de confusão. Primeiramente o modelo multivariado (linear e logístico) foi considerado sem o poluente, ou seja, a exposição de interesse. As variáveis independentes foram entrando uma a uma, tanto na regressão linear quanto na logística, utilizando-se como critério da ordem de entrada, o maior valor do OR observado na análise logística 
univariada, uma vez que todas mostraram associação estatisticamente significante $(p<0,001)$. E ainda, para verificação da importância de cada variável para o modelo e sua permanência neste, foi utilizada a razão de verossimilhança (likelihood-ratio test), permanecendo no final da análise apenas as variáveis com $p<0,05$. Apenas após obter o modelo completo é que foram incluídos os poluentes, individualmente, e testada sua associação com o peso ao nascimento e o BPN.

Uma observação que deve ser feita é quanto à variável mês de nascimento, que seria considerada na análise para controlar o possível efeito de confusão da sazonalidade dos nascimentos na relação entre poluição do ar e peso ao nascer. Devido à forte associação desta variável com os diversos poluentes, verificada durante a análise, indicando colinearidade, o mês de nascimento não foi incluído no modelo multivariado. Por exemplo, o coeficiente de correlação entre a média de concentração do $\mathrm{PM}_{10}$ no $1^{\circ}$ trimestre e o mês de nascimento foi de 0,73 . O teste de correlação pode ser considerado como o grau no qual duas variáveis variam juntas. Dessa forma, a permanência no mesmo modelo de duas variáveis que apresentam colinearidade (mês de nascimento e exposição materna aos poluentes) conduziria a um resultado final errôneo, pois é como se estivessem medindo a mesma coisa (ARMITAGE; BERRY, 1994). Na presença de variáveis independentes correlacionadas, o coeficiente de regressão linear não reflete o real efeito particular destas variáveis sobre o desfecho, mas apenas um efeito parcial. A interpretação de que o coeficiente de regressão se altera conforme aumento de uma unidade da variável independente enquanto que as demais permanecem constantes não é completamente aplicável quando existe 
multicolinearidade, pois ocorre uma imprecisão do verdadeiro valor individual do coeficiente de regressão linear (ref.?).

A análise estatística foi realizada nos programas SPSS e STATA (SPSS, 1993; STATACORP, 1999).

\subsection{ASPECTOS ÉTICOS}

Este estudo foi desenvolvido junto ao Departamento de Medicina Preventiva da Faculdade de Medicina da Universidade de São Paulo e contou com informações dos bancos de dados de rotina da CETESB e da Fundação SEADE. As exigências referentes às pesquisas que envolvem coleta de dados primários, de material biológico ou manipulação medicamentosa não se aplicam ao estudo proposto.

O projeto de pesquisa foi aprovado pela Comissão de Ética para Análise de Projetos de Pesquisa (CAPPesq). 


\section{RESULTADOS}

\subsection{Descrição}

No período entre 1998 e 2000 ocorreram 595.559 nascimentos de mães residindo no município de São Paulo, deste total observou-se 53.035 (8,9\%) de crianças com baixo peso. Com relação a prematuridade, $34.688(6,2 \%)$ dos nascimentos foram prematuros. Na tabela 1 pode-se verificar que a prevalência de BPN foi de $56,1 \%$ entre os prematuros e confirma-se que a prematuridade é um fator de risco importante para o $\mathrm{BPN}(\mathrm{OR}=20,1$; IC 95\%, 19,6-20,5), bem como a ausência de pré-natal $(\mathrm{OR}=3,3 ; \mathrm{IC} 95 \%, 3,1-3,4)$. Também pode-se constatar que quase a totalidade dos partos foi em ambiente hospitalar, sendo a freqüência do parto vaginal pouco superior aos de cesárea. Quanto à variável raça, $319.869(53,7 \%)$ nascimentos não tiveram o campo da declaração de nascido vivo preenchido. 
TABELA 1 -PREVALÊNCIA E OR COM RESPECTIVOS INTERVALOS DE CONFIANÇA (IC 95\%) DE BAIXO PESO AO NASCER $(<2500 G)$, DOS NASCIDOS VIVOS NO MUNICÍPIO DE SÃO PAULO DE MÃES RESIDENTES NESTA CIDADE NO PERÍODO ENTRE 1998 E 2000, SEGUNDO VARIÁVEIS RELATIVAS À MÃE, RECÉM-NASCIDO, GESTAÇÃO E PARTO.

\begin{tabular}{|c|c|c|c|c|c|}
\hline VARIÁVEIS & $\mathrm{N}=595.559$ & $\begin{array}{r}\text { PREVALÊNCIA DE BAIXO } \\
\text { PESO AO NASCER } \\
\end{array}$ & OR & IC $95 \%$ & $\mathbf{p}$ \\
\hline Ano de nascimento & & & & & - \\
\hline 1998 & 196.791 & 9,07 & - & - & \\
\hline 1999 & 204.911 & 8,71 & - & - & \\
\hline 2000 & 193.857 & 8,94 & - & - & \\
\hline Sexo & & & & & $<0,001$ \\
\hline Masculino & 304.113 & 8,11 & 1,00 & - & \\
\hline Feminino & 291.394 & 9,73 & 1,22 & $1,20-1,24$ & \\
\hline Raça & & & & & $<0,001$ \\
\hline Branca & 191.095 & 8,40 & 1,00 & & \\
\hline Preta & 4.905 & 9,70 & 1,17 & $1,06-1,29$ & \\
\hline Amarela & 1.936 & 8,26 & 0,98 & $0,83-1,16$ & \\
\hline Parda & 77.384 & 9,37 & 1,13 & $1,09-1,16$ & \\
\hline Indígena & 370 & 8,65 & 1,03 & $0,72-1,48$ & \\
\hline Prematuridade & & & & & $<0,001$ \\
\hline Sim & 34.688 & 56,09 & 20,06 & $19,58-20,54$ & \\
\hline Não & 524.746 & 5,99 & 1,00 & - & \\
\hline $\begin{array}{l}\text { Escolaridade materna } \\
\text { (anos) }\end{array}$ & & & & & $<0,001$ \\
\hline Nenhuma & 7.772 & 10,59 & 1,37 & $1,27-1,48$ & \\
\hline $1^{\circ}$ grau incompleto & 231.231 & 9,16 & 1,16 & $1,13-1,20$ & \\
\hline $1^{\circ}$ grau completo e $2^{\circ}$ grau & 180.971 & 8,51 & 1,07 & $1,04-1,11$ & \\
\hline Universitário & 74.144 & 7,97 & 1,00 & - & \\
\hline Local de ocorrência & & & & & 0,002 \\
\hline Hospital & 590.085 & 8,92 & 1,00 & - & \\
\hline Outro estabelec. de saúde & 1.868 & 8,08 & 0,90 & $0,76-1,06$ & \\
\hline Domicílio & 1.635 & 13,76 & 1,63 & $1,42-1,88$ & \\
\hline Outros & 440 & 5,68 & 0,61 & $0,41-0,92$ & \\
\hline Tipo de parto & & & & & 0,119 \\
\hline Vaginal & 315.969 & 8,90 & 1,00 & - & \\
\hline Cesáreo & 270.794 & 9,02 & 1,01 & $1,00-1,03$ & \\
\hline Consulta de pré-natal & & & & & $<0,001$ \\
\hline nenhuma & 12.952 & 19,48 & 3,27 & $3,12-3,42$ & \\
\hline Até 6 consultas & 185.157 & 10,80 & 1,64 & $1,60-1,67$ & \\
\hline Mais de 6 consultas & 235.581 & 6,89 & 1,00 & - & \\
\hline
\end{tabular}

NOTA: O número de não registros para as variáveis sexo, raça, peso ao nascimento, prematuridade, escolaridade materna, local de ocorrência, tipo de parto e consulta pré-natal, foram respectivamente: 52, 319.869, 8.112, $36.125,101.441,1.531,8.796$ e 161.869 . 
A média do peso ao nascer neste período foi de $3.122 \mathrm{~g}$ com desvio-padrão de 543, mediana de 3.150, com valores mínimo e máximo respectivamente de 210 e 6.425, sendo que o valor mínimo não pode ser considerado de um nascido vivo. A média da idade das mães foi de 26 anos com desvio-padrão de 6 , com mediana de 25 , valores mínimo e máximo respectivamente de 11 e 55 (Tabela 2).

TABELA 2 - ANÁLISE DESCRITIVA DO PESO AO NASCER DO RN E IDADE MATERNA NO MUNICÍPIO DE SÃO PAULO ENTRE 1998 E 2000 (N=595.559).

\begin{tabular}{lrrrrrrr}
\hline $\begin{array}{l}\text { VARIÁVEIS } \\
\text { CONTÍNUAS }\end{array}$ & $\begin{array}{r}\text { VALOR } \\
\text { MÍNIMO }\end{array}$ & $\mathbf{2 5 \%}$ & MEDIANA & $\mathbf{7 5 \%}$ & $\begin{array}{r}\text { VALOR } \\
\text { MÁXIMO }\end{array}$ & MÉDIA & $\begin{array}{r}\text { DESVIO- } \\
\text { PADRÃO }\end{array}$ \\
\hline PESO & 210 & 2.800 & 3.150 & 3.470 & 6.425 & 3.122 & 543 \\
IDADE & 11 & 21 & 25 & 30 & 55 & 26 & 6 \\
MATERNA & & & & & & & \\
\hline
\end{tabular}

O gráfico 1 exibe as médias diárias de peso do recém-nascido nos anos de 1998, 1999 e 2000, podendo-se observar uma ligeira tendência de aumento do peso médio neste intervalo.

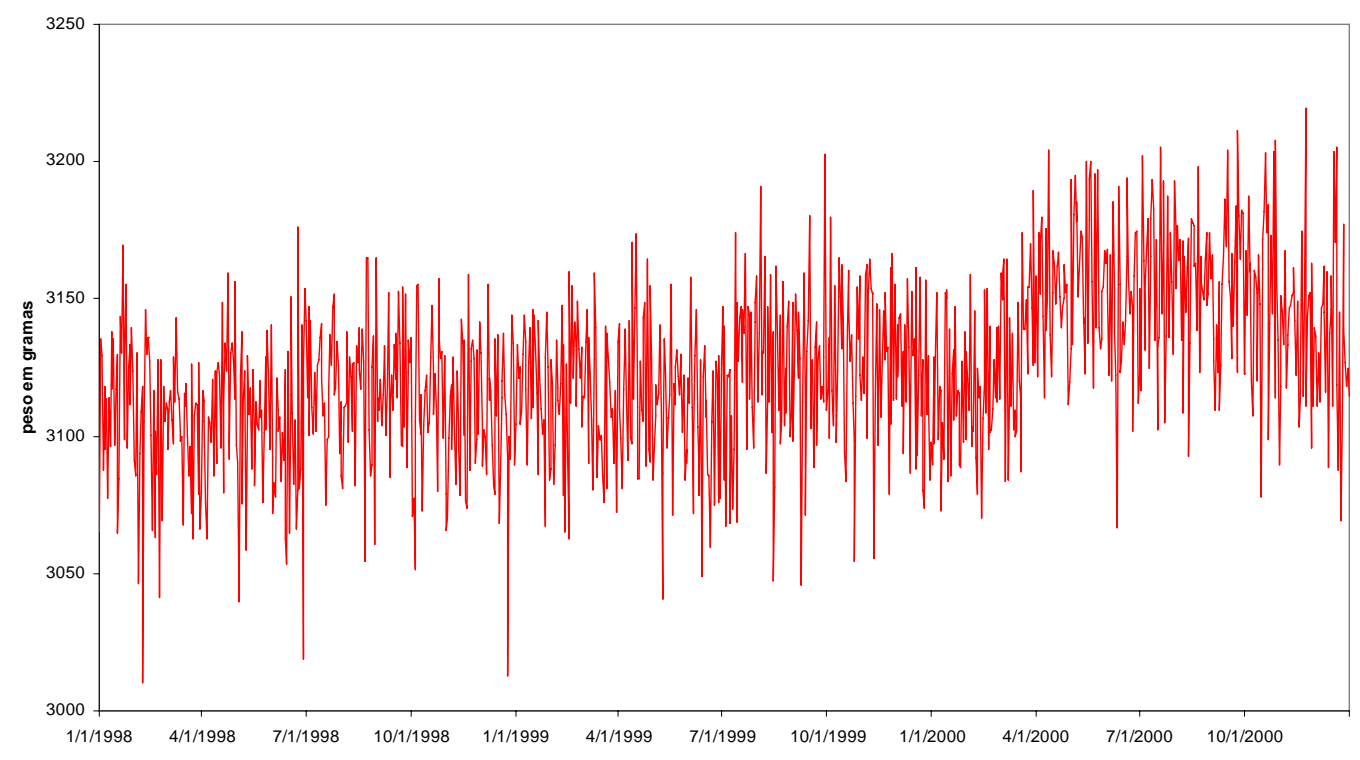

GRÁFICO 1 - MÉDIA DIÁRIA DO PESO DO RN DE MÃES RESIDENTES NO MUNICÍPIO DE SÃO PAULO NO PERÍODO ENTRE 1998 E 2000. 
As variáveis malformação congênita e estado civil foram analisadas em separado das demais variáveis contidas na tabela 1 pelo fato de estarem presentes apenas nos anos de 1999 e 2000. Assim, com relação a essas variáveis, observou-se respectivamente que $274.646(68,9 \%)$ e 109.038 (27,3\%) dos formulários estavam sem preenchimento. Quanto ao estado civil, a maioria das mulheres tinha companheiro $(62,1 \%)$ (Tabela 3$)$.

TABELA 3 - DISTRIBUIÇÃO DOS NASCIDOS VIVOS NO MUNICÍPIO DE SÃO PAULO DE MÃES
RESIDENTES NESTA CIDADE NO PERÍODO DE 2 ANOS (1999 E 2000), SEGUNDO
MALFORMAÇÃO CONGÊNITA E ESTADO CIVIL.

\begin{tabular}{lrr}
\hline \multicolumn{1}{c}{ VARIÁVEIS } & $\mathrm{N}=398.768$ & $\%$ \\
Malformação congênita & 1.389 & 1,1 \\
Sim & 122.733 & 98,9 \\
Não & & \\
& 179.874 & 62,1 \\
Estado civil & 109.856 & 37,9 \\
"Casada" & \\
"Separada" & NOTA: O número de não registros para as variáveis malformação congênita e estado \\
civil foi respectivamente: 274.646 e 109.038. &
\end{tabular}

A análise descritiva, referente aos níveis diários de poluição atmosférica, encontra-se na Tabela 4, onde pôde-se constatar que os níveis de todos os poluentes (exceto o $\mathrm{SO}_{2}$ ) ultrapassaram, em algum momento, os limites estabelecidos pela CETESB, em que se considera boa qualidade do ar (Tabela 5). A classificação do Índice de Qualidade do Ar é dada para cada poluente, não significa que se apenas um poluente estiver adequado, $\mathrm{o}$ ar será considerado bom. 
TABELA 4 - ANÁLISE DESCRITIVA DOS NÍVEIS DIÁRIOS DE POLUIÇÃO DO AR NO MUNICÍPIO DE SÃO PAULO ENTRE 1998 E 2000.

\begin{tabular}{lrrrrrrrr}
\hline POLUENTES & MÉDIA (DP) & MINIMO & $\mathbf{5} \%$ & $\mathbf{2 5 \%}$ & $\mathbf{5 0} \%$ & $\mathbf{7 5 \%}$ & $\mathbf{9 5 \%}$ & MÁXIMO \\
\hline $\mathrm{PM}_{10\left(\mu \mathrm{g} / \mathrm{m}^{3}\right)}$ & $48,60(21,18)$ & 13,93 & 15,23 & 17,07 & 48,60 & 131,17 & 140,14 & 157,27 \\
$\mathrm{SO}_{2\left(\mu \mathrm{g} / \mathrm{m}^{3}\right)}$ & $15,34(8,24)$ & 2,58 & 2,9 & 3,1 & 15,34 & 48,53 & 51,86 & 71,47 \\
$\mathrm{NO}_{2\left(\mu \mathrm{g} / \mathrm{m}^{3}\right)}$ & $93,01(41,28)$ & 22,24 & 24,25 & 26,83 & 93,01 & 252,07 & 276,57 & 303 \\
$\mathrm{O}_{3\left(\mu \mathrm{g} / \mathrm{m}^{3}\right)}$ & $73,33(44,49)$ & 10,18 & 13,33 & 14,5 & 76,33 & 356,93 & 379,54 & 389,45 \\
$\mathrm{CO}(\mathrm{ppm})$ & $2,86(1,43)$ & 0,54 & 0,73 & 0,79 & 2,86 & 9,23 & 10,28 & 11,06 \\
\hline
\end{tabular}

TABELA 5. VALORES DAS CONCENTRAÇÕES DOS POLUENTES DO AR DE ACORDO COM O ÍNDICE DA QUALIDADE DO AR

\begin{tabular}{lrrrrrr}
\hline $\begin{array}{l}\text { ÍNDICE DE } \\
\text { QUALIDADE } \\
\text { DO AR }\end{array}$ & $\begin{array}{r}\text { NíVEL DE } \\
\text { QUALIDADE } \\
\text { DO AR }\end{array}$ & $\begin{array}{r}\mathrm{PM}_{10}{ }^{*} \\
\mu \mathrm{g} / \mathrm{m}^{3}\end{array}$ & $\begin{array}{r}\mathrm{SO}_{2}{ }^{*} \\
\mu \mathrm{g} / \mathrm{m}^{3}\end{array}$ & $\begin{array}{r}\mathrm{CO}^{*} \\
\mathrm{pmm}\end{array}$ & $\begin{array}{r}\mathrm{NO}_{2}{ }^{*} \\
\mu \mathrm{g} / \mathrm{m}^{3}\end{array}$ & $\begin{array}{r}\mathrm{O}_{3}{ }^{*} \\
\mu \mathrm{g} / \mathrm{m}^{3}\end{array}$ \\
\hline $\begin{array}{l}\text { Boa } \\
(0-50)\end{array}$ & $50 \%$ PQAR & 50 & 80 & 4,5 & 100 & 80 \\
$\begin{array}{l}\text { Regular } \\
(51-100)\end{array}$ & PQAR & 150 & 365 & 9,0 & 320 & 160 \\
$\begin{array}{l}\text { Inadequada } \\
(101-199)\end{array}$ & ATENÇÃO & 250 & 800 & 15,0 & 1.130 & 200 \\
$\begin{array}{l}\text { Má } \\
(200-299)\end{array}$ & ALERTA & 420 & 1.600 & 30,0 & 2.260 & 800 \\
$\begin{array}{l}\text { Péssima } \\
(300-399)\end{array}$ & EMERGÊNCIA & 500 & 2.100 & 40,0 & 3.000 & 1.000 \\
$\begin{array}{l}\text { Crítica } \\
(>400)\end{array}$ & CRÍTICO & 600 & 2.620 & 50,0 & 3.750 & 1.200 \\
\hline
\end{tabular}

FONTE: CETESB

PM10 - material particulado; SO2 - dióxido de enxofre; $\mathrm{CO}$ - monóxido de carbono; NO2 - dióxido de nitrogênio e $\mathrm{O} 3$ - ozônio.

PQA - Padrão de qualidade do ar / ppm - partes por milhão.

* PM10 e SO2 - média 24 h; CO - média 8 h; NO2 e O3 - média 1 h.

Os gráficos 2 a 6 mostram respectivamente a distribuição das concentrações diárias do $\mathrm{PM}_{10}, \mathrm{SO}_{2}, \mathrm{CO}, \mathrm{NO}_{2}$ e $\mathrm{O}_{3}$. Todos, com exceção do $\mathrm{O}_{3}$, tiveram picos durante o período de inverno e o único que manteve seus níveis abaixo dos limites estabelecidos pela CETESB foi o $\mathrm{SO}_{2}$. 


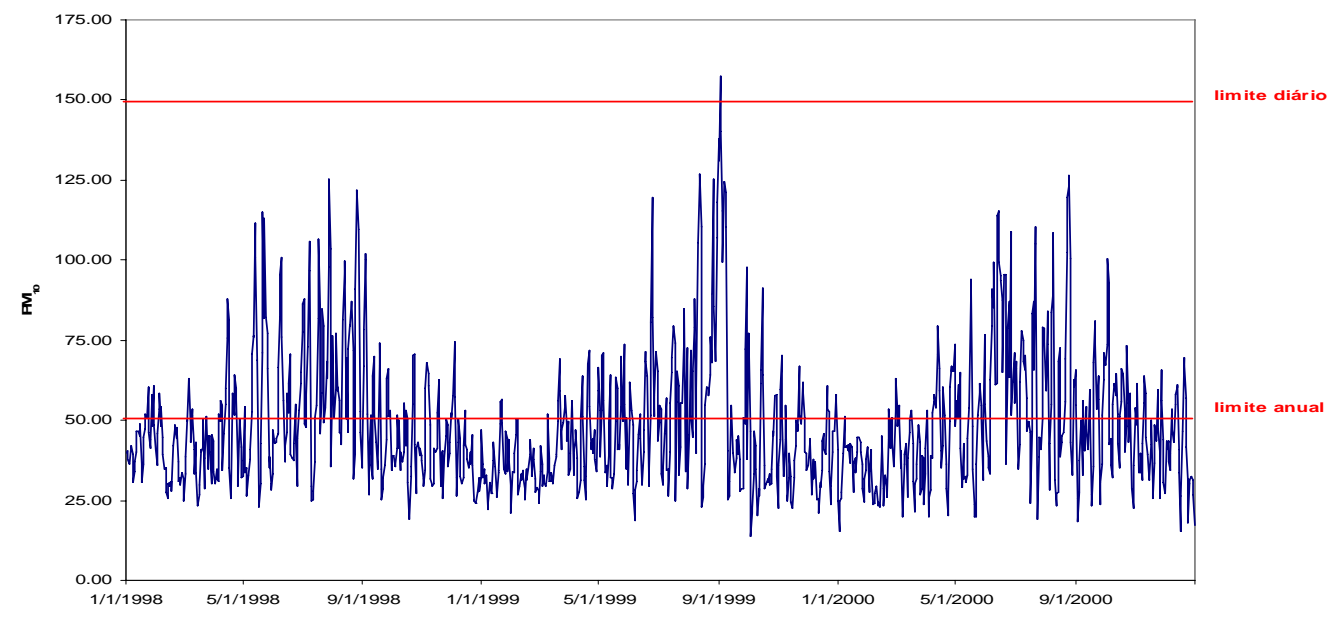

GRÁFICO 2 - MÉDIAS DIÁRIAS DE PM $10\left(\mu \mathrm{g} / \mathrm{m}^{3}\right)$ NO MUNICÍPIO DE SÃO PAULO ENTRE 1998 E 2000.

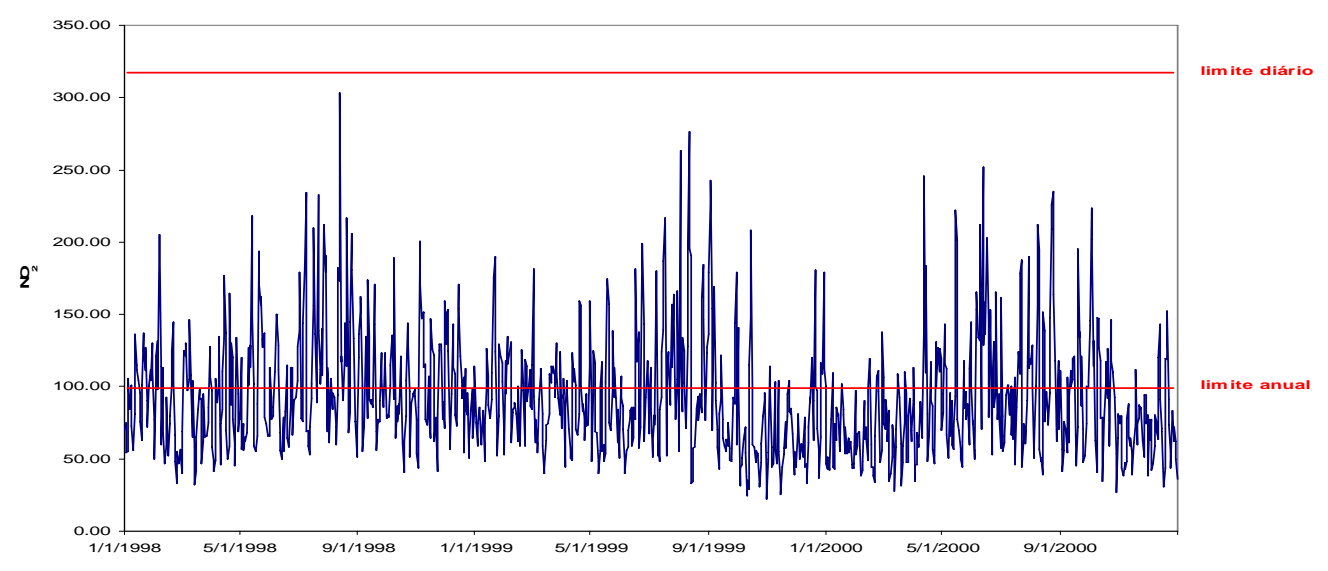

GRÁFICO 3 - MÉDIAS DIÁRIAS DE $\mathrm{NO}_{2}\left(\mu \mathrm{g} / \mathrm{m}^{3}\right)$ NO MUNICÍPIO DE SÃO PAULO ENTRE 1998 E 2000. 


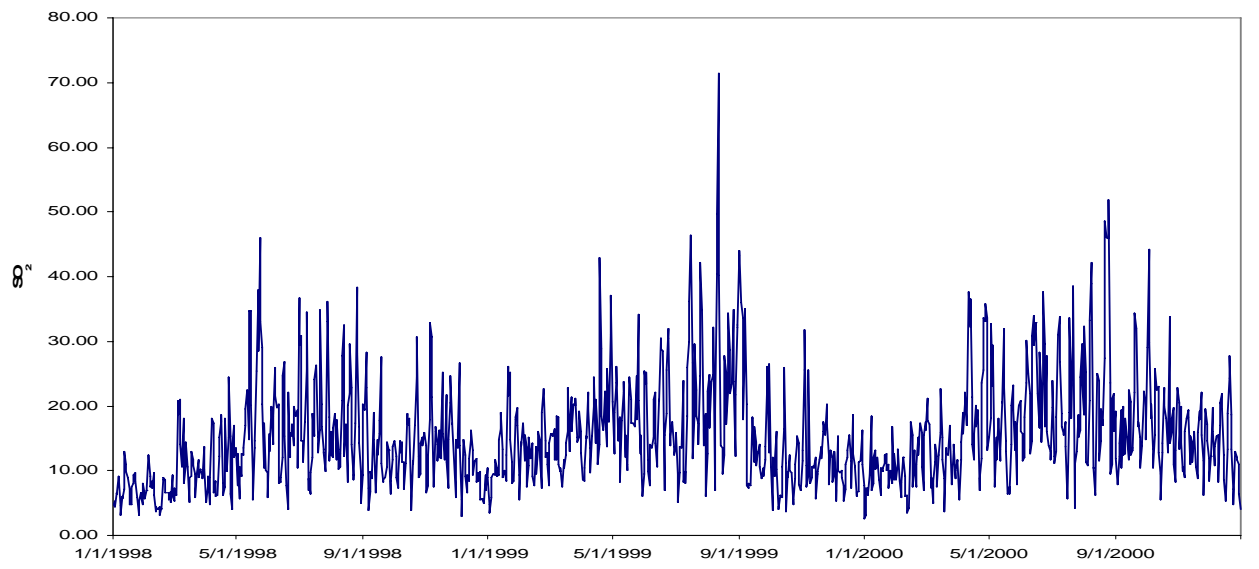

GRÁFICO 4 - MÉDIAS DIÁRIAS DE SO $\left(\mu \mathrm{g} / \mathrm{m}^{3}\right)$ NO MUNICÍPIO DE SÃO PAULO ENTRE 1998 E 2000.

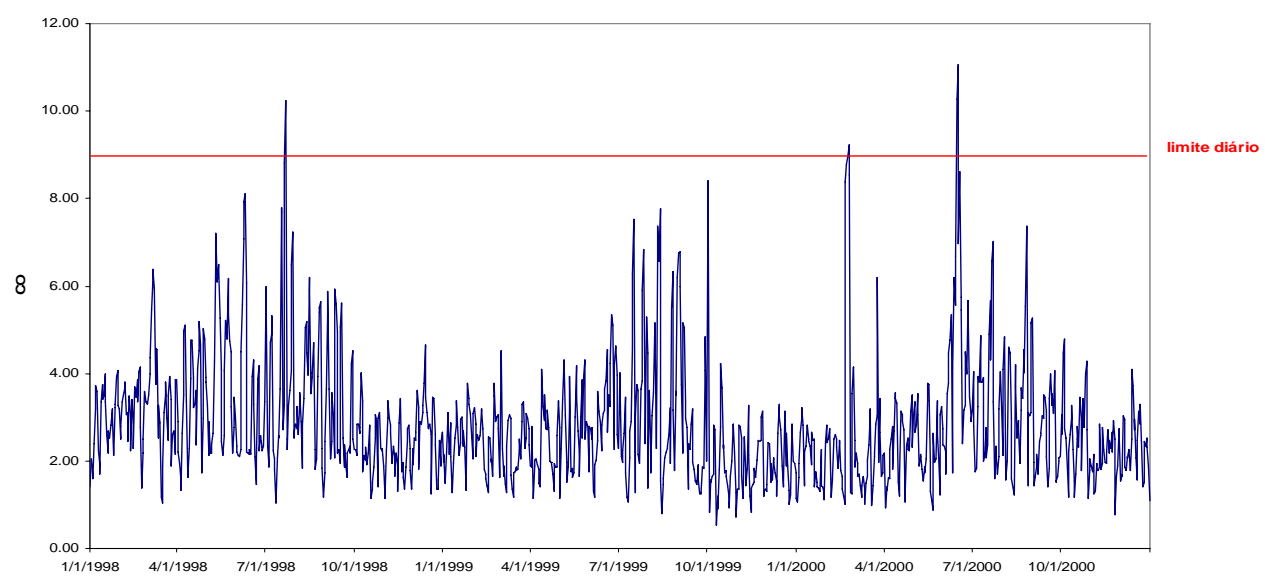

GRÁFICO 5 - MÉDIAS DIÁRIAS DE CO (ppm) NO MUNICÍPIO DE SÃO PAULO ENTRE 1998 E 2000. 


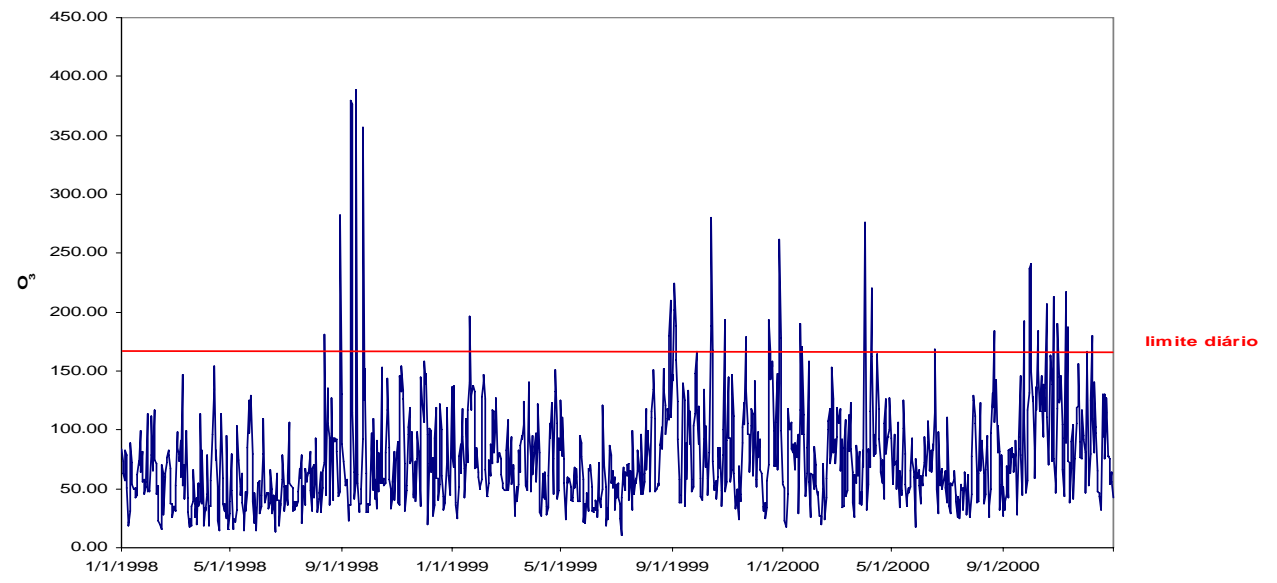

GRÁFICO 6 - MÉDIAS DIÁRIAS DE $\mathrm{O}_{3}\left(\mu \mathrm{g} / \mathrm{m}^{3}\right)$ NO MUNICÍPIO DE SÃO PAULO ENTRE 1998 e 2000.

As informações sobre o peso do RN e as concentrações dos poluentes encontram-se na tabela 6 de acordo com os meses do ano correspondentes às estações do ano. Pode-se constatar que a média do peso ao nascer e dos níveis de poluição, com exceção do $\mathrm{O}_{3}$, são maiores no inverno, enquanto que nos períodos mais quentes do ano ocorre o inverso. Como existe uma defasagem entre o início da gestação e o nascimento (nove meses) é possível que a exposição materna com início da gestação durante períodos mais frios (quando a poluição é mais alta) esteja contribuindo para um menor valor do peso do RN que nascerá nos meses mais quentes. Em estudo realizado por MURRAY et al (2000) foi observado uma menor média de peso ao nascer no final da primavera e no verão, confirmando assim os resultados desta dissertação. 
TABELA 6 - DISTRIBUIÇÃO DA MÉDIA DO PESO AO NASCER E DA MÉDIA DOS POLUENTES DO AR, COM SEUS RESPECTIVOS DESVIOS-PADRÕES (DP), DE ACORDO COM OS MESES DO ANO CORRESPONDENTES ÀS ESTAÇÕES DO ANO.

\begin{tabular}{lrrrr}
\hline & Jan-Mar & Abr-Jun & Jul-Set & Out-Dez \\
\hline $\begin{array}{c}\text { Peso ao nascer } \\
(\mathrm{g})\end{array}$ & 3111,4 & 3121,1 & 3130,4 & 3124,1 \\
$\mathrm{PM}_{10}\left(\mu \mathrm{g} / \mathrm{m}^{3}\right)$ & $(542,9)$ & $(539,2)$ & $(539,6)$ & $(549,0)$ \\
$\mathrm{SO}_{2}\left(\mu \mathrm{g} / \mathrm{m}^{3}\right)$ & $38,3(9,6)$ & $52,4(20,9)$ & $60,8(27,7)$ & $42,7(14,0)$ \\
$\mathrm{CO}(\mathrm{ppm})$ & $11,0(4,7)$ & $17,9(8,1)$ & $19,1(10,2)$ & $13,4(6,1)$ \\
$\mathrm{NO}_{2}\left(\mu \mathrm{g} / \mathrm{m}^{3}\right)$ & $2,7(1,3)$ & $3,2(1,5)$ & $3,3(1,7)$ & $2,3(0,9)$ \\
$\mathrm{O}_{3}\left(\mu \mathrm{g} / \mathrm{m}^{3}\right)$ & $83,4(30,4)$ & $95,7(40,4)$ & $108,6(49,8)$ & $84,2(36,8)$ \\
\hline
\end{tabular}

Além disso, constatou-se que a média da concentração dos poluentes (com exceção do O3) foi menor no $3^{\circ}$ trimestre de gestação em relação ao $1^{\circ}$ trimestre. Enquanto que as médias da concentração no $1^{\circ}$ trimestre do $\mathrm{CO}, \mathrm{NO} 2, \mathrm{SO} 2, \mathrm{PM} 10$ e O3 foram respectivamente $3,1 \mathrm{ppm} ; 100,4 \mu \mathrm{g} / \mathrm{m}^{3} ; 15,6 \mu \mathrm{g} / \mathrm{m}^{3} ; 51,8 \mu \mathrm{g} / \mathrm{m}^{3}$ e 71,1 $\mu \mathrm{g} / \mathrm{m}^{3}$, no $3^{\circ}$ trimestre foram $2,9 \mathrm{ppm} ; 94,9 \mu \mathrm{g} / \mathrm{m}^{3} ; 15,3 \mu \mathrm{g} / \mathrm{m}^{3} ; 49,1 \mu \mathrm{g} / \mathrm{m}^{3}$ e 75,4 .

\subsection{Análise Univariada}

A partir da Tabela 7 os dados foram organizados através das seguintes exclusões: dos que nasceram em outro município e fora do ambiente hospitalar, dos partos gemelares, pré-termos e pós-termos, dos que nasceram com peso abaixo de 
$1000 \mathrm{~g}$ e acima de 5500g, e residentes em distritos mais periféricos. Desse modo, restaram para as análises subseqüentes apenas 311.735 nascimentos.

$\mathrm{Na}$ tabela 7 estão algumas variáveis relativas ao recém-nascido com sua distribuição e a prevalência de BPN. Pode-se observar que houve associação estatisticamente significante $(\mathrm{p}<0,001)$ entre BPN e todas as variáveis analisadas.

Do total das crianças estudadas, $14.388(4,6 \%)$ apresentaram peso abaixo de 2.500g. A queda acentuada observada entre o conjunto de 595.559 e os 311.735 devese principalmente à exclusão dos prematuros e dos gemelares. 
TABELA 7 -PREVALÊNCIA E OR COM RESPECTIVOS INTERVALOS DE CONFIANÇA (IC 95\%) DE BAIXO PESO AO NASCER ( $<2500 G)$, DOS NASCIDOS VIVOS A TERMO E NÃO GEMELARES NO MUNICÍPIO DE SÃO PAULO (EXCLUINDO REGIÕES MAIS PERIFÉRICAS) DE MÃES RESIDENTES NESTA CIDADE NO PERÍODO ENTRE $1998 \mathrm{E}$ 2000, SEGUNDO VARIÁVEIS RELATIVAS À MÃE, RECÉM-NASCIDO, GESTAÇÃO E PARTO.

\begin{tabular}{|c|c|c|c|c|c|}
\hline VARIÁVEIS & $\mathrm{N}=311.735$ & $\begin{array}{r}\text { PREVALÊNCIA DE BAIXO } \\
\text { PESO AO NASCER }\end{array}$ & OR & IC95\% & $\bar{p}$ \\
\hline Sexo & & & & & $<0,001$ \\
\hline Masculino & 158.782 & 3,86 & 1,00 & - & \\
\hline Feminino & 152.942 & 5,40 & 1,42 & $1,37-1,47$ & \\
\hline Idade materna (anos) & & & & & $<0,001$ \\
\hline Abaixo 20 anos & 48.070 & 5,80 & 1,50 & $1,42-1,58$ & \\
\hline Entre 20 e 24 anos & 85.133 & 4,54 & 1,15 & $1,10-1,21$ & \\
\hline Entre 25 e 29 anos & 82.489 & 3,96 & 1,00 & - & \\
\hline Entre 30 e 34 anos & 61.011 & 4,24 & 1,07 & $1,02-1,13$ & \\
\hline Entre 35 e 39 anos & 28.376 & 4,92 & 1,26 & $1,18-1,34$ & \\
\hline Acima de 39 anos & 6.447 & 7,35 & 1,93 & $1,74-2,13$ & \\
\hline Escolaridade materna & & & & & $<0,001$ \\
\hline Nenhuma & 3.784 & 5,87 & 1,89 & $1,64-2,18$ & \\
\hline $1^{\circ}$ grau incompleto & 110.974 & 5,10 & 1,63 & $1,54-1,73$ & \\
\hline $1^{\circ}$ grau completo e $2^{\circ}$ grau & 98.195 & 4,32 & 1,37 & $1,29-1,45$ & \\
\hline Universitário & 51.270 & 3,19 & 1,00 & - & \\
\hline $\mathrm{N}^{o}$ de filhos vivos & & & & & $<0,001$ \\
\hline Nenhum & 120.843 & 4,96 & 1,29 & $1,24-1,34$ & \\
\hline Entre 1 e 3 & 132.225 & 3,89 & 1,00 & & \\
\hline Mais de 3 & 58.667 & 5,55 & 1,45 & $1,39-1,52$ & \\
\hline $\mathrm{N}^{\circ}$ de filhos mortos & & & & & $<0,001$ \\
\hline Nenhum & 225.734 & 4,41 & 1,00 & - & \\
\hline Um ou mais & 12.079 & 5,96 & 1,38 & $1,27-1,49$ & \\
\hline Tipo de parto & & & & & $<0,001$ \\
\hline Vaginal & 156.695 & 5,07 & 1,23 & $1,19-1,28$ & \\
\hline Cesáreo & 153.180 & 4,15 & 1,00 & ( & \\
\hline Consulta de pré-natal & & & & & $<0,001$ \\
\hline nenhuma & 5.215 & 9,26 & 2,65 & $2,40-2,92$ & \\
\hline Até 6 consultas & 86.913 & 5,44 & 1,49 & $1,43-1,56$ & \\
\hline Mais de 6 consultas & 132.999 & 3,71 & 1,00 & - & \\
\hline
\end{tabular}

NOTA: $\mathrm{o} \mathrm{n}^{\mathrm{o}}$ de ignorados para as variáveis sexo, idade materna, escolaridade materna, $\mathrm{n}^{\circ}$ de filhos mortos, tipo de parto e consulta pré-natal foi respectivamente: $11,209,47.512,73.922,1.860$ e 86.608 .

Foram constatadas maiores freqüências de BPN na faixa etária mais jovem (abaixo de 24 anos) e também na faixa etária acima de 35 anos. Quanto ao número de filhos vivos, mães com nenhum ou mais de 3 filhos vivos têm maior chance de ter um 
$\mathrm{RN}$ com peso abaixo de $2.500 \mathrm{~g}$. A mãe com maior grau de instrução tem menor risco de ter um filho com BPN. Com relação a história materna de pelo menos um filho morto o risco também aparece. Para as características de gestação e parto, observa-se que as crianças nascidas de parto normal apresentaram maior risco de baixo peso em relação à cesárea, (OR 1,23; IC 95\%, 1,19-1,28). Além disso, há um aumento crescente deste risco quanto menor o número de consultas pré-natais, apresentando $\mathrm{OR}=2,65$ (IC 95\%, 2,40-2,92) para aqueles nascimentos onde não foi realizado prénatal.

Ainda na análise univariada, examinou-se a associação da exposição materna durante a gestação à poluição do ar e o peso do RN, através de modelos lineares (peso ao nascer) e logísticos (BPN).

\subsubsection{Regressão linear}

Na regressão linear todos os poluentes mostraram-se associados negativamente ao peso ao nascer principalmente no $1^{\circ}$ trimestre, com exceção do $\mathrm{O}_{3}$. O monóxido de carbono foi o poluente que mais interferiu sobre o peso do RN, para cada $1 \mathrm{ppm}$ de aumento de sua concentração na exposição materna, a criança teve um decréscimo de 21,1g no seu peso de nascimento (Tabela 8). Já a exposição materna aos poluentes no $2^{\circ}$ e $3^{\circ}$ trimestres de gestação nem sempre apresentou um efeito negativo sobre o peso do recém-nascido. 
TABELA 8 - VARIAÇÃO DO PESO AO NASCER PARA CADA $1 \mu \mathrm{g} / \mathrm{m}^{3}$ DE AUMENTO NA EXPOSIÇÃO MÉDIA MATERNA AOS POLUENTES DO AR (EXCETO CO PARA O QUAL É USADA A MEDIDA DE 1ppm) EM CADA TRIMESTRE DA GESTAÇÃO, NO MUNICÍPIO DE SÃO PAULO ENTRE 1998 E 2000 (ANÁLISE LINEAR UNIVARIADA).

\begin{tabular}{|c|c|c|c|}
\hline & TRIMESTRES & COEFICIENTE (DP) & IC 95\% \\
\hline & $\mathrm{CO}$ & & \\
\hline $1^{\circ}$ & & $-21,1(1,1)$ & $-23,3$ a $-19,0$ \\
\hline $2^{\circ}$ & & $-12,8(1,4)$ & $-15,4$ a $-10,1$ \\
\hline \multirow[t]{2}{*}{3} & & $-3,1(1,6)$ & $-6,2$ a $-0,1$ \\
\hline & PM10 & & \\
\hline $1^{\circ}$ & & $-1,0(0,1)$ & $-1,1 \mathrm{a}-0,8$ \\
\hline $2^{\circ}$ & & $-4,3(1,6)$ & $-7,4 \mathrm{a}-1,1$ \\
\hline \multirow[t]{2}{*}{3} & & $0,8(0,1)$ & 0,6 a 1,0 \\
\hline & NO2 & & \\
\hline $1^{\circ}$ & & $-0,9(0,04)$ & $-1,0$ a $-0,8$ \\
\hline $2^{\circ}$ & & $-0,7(0,1)$ & $-0,8$ a $-0,6$ \\
\hline \multirow[t]{2}{*}{3} & & $-0,1(0,1)$ & $-0,2$ a 0,1 \\
\hline & $\mathrm{O} 3$ & & \\
\hline $1^{\circ}$ & & $1,1(0,1)$ & 1,00 a 1,2 \\
\hline $2^{\circ}$ & & $0,6(0,1)$ & 0,4 a 0,7 \\
\hline \multirow[t]{2}{*}{$3^{\circ}$} & & $0,6(0,1)$ & 0,5 a 0,7 \\
\hline & $\mathrm{SO} 2$ & & \\
\hline $1^{\circ}$ & & $-1,2(0,2)$ & $-1,6$ a $-0,9$ \\
\hline $2^{\circ}$ & & $1,5(0,2)$ & 1,0 a 1,9 \\
\hline $3^{\circ}$ & & $3,2(0,2)$ & 2,8 a 3,6 \\
\hline
\end{tabular}

\subsubsection{Regressão logística}

Quanto à análise logística univariada, a exposição materna ao $\mathrm{CO}\left(1^{\circ}, 2^{\circ}\right.$ e $3^{\circ}$ trimestres $)$, ao $\mathrm{NO}_{2}\left(1^{\circ}\right.$ e $2^{\circ}$ trimestres $)$ e ao $\mathrm{PM}_{10}\left(1^{\circ}\right.$ trimestre $)$ apresenta um maior risco para o nascimento de uma criança com baixo peso conforme o aumento de suas concentrações, representadas pelos quartis. Estes resultados foram estatisticamente significantes, com exceção do $3^{\circ}$ trimestre do CO (Tabela 9). Apesar do resultado da análise da exposição materna no $1^{\circ}$ trimestre ao $\mathrm{SO}_{2}$ mostrar-se como risco para $\mathrm{BPN}$, ela não foi estatisticamente significante. Todavia, para o $2^{\circ}$ e $3^{\circ}$ trimestres a exposição 
ao $\mathrm{SO}_{2}$ aparece como fator de proteção. Ao se analisar o ozônio, verifica-se também ser um fator de proteção para o BPN nos três trimestres de exposição materna.

TABELA 9 - ODDS RATIO (OR), INTERVALOS DE CONFIANÇA (IC 95\%) PARA BAIXO PESO AO NASCER DE ACORDO COM OS QUARTIS DE CONCENTRAÇÃO DOS POLUENTES ATMOSFÉRICOS EM CADA TRIMESTRE GESTACIONAL, NO MUNICÍPIO DE SÃO PAULO ENTRE 1998 E 2000 (ANÁLISE LOGÍSTICA UNIVARIADA).

\begin{tabular}{|c|c|c|c|c|c|c|c|}
\hline \multicolumn{2}{|c|}{ QUARTIL } & \multicolumn{2}{|c|}{$1^{\circ}$ TRIMESTRE } & \multicolumn{2}{|c|}{$2^{\circ}$ TRIMESTRE } & \multicolumn{2}{|c|}{$3^{\circ}$ TRIMESTRE } \\
\hline & & OR & IC95\% & OR & IC95\% & OR & IC95\% \\
\hline \multirow{5}{*}{ PM10 } & $1^{\circ}$ & & 1 & & 1 & & 1 \\
\hline & $2^{\circ}$ & 1,06 & $(1,01-1,12)$ & 1,04 & $(0,99-1,09)$ & 1,04 & $(0,99-1,09)$ \\
\hline & $3^{\circ}$ & 1,07 & $(1,02-1,12)$ & 1,04 & $(1,01-1,10)$ & 1,01 & $(0,95-1,04)$ \\
\hline & $4^{\circ}$ & 1,13 & $(1,08-1,18)$ & 1,03 & $(0,98-1,08)$ & 0,96 & $(0,91-1,01)$ \\
\hline & & & $\mathrm{p}<0,001$ & & $p=0,187$ & & $\mathrm{p}=0,027$ \\
\hline \multirow{5}{*}{$\mathrm{CO}$} & $1^{\circ}$ & & 1 & & 1 & & 1 \\
\hline & $2^{\circ}$ & 1,04 & $(0,99-1,09)$ & 1,06 & $(1,01-1,11)$ & 1,01 & $(0,98-1,07)$ \\
\hline & $3^{\circ}$ & 1,06 & $(1,01-1,11)$ & 1,10 & $(1,04-1,15)$ & 1,02 & $(0,97-1,07)$ \\
\hline & $4^{\circ}$ & 1,15 & $(1,10-1,21)$ & 1,08 & $(1,03-1,13)$ & 1,05 & $(1,00-1,09)$ \\
\hline & & & $\mathrm{p}<0,001$ & & $\mathrm{p}=0,001$ & & $\mathrm{p}=0,106$ \\
\hline \multirow{5}{*}{$\mathrm{SO} 2$} & $1^{\circ}$ & & 1 & & 1 & & 1 \\
\hline & $2^{\circ}$ & 1,01 & $(0,96-1,06)$ & 1,02 & $(0,97-1,06)$ & 1,01 & $(0,97-1,06)$ \\
\hline & $3^{\circ}$ & 1,01 & $(0,96-1,06)$ & 0,98 & $(0,93-1,03)$ & 0,99 & $(0,95-1,04)$ \\
\hline & $4^{\circ}$ & 1,04 & $(0,99-1,09)$ & 0,94 & $(0,90-0,99)$ & 0,90 & $(0,86-0,94)$ \\
\hline & & & $\mathrm{p}=0,138$ & & $\mathrm{p}=0,007$ & & $\mathrm{p}<0,001$ \\
\hline \multirow{3}{*}{ NO2 } & $1^{\mathrm{o}}$ & & 1 & & 1 & & 1 \\
\hline & $2^{\circ}$ & 1,04 & $(0,99-1,09)$ & 1,06 & $(1,01-1,11)$ & 1,09 & $(1,04-1,14)$ \\
\hline & $3^{\circ}$ & 1,05 & $(1,01-1,10)$ & 1,04 & $(0,99-1,09)$ & 1,04 & $(0,99-1,09)$ \\
\hline \multirow{7}{*}{$\mathrm{O} 3$} & $4^{\circ}$ & 1,12 & $(1,07-1,17)$ & 1,10 & $(1,05-1,15)$ & 1,01 & $(0,96-1,06)$ \\
\hline & & & $\mathrm{p}<0,001$ & & $\mathrm{p}=0,001$ & & $\mathrm{p}=0,828$ \\
\hline & $1^{\circ}$ & & 1 & & 1 & & 1 \\
\hline & $2^{\circ}$ & 0,98 & $(0,94-1,03)$ & 0,96 & $(0,92-1,01)$ & 0,93 & $(0,89-0,98)$ \\
\hline & $3^{\circ}$ & 0,88 & $(0,84-0,92)$ & 0,93 & $(0,88-0,97)$ & 0,93 & $(0,89-0,98)$ \\
\hline & $4^{\circ}$ & 0,88 & $(0,84-0,93)$ & 0,93 & $(0,89-0,98)$ & 0,93 & $(0,89-0,97)$ \\
\hline & & & $\mathrm{p}<0,001$ & & $\mathrm{p}=0,001$ & & $\mathrm{p}=0,003$ \\
\hline
\end{tabular}




\subsection{Análise multivariada}

\subsubsection{Regressão Linear}

Nesta análise houve o ajustamento para as seguintes variáveis: pré-natal, escolaridade e idade materna, sexo do recém-nascido, $\mathrm{n}^{\mathrm{o}}$ de filhos mortos, tipo de parto, número de filhos vivos e ano de nascimento.

No $1^{\circ}$ trimestre a exposição materna para todos os poluentes, com exceção do $\mathrm{O}_{3}$, ocasionou uma diminuição da média do peso ao nascer. $\mathrm{O}$ decréscimo do peso foi de $0,60 \mathrm{~g} ; 11,87 \mathrm{~g} ; 0,47 \mathrm{~g}$ e $1,26 \mathrm{~g}$ respectivamente para um aumento na exposição média materna de $1 \mu \mathrm{g} / \mathrm{m}^{3}$ do $\mathrm{PM}_{10}, \mathrm{NO}_{2}$ e $\mathrm{SO}_{2}$ e $1 \mathrm{ppm}$ do $\mathrm{CO}$, sendo estatisticamente significante para todos (Tabela 10). No entanto, durante o $2^{\circ}$ trimestre de gestação, a exposição materna ao $\mathrm{CO}$ e $\mathrm{SO}_{2}$, indica um acréscimo do peso ao nascer do $\mathrm{RN}$, enquanto que no $3^{\mathrm{o}}$ trimestre este acréscimo aparece com a exposição a todos os poluentes (com exceção do $\mathrm{O}_{3}$ ), sendo estes resultados estatisticamente significantes. 
TABELA 10 - COEFICIENTES DE REGRESSÃO COM SEUS RESPECTIVOS DESVIOS-PADRÕES (DP) E INTERVALOS DE CONFIANÇA DE 95\%, SEGUNDO AS MÉDIAS TRIMESTRAIS DA CONCENTRAÇÃO DOS POLUENTES ATMOSFÉRICOS CORRESPONDENTES AOS TRIMESTRES GESTACIONAIS (REGRESSÃO LINEAR MÚLTIPLA).

\begin{tabular}{llrr}
\hline & POLUENTES & COEFICIENTE (DP) & IC95\% \\
\hline PM10 & $1^{\circ}$ trimestre & $-0,6(0,1)$ & $-0,8 \mathrm{a}-0,4$ \\
& $2^{\mathrm{o}}$ trimestre & $0,04(0,1)$ & $-0,2 \mathrm{a} 0,3$ \\
& $3^{\mathrm{o}}$ trimestre & $0,8(0,1)$ & $0,57 \mathrm{a} 1,02$ \\
& & & \\
$\mathrm{CO} \quad$ & $1^{\mathrm{o}}$ trimestre & $-11,9(1,9)$ & $-15,5 \mathrm{a}-8,2$ \\
& $2^{\mathrm{o}}$ trimestre & $4,9(2,3)$ & $0,5 \mathrm{a} 9,3$ \\
& $3^{\mathrm{o}}$ trimestre & $12,1(2,3)$ & $7,6 \mathrm{a} 16,6$ \\
& & & \\
$\mathrm{NO}_{2}$ & $1^{\circ}$ trimestre & $-0,5(0,1)$ & $-0,6 \mathrm{a}-0,3$ \\
& $2^{\mathrm{o}}$ trimestre & $-0,02(0,1)$ & $-0,2 \mathrm{a} 0,1$ \\
& $3^{\mathrm{o}}$ trimestre & $0,6(0,1)$ & $0,4 \mathrm{a} 0,7$ \\
& & & \\
$\mathrm{O}_{3}$ & $1^{\circ}$ trimestre & $0,5(0,1)$ & $0,3 \mathrm{a} 0,7$ \\
& $2^{\mathrm{o}}$ trimestre & $-0,7(0,1)$ & $-1,0 \mathrm{a}-0,5$ \\
& $3^{\mathrm{o}}$ trimestre & $0,1(0,1)$ & $-0,1 \mathrm{a} 0,2$ \\
& & & \\
$\mathrm{SO}_{2}$ & $1^{\circ}$ trimestre & $-1,3(0,2)$ & $-1,7 \mathrm{a}-0,8$ \\
& $2^{\circ}$ trimestre & $0,7(0,3)$ & $0,2 \mathrm{a} 1,3$ \\
& $3^{\mathrm{o}}$ trimestre & $2,0(0,3)$ & $1,5 \mathrm{a} 2,6$ \\
\hline
\end{tabular}

NOTA: Modelo ajustado para as variáveis: pré-natal, idade e escolaridade materna, sexo do recémnascido, tipo de parto, $\mathrm{n}^{\mathrm{o}}$ de filhos mortos e vivos, e ano de nascimento.

\subsubsection{Regressão logística}

A exposição materna a cada poluente foi analisada em quartis e realizada análise segundo o $1^{\circ}, 2^{\circ}$ e $3^{\circ}$ trimestres da gestação, os quais foram calculados a partir da data de nascimento da criança. Nesta análise houve o ajustamento para as seguintes variáveis: pré-natal, escolaridade e idade materna, sexo do recém-nascido, $\mathrm{n}^{\circ}$ de filhos mortos, tipo de parto, número de filhos vivos e ano de nascimento. $\mathrm{O} 1^{\mathrm{o}}$ quartil foi a referência para o cálculo dos resultados. Nenhum poluente apresentou resultado estatisticamente significante (Tabela 11). Além disso, não foi constatada uma tendência de aumento no risco para um aumento da concentração dos poluentes, não aumentando nem diminuindo o risco de BPN com a exposição materna, apesar que, 
durante o $2^{\circ}$ trimestre gestacional a exposição ao $\mathrm{PM}_{10}, \mathrm{SO}_{2}$, e $\mathrm{O}_{3}$ não aparece como fator de risco, enquanto que no $1^{\circ}$ e $3^{\circ}$ trimestres isso ocorre respectivamente com o $\mathrm{CO}$ e $\mathrm{O}_{3}$.

TABELA 11 - ODDS RATIO (OR), INTERVALOS DE CONFIANÇA (IC 95\%) PARA BAIXO PESO AO NASCER DE ACORDO COM OS QUARTIS DE CONCENTRAÇÃO DOS POLUENTES ATMOSFÉRICOS EM CADA TRIMESTRE GESTACIONAL, NO MUNICÍPIO DE SÃO PAULO ENTRE 1998 E 2000 (REGRESSÃO LOGÍSTICA MÚLTIPLA).

\begin{tabular}{|c|c|c|c|c|c|c|c|}
\hline \multirow[b]{2}{*}{ POLUENTES } & \multirow[t]{2}{*}{ QUARTIL } & \multicolumn{2}{|c|}{$1^{\circ}$ TRIMESTRE } & \multicolumn{2}{|c|}{$2^{\circ}$ TRIMESTRE } & \multicolumn{2}{|c|}{$3^{\circ}$ TRIMESTRE } \\
\hline & & OR & IC95\% & OR & IC95\% & OR & IC95\% \\
\hline \multirow{4}{*}{ PM10 } & $1^{\circ}$ & & 1 & & 1 & & - \\
\hline & $2^{\circ}$ & 1,01 & $(0,94-1,07)$ & 0,99 & $(0,93-1,05)$ & 1,01 & $(0,94-1,08)$ \\
\hline & $3^{\circ}$ & 1,03 & $(0,97-1,10)$ & 0,97 & $(0,91-1,04)$ & 1,00 & $(0,94-1,07)$ \\
\hline & $4^{\circ}$ & 1,01 & $(0,95-1,08)$ & 0,97 & $(0,91-1,04)$ & 0,99 & $(0,93-1,05)$ \\
\hline \multirow{4}{*}{$\mathrm{CO}$} & $1^{\circ}$ & & 1 & & 1 & & \\
\hline & $2^{\circ}$ & 0,98 & $(0,92-1,04)$ & 1,02 & $(0,95-1,08)$ & 1,03 & $(0,97-1,10)$ \\
\hline & $3^{\circ}$ & 0,98 & $(0,91-1,05)$ & 1,03 & $(0,96-1,10)$ & 0,95 & $(0,89-1,02)$ \\
\hline & $4^{\circ}$ & 0,98 & $(0,91-1,06)$ & 0,97 & $(0,90-1,05)$ & 1,03 & $(0,96-1,11)$ \\
\hline \multirow{4}{*}{$\mathrm{SO} 2$} & $1^{\mathrm{o}}$ & & 1 & & 1 & & \\
\hline & $2^{\circ}$ & 1,04 & $(0,97-1,11)$ & 0,97 & $(0,91-1,04)$ & 1,03 & $(0,96-1,10)$ \\
\hline & $3^{\circ}$ & 1,03 & $(0,96-1,10)$ & 0,95 & $(0,89-1,01)$ & 1,04 & $(0,98-1,11)$ \\
\hline & $4^{\circ}$ & 1,01 & $(0,95-1,07)$ & 0,97 & $(0,91-1,03)$ & 1,01 & $(0,93-1,07)$ \\
\hline \multirow{4}{*}{$\mathrm{NO} 2$} & $1^{\circ}$ & & 1 & & 1 & & \\
\hline & $2^{o}$ & 0,99 & $(0,93-1,06)$ & 1,01 & $(0,93-1,07)$ & 1,06 & $(0,98-1,13)$ \\
\hline & $3^{\circ}$ & 1,00 & $(0,94-1,07)$ & 0,98 & $(0,92-1,05)$ & 0,98 & $(0,92-1,05)$ \\
\hline & $4^{\circ}$ & 1,00 & $(0,93-1,08)$ & 0,98 & $(0,91-1,05)$ & 0,99 & $(0,93-1,06)$ \\
\hline \multirow{4}{*}{$\mathrm{O} 3$} & $1^{o}$ & & 1 & & 1 & & \\
\hline & $2^{\circ}$ & 1,03 & $(0,96-1,09)$ & 0,99 & $(0,93-1,06)$ & 0,95 & $(0,89-1,02)$ \\
\hline & $3^{\circ}$ & 0,99 & $(0,92-1,07)$ & 0,98 & $(0,91-1,07)$ & 0,95 & $(0,88-1,02)$ \\
\hline & $4^{\circ}$ & 1,01 & $(0,92-1,08)$ & 0,99 & $(0,91-1,08)$ & 0,98 & $(0,91-1,05)$ \\
\hline
\end{tabular}

NOTA: Modelo ajustado para as variáveis: pré-natal, escolaridade e idade materna, sexo do recém-nascido, $n^{\circ}$ de filhos mortos e vivos, tipo de parto e ano de nascimento. 


\subsubsection{Modelo com múltiplos poluentes}

Apesar da grande correlação existente entre os poluentes atmosféricos, tentouse estimar o efeito individual de cada um através da análise linear multivariada com mais de um poluente.

Essa análise foi realizada apenas com o $1^{\circ}$ trimestre de gestação, já que o $3^{\circ}$ apareceu como fator de proteção no resultado anterior, quando da inclusão de apenas um poluente. Com relação aos poluentes, $\mathrm{CO}, \mathrm{NO}_{2}, \mathrm{SO}_{2}$ e $\mathrm{PM}_{10}$ foram examinados, pois obtiveram resultados estatisticamente significantes no modelo com um poluente. $\mathrm{O}_{3}$ não foi incluído na análise pelo fato de ter um comportamento totalmente diferente dos demais.

Dessa forma, $\mathrm{CO}, \mathrm{NO}_{2}, \mathrm{SO}_{2}$ e $\mathrm{PM}_{10}$ foram analisados dois a dois e depois todos os quatro simultaneamente. Verificou-se, através da variação do coeficiente linear em modelo com um poluente e com quatro poluentes, que o $\mathrm{NO}_{2}$ permaneceu mais estável no modelo (0,0\%), seguido do $\mathrm{PM}_{10}(33,0 \%)$ e do $\mathrm{CO}(49,6 \%)$; enquanto que o $\mathrm{SO}_{2}$ apresentou grande instabilidade (98,0\%) (Quadro 3). 
QUADRO 3 - Coeficientes obtidos da regressão linear múltipla em modelos com um, dois, três e quatro poluentes, de acordo com exposição materna no $1^{\circ}$ trimestre.

\begin{tabular}{|l|l|l|l|l|l|l|l|l|}
\hline Poluentes & $\begin{array}{l}\text { Modelo } \\
\text { com um } \\
\text { poluente }\end{array}$ & $\begin{array}{l}\text { Modelo } \\
\text { com dois } \\
\text { poluentes } \\
(\mathrm{CO} \\
\left.\mathrm{ePM}_{10}\right)\end{array}$ & $\begin{array}{l}\text { Modelo } \\
\text { com dois } \\
\text { poluentes } \\
\left(\mathrm{PM}_{10} \mathrm{e}\right. \\
\left.\mathrm{SO}_{2}\right)\end{array}$ & $\begin{array}{l}\text { Modelo } \\
\text { com dois } \\
\text { poluentes } \\
(\mathrm{CO} \text { e } \\
\left.\mathrm{SO}_{2}\right)\end{array}$ & $\begin{array}{l}\text { Modelo } \\
\text { com dois } \\
\text { poluentes } \\
(\mathrm{CO} \text { e } \\
\left.\mathrm{NO}_{2}\right)\end{array}$ & $\begin{array}{l}\text { Modelo } \\
\text { com dois } \\
\text { poluentes } \\
\left(\mathrm{PM}_{10} \mathrm{e}\right. \\
\left.\mathrm{NO}_{2}\right)\end{array}$ & $\begin{array}{l}\text { Modelo } \\
\text { com dois } \\
\text { poluentes } \\
\left(\mathrm{SO}_{2} \mathrm{e}\right. \\
\left.\mathrm{NO}_{2}\right)\end{array}$ & $\begin{array}{l}\text { Modelo } \\
\text { com os } \\
\text { quatro } \\
\text { poluentes }\end{array}$ \\
\hline $\mathrm{CO}$ & $-11,9$ & $-8,0^{*}$ & - & $-10,6$ & $-1,7 *$ & - & - & $-6,0 *$ \\
\hline $\mathrm{PM}_{10}$ & $-0,6$ & $-0,2^{*}$ & $-0,5$ & - & - & $0,2 *$ & - & $0,4 *$ \\
\hline $\mathrm{SO}_{2}$ & $-1,3$ & - & $-0,2^{*}$ & $-0,2^{*}$ & - & - & $0,1 *$ & $-0,02 *$ \\
\hline $\mathrm{NO}_{2}$ & $-0,5$ & - & - & - & $-0,4$ & $-0,6$ & $-0,5$ & $-0,5$ \\
\hline
\end{tabular}

NOTA: Modelo ajustado para as variáveis: pré-natal, escolaridade e idade materna, sexo do recém-nascido, $\mathrm{n}^{\circ}$ de filhos mortos e vivos, tipo de parto e ano de nascimento.

* não estatisticamente significante. $p>0,05$

A razão fundamental para esse tipo de análise é que ao se considerar a alta correlação entre os poluentes, um deles poderia praticamente não ter um efeito próprio, mas expressaria a ação dos outros, como é o caso do $\mathrm{SO}_{2}$. Assim, o resultado do modelo, com dois ou mais poluentes, atenuaria esse efeito e forneceria um valor mais próximo do real, podendo-se identificar qual poluente estaria tendo um comportamento mais instável. 


\section{DISCUSSÃo}

O BPN esteve associado com todas as variáveis estudadas referentes às características da mãe, do recém-nascido, gestação e parto. A prevalência e o risco de nascer com baixo peso foi maior para o $\mathrm{RN}$ do sexo feminino, em mães com idade inferior a 24 anos e superior a 35 anos, com menor nível de instrução, em nulíparas e multíparas com mais de três filhos, com história de um ou mais filhos mortos, quando o parto foi vaginal e quando as mães realizaram menos de seis consultas de pré-natal. Esses resultados confirmam os dados presentes na literatura e reforçam a necessidade de ações voltadas para a efetivação dos programas de saúde materno-infantil, principalmente para a camada mais pobre da população.

A associação da exposição materna durante a gestação à poluição do ar e o peso do RN também foi analisada. Entretanto, é importante lembrar que neste estudo toda a população de gestantes está exposta aos poluentes. Desse modo, o que se buscou analisar aqui foi a diferença entre o grau de exposição nos diferentes trimestres da gravidez, caracterizando de altas a baixas exposições. A quantificação da diferença encontrada é o que se chama de medida de associação (KALE; COSTA; LUIZ, 2002). Nesta pesquisa utilizou-se como medida de associação o Odds Ratio (OR), já que o objetivo foi de responder, se a chance de ter um filho com baixo peso ao nascer é maior ou menor segundo a exposição materna aos poluentes, ou seja, a medida estimada foi a razão de chances. Também se utilizou como medida de associação o coeficiente linear que representou o acréscimo ou o decréscimo no peso ao nascer em gramas segundo a exposição materna nos diferentes trimestres de gestação. 
Ao se analisar a poluição do ar, evidenciou-se que o $\mathrm{CO}, \mathrm{NO}_{2}, \mathrm{SO}_{2}$ e $\mathrm{PM}_{10}$ mostraram associação estatisticamente significante com o peso do $\mathrm{RN}$, indicando um menor ganho de peso quando da exposição materna durante o $1^{\circ}$ trimestre de gestação. Essa análise foi controlada pelas variáveis pré-natal, idade e escolaridade materna, sexo do recém-nascido, tipo de parto, $\mathrm{n}^{\mathrm{o}}$ de filhos mortos e vivos, e ano de nascimento.

Apesar da dificuldade em isolar o efeito de cada poluente, devido a alta correlação entre eles, pôde-se observar que o $\mathrm{SO}_{2}$ apresentou grande instabilidade, aparecendo com efeito pouco expressivo em relação aos demais. Ao se considerar o tamanho do efeito, a plausibilidade biológica e a estabilidade, o $\mathrm{CO}$ tem um efeito proporcionalmente maior que o $\mathrm{NO}_{2}$ e o $\mathrm{PM}_{10}$. $\mathrm{O}$ monóxido de carbono determinou um menor ganho de peso ao nascer $(-11,9 \mathrm{~g})$, quando a exposição ocorreu durante o $1^{\circ}$ trimestre gestacional, sendo este resultado estatisticamente significante. No modelo com múltiplos poluentes o $\mathrm{CO}$ não foi o mais instável, além disso, muito se conhece na literatura o seu efeito no transporte de oxigênio pelo sangue.

Diferente do que ocorreu no $1^{\circ}$ trimestre de gestação, todos os poluentes estiveram associados ao ganho de peso do $\mathrm{RN}$ no $3^{\circ}$ trimestre e os resultados foram estatisticamente significantes (com exceção do $\mathrm{O}_{3}$ ).

Essa relação entre exposição no terceiro trimestre e baixo peso ao nascer, não implica em efeito protetor da poluição do ar, mas pode ser atribuída a diversas possibilidades. Primeiro, devido a característica do padrão sazonal da poluição atmosférica, o nível de exposição no $1^{\circ}$ e $2^{\circ}$ trimestres é quase sempre inversamente associado com o terceiro trimestre. Ao se analisar a média da concentração, para todos os poluentes em todos os trimestres, pode-se constatar que não foram elevadas. No 
entanto, a média da concentração dos poluentes foi menor no $3^{\circ}$ trimestre em relação ao $1^{\mathrm{o}}$ trimestre. Segundo, durante a gravidez, a velocidade do ganho de peso fetal apresenta um período de crescimento máximo que ocorre entre a $28^{\mathrm{a}}$ e a $37^{\mathrm{a}}$ semana de gestação. O hormônio liberador de corticotrofina (HLC) placentário participa no pico dos glicocorticóides fetais associados à maturação fetal no final do terceiro trimestre (LINTON et al, 1993). O HLC placentário estimula a liberação placentária de adrenocorticotrofina $(\mathrm{ACTH})$ in vitro em uma relação dose-dependente. A secreção de HLC e ACTH aumenta quando o fluxo sanguíneo uterino é restrito. O HLC é um potente vasodilatador uteroplacentário. Esse hormônio é liberado para a circulação fetal em resposta ao stress fetal e em condições que levam à restrição do crescimento (PERKINS et al, 1995). O HLC freqüentemente está elevado na pré-eclampsia, asfixia fetal, e trabalho de parto prematuro, e em várias condições que causam restrição do crescimento. Portanto, enquanto a exposição materna no $1^{\circ}$ trimestre aos poluentes do ar pode contribuir na restrição do crescimento fetal, a exposição crônica à poluição atmosférica no decorrer da gestação pode ser responsável pelo stress fetal que aumentará a liberação do HLC no final da gestação. O HLC liberado vai aumentar os glicocorticóides fetais, levando à maturação do feto no final do terceiro trimestre e favorecendo o ganho de peso neste período.

$\mathrm{Na}$ regressão logística multivariada nenhum poluente apresentou resultado estatisticamente significante, além disso, não foi constatada uma tendência de aumento no risco para um aumento da concentração dos poluentes, não aumentando nem diminuindo o risco de BPN com a exposição materna. 
Quanto a diferença observada entre os resultados dos modelos logístico e linear, provavelmente se deve a escala de medida utilizada neste último, onde a variável dependente é contínua e não discreta, possibilitando assim uma análise mais detalhada. A regressão linear possibilita a identificação de pequenas variações que o peso ao nascer pode estar sofrendo em decorrência de alguns fatores, como por exemplo, a poluição atmosférica. Já na regressão logística, como a variável peso ao nascer está dicotomizada, esta análise não permite identificar os recém-nascidos que tiveram um menor ganho de peso independente do valor de referência que é $2500 \mathrm{~g}$. Nesse aspecto, a regressão logística é muito mais restritiva do que o modelo linear. Com isso, pode-se entender que os resultados desse trabalho mostram que a poluição interfere negativamente sobre o peso ao nascer, mas não necessariamente irá determinar o baixo peso ao nascer. No entanto, as gestantes com alto risco para baixo peso ao nascer são particularmente susceptíveis aos efeitos adversos da poluição atmosférica.

\subsection{ESTUDOS EPIDEMIOLÓGICOS SOBRE BAIXO PESO AO NASCER E POLUIÇÃO DO AR}

A literatura é muito limitada com relação aos efeitos da poluição do ar sobre o BPN e os resultados desses estudos são um tanto controversos. Enquanto um estudo não encontra associação, e outros não especificam o período de exposição, alguns encontraram uma associação consistente quando a exposição ocorreu durante o $3^{\circ}$ trimestre gestacional, e outros no $1^{\mathrm{o}}$ trimestre. Dessa forma é importante comparar os resultados encontrados nesta pesquisa com o que vem sendo desenvolvido em outros 
locais, em diferentes momentos, destacando-se os poluentes estudados, a magnitude dos resultados encontrados, os trimestres incluídos ou não e as limitações.

Em relação aos poluentes analisados, encontrou-se nesta dissertação que o $\mathrm{PM}_{10}, \mathrm{NO}_{2}$ e $\mathrm{CO}$ estavam associados a um menor ganho de peso ao nascer, mas tendo o $\mathrm{CO}$ um efeito proporcionalmente maior que os demais. As pesquisas realizadas por HA et al (2001) e GOUVEIA et al (2004) também analisaram todos os poluentes e constataram que a exposição materna ao $\mathrm{CO}, \mathrm{PM}_{10}, \mathrm{SO}_{2}$ e $\mathrm{NO}_{2}$ contribuiu para um menor ganho de peso do recém-nascido, porémm estes autores apontaram um maior efeito do $\mathrm{CO}$ sobre o peso. Além disso, $\mathrm{o}_{3}$ apresenta um efeito contrário aos demais poluentes, ou seja, aparece como fator de "proteção", o que provavelmente seja em decorrência de sua característica de ser um poluente secundário e das variações de suas concentrações durante o ano não acompanharem as dos outros poluentes.

No entanto, nos trabalhos de RITZ; YU (1999) e no de ALDERMAN et al (1987) apenas o CO foi analisado, o que torna difícil uma comparação mais adequada com este estudo. Essa preocupação com o $\mathrm{CO}$ se deve ao grande número de veículos nos centros urbanos, uma das principais fontes deste poluente. Além disso, muito se conhece sobre como ele interfere no transporte do oxigênio pela hemoglobina.

Entre os trabalhos realizados que não incluíram o monóxido de carbono tem um realizado na China e um outro na República Tcheca. Em Beijing, o PTS e o $\mathrm{SO}_{2}$ apareceram associados com BPN (WANG et al, 1997). Porém, nesse estudo nas áreas estudadas não existem grandes indústrias e o principal meio de transporte é a bicicleta. Além disso, o fogão a lenha é usado para aquecer ou cozinhar em 97\% das famílias, sendo considerada a principal fonte de poluição nesta região. Dessa forma, ao analisar 
esse estudo com a presente dissertação, verifica-se que a principal fonte emissora de poluentes não corresponde a da cidade de São Paulo e que especificamente a concentração do $\mathrm{SO}_{2}$ encontrava-se em níveis superiores aos encontrados neste município. Mesmo assim pôde-se verificar o efeito negativo do $\mathrm{SO}_{2}$ sobre o peso do RN de mães residentes em São Paulo.

Um estudo ecológico realizado entre 1986 a 1988, na República Tcheca, $\mathrm{SO}_{2}$, NOx e PTS apareceram como fatores de risco para o BPN, mas apenas o resultado do efeito do $\mathrm{SO}_{2}$ foi estatisticamente significante (BOBAK; LEON, 1999).

Ao se analisar a magnitude do efeito da poluição do ar sobre o crescimento fetal, observa-se na maioria dos estudos que a exposição materna ao $\mathrm{CO}$, ao $\mathrm{PM}_{10}$ e ao $\mathrm{NO}_{2}$ esta associada com a redução do peso ao nascer (RITZ; YU, 1999; MAISONET et al, 2001; HA et al, 2001; GOUVEIA et al, 2003), o que confirma as informações presentes nesta dissertação, em que foi encontrada uma redução de $12 \mathrm{~g} ; 0,6$ e 0,5 respectivamente para exposição materna ao $\mathrm{CO}, \mathrm{PM}_{10}$ e $\mathrm{NO}_{2}$.

Em estudo realizado por GOUVEIA et al (2004) constatou-se que o peso ao nascer sofreu redução de 23 gramas para cada 1 ppm de aumento da concentração do CO e uma redução de 1,3 gramas para cada $1 \mu \mathrm{g} / \mathrm{m}^{3}$ de aumento da concentração do PM10 enquanto que para os demais poluentes esta redução não foi observada. Nesta dissertação encontrou-se respectivamente uma redução do peso ao nascer de 12 gramas e 0,6 gramas para cada 1ppm de aumento da concentração do $\mathrm{CO}$ e para cada $1 \mu \mathrm{g} / \mathrm{m}^{3}$ de aumento da concentração do PM10. Talvez a diferença nos valores encontrados possa ser em decorrência dos períodos de tempo analisados. A pesquisa 
desenvolvida por GOUVEIA et al (2004) incluiu os nascidos vivos do período de um ano apenas (1997), enquanto que esta dissertação abrangeu três anos (1998-2000).

CHEN et al (2002), em trabalho desenvolvido no norte de Nevada, verificaram que para cada $1 \mu \mathrm{g} / \mathrm{m}^{3}$ de aumento na concentração do $\mathrm{PM}_{10}$ há a possibilidade de redução do peso do recém-nascido em $1,1 \mathrm{~g}$.

Uma pesquisa desenvolvida em Taiwan identificou a redução de 0,52 g do peso ao nascer para cada $1 \mu \mathrm{g} / \mathrm{m}^{3}$ de aumento na concentração tanto de $\mathrm{SO}_{2}$ como do $\mathrm{PM}_{10}$ (YANG et al, 2003), ou seja, um valor próximo ao encontrado para o $\mathrm{PM}_{10}$ nesta dissertação.

A magnitude do efeito dos poluentes também pode ser verificada comparandose o risco de nascer com baixo peso através dos valores dos odds ratios, utilizando-se por exemplo, a regressão logística multivariada, com a média da concentração trimestral dos poluentes categorizados em quartis. Nesta dissertação os resultados encontrados nesse tipo de análise, não foram estatisticamente significantes. Em estudo realizado no nordeste dos Estados Unidos, os poluentes foram categorizados em quintis na análise logística, mas também não se constatou significância estatística (MAISONET et al, 2001). Na região norte de Nevada CHEN et al (2002) não constataram risco de BPN na análise logística.

No entanto, no sul da Califórnia, ao se categorizar a média da concentração trimestral do $\mathrm{CO}$, obteve-se para o quartil de maior concentração $(>=95 \%) \mathrm{OR}=1,22$ (IC 95\% 1,03-1,44), ou seja, um risco estatisticamente significante de nascer com baixo peso (RITZ; YU, 1999). 
Com relação aos trimestres de exposição materna e risco de menor peso ao nascer, nem todos os trabalhos identificaram associação entre a poluição do ar e BPN no mesmo trimestre, bem como nem todos analisaram os três trimestres de gestação.

Esta pesquisa pôde identificar um efeito negativo dos poluentes (com exceção do $\mathrm{O}_{3}$ ) sobre o peso do recém-nascido durante a exposição materna no $1^{\circ}$ trimestre de gestação.

Dos que incluíram os três trimestres de gravidez e identificaram associação entre BPN e poluição do ar no $1^{\circ}$ trimestre estão o estudo de GOUVEIA et al (2004), BOBAK (2000), YANG et al (2003) e o que identificou no $3^{\circ}$ trimestre está o de WANG et al (1997).

Em pesquisa realizada na República Tcheca, a exposição materna no $1^{\circ}$ trimestre ao PTS e ao SO2 foi identificada com um maior risco para o BPN (BOBAK, 2000). Foram analisados os nascimentos que ocorreram no período de um ano e exposição materna nos três trimestres de gestação. Diferentemente do que foi realizado nesta dissertação, BOBAK (2000) incluiu os prematuros durante a análise. Dessa forma, torna-se difícil comparar os resultados desse estudo com os desta dissertação.

Um trabalho desenvolvido em Taiwan também identificou a redução de peso ao nascer para exposição materna ao $\mathrm{PM}_{10}$ e ao $\mathrm{SO}_{2}$ durante $\mathrm{o} 1^{\circ}$ trimestre de gestação (YANG et al, 2003). Foram analisados os nascimentos de um período de três anos e os três trimestres de gestação.

No Brasil, mais especificamente na cidade de São Paulo, um estudo preliminar mostrou associação entre o peso ao nascer e a exposição materna aos poluentes no $1^{\circ}$ trimestre de gestação (GOUVEIA et al, 2004). Foram analisados os três trimestres de 
gestação num período de um ano. Essa pesquisa confirma os resultados encontrados nesta dissertação, em que é maior a vulnerabilidade materna no $1^{\circ}$ trimestre de gestação e principalmente ao CO.

A pesquisa de $\mathrm{HA}$ et al (2001) incluiu apenas o $1^{\circ}$ e $3^{\circ}$ trimestres de gestação num período de 2 anos e constataram associação entre BPN e poluição do ar no $1^{\circ}$ trimestre de exposição materna. No $3^{\circ}$ trimestre a exposição materna à todos os poluentes, com exceção ao $\mathrm{O}_{3}$, aparece como fator de "proteção", sendo estatisticamente significante. Os resultados desse estudo confirmam os encontrados no presente trabalho, em que o efeito dos poluentes no $1^{\circ}$ trimestre determina um menor ganho de peso no recém-nascido, enquanto que no $3^{\circ}$ trimestre ocorre o inverso.

Os trabalhos realizados no Colorado e no sul da Califórnia estão entre aqueles que não incluíram os três trimestres para análise.

No Colorado a exposição ao CO durante a gestação não foi associada ao BPN. No entanto, foi analisado apenas o $3^{\circ}$ trimestre gestacional (ALDERMAN et al, 1987).

No sul da Califórnia constatou-se que a exposição para altas concentrações de monóxido de carbono (CO) durante o último trimestre de gravidez esteve associado com aumento do risco para o BPN, OR=1,22 (IC 95\% 1,03-1,44) (RITZ; YU, 1999). Esse estudo, no entanto analisou apenas um único poluente (CO) e o último trimestre de gestação, com isso, torna-se difícil estabelecer uma comparação mais adequada em relação a esta dissertação que incluiu os três trimestres de exposição materna aos diversos poluentes.

Os resultados desta dissertação identificaram um efeito negativo e maior sobre o peso do $\mathrm{RN}$ no $1^{\circ}$ trimestre de exposição materna, confirmando assim os resultados 
encontrados em Seul (HA et al, 2001), na República Tcheca (BOBAK, 2000), em Taiwan (YANG et al, 2003) e em São Paulo (GOUVEIA et al, 2004).

Ao se identificar as limitações presentes nos estudos, observou-se que nem todos os trabalhos examinaram todos os poluentes (RITZ; YU, 1999), nem todos incluíram os três trimestres de gestação (ALDERMAN et al, 1987) ou consideraram mais de um poluente no modelo de regressão (WANG et al, 1997). Também verificouse que a maioria das pesquisas aponta a possibilidade de atenuação dos efeitos adversos da poluição devido a dificuldade na classificação da exposição, bem como a falta de informação sobre alguns dos determinantes do peso ao nascer (MAISONET et al, 2001; RITZ; YU, 1999; GOUVEIA et al, 2003; WANG et al, 1997). Entre os determinantes do peso ao nascer que não foram abordados nos diversos estudos estão os problemas gestacionais prévios, exposição ocupacional, nutrição materna, peso prégestacional, ganho de peso gestacional e tabagismo materno.

A dificuldade e o alto custo de se medir a exposição de forma individual, através de biomarcadores como DNA adducts, imunidade celular e humoral que são analisados no sangue obtidos da placenta (SRAM et al, 1996), faz com que a maioria dos estudos meça a exposição a partir da média da concentração dos poluentes obtidas das estações de monitoramento. No entanto, para se obter as informações referentes ao desfecho (BPN), a maioria das pesquisas trabalharam com dados de forma individual na tentativa de se obter uma melhor estimação do efeito da poluição do ar sobre o peso do recém-nascido.

Os autores BOBAK; LEON (1999) realizaram um estudo ecológico, onde a associação observada entre as variáveis de um grupo não representa necessariamente a 
associação existente a nível individual. Quanto a exposição à poluição do ar, esta foi calculada através da média da concentração dos poluentes a partir das estações monitoras. Além disso, o desfecho (BPN) não foi analisado individualmente. Como a unidade de análise foi distrito-ano, os distritos foram incluídos três vezes durante a análise conforme o período de três anos considerado no estudo. Dessa forma, tanto o desfecho quanto a exposição não foram analisados a partir de medidas individuais, o que foi uma desvantagem desse trabalho em relação aos demais que avaliaram as características individuais de cada recém-nascido.

Em pesquisa realizada no sul da Califórnia foram incluídas apenas as mães residindo numa área ao redor de 2 milhas (1.609 metros) da estação monitora da qualidade do ar (RITZ; YU, 1999). Assim, apesar da proximidade que se tem do local onde foi medida a poluição atmosférica, tem-se uma maior chance do indivíduo estudado deslocar-se para fora dessa área de abrangência. Outra limitação dessa pesquisa que também merece ser comentada é que apenas a exposição materna ao $\mathrm{CO}$ no $3^{\circ}$ trimestre foi considerada na análise.

No Brasil, em estudo realizado por GOUVEIA et al (2004) na cidade de São Paulo foi analisado o período de um ano apenas, talvez um período maior fosse mais apropriado para se obter uma melhor medida do efeito da exposição e caracterizar a sazonalidade. 


\subsection{VALIDADE DO ESTUDO}

Medir a ocorrência de um desfecho ou de uma exposição em um estudo epidemiológico não é fácil, pois há muitas possibilidades de erros nessas medidas. Atenção deve ser dada para minimizar os erros, já que não podem ser totalmente eliminados. Os erros podem ser aleatórios ou sistemáticos.

\subsubsection{ERRO ALEATÓRIO}

É o erro ocorrido ao acaso e que resulta em uma falta de precisão na medida de associação, que pode ocorrer por exemplo devido a variação biológica individual, erro amostral ou erro de medida (BEAGLEHOLE; BONITA; KJELLSTRÖM, 1996).

O erro aleatório nunca pode ser completamente eliminado, pois quase sempre se estuda uma amostra da população, as diferenças individuais sempre ocorrem e nenhuma medida será perfeitamente precisa. Para minimizar esses erros deve-se ter o cuidado na mensuração da exposição (poluição do ar) e do desfecho (BPN), e quando possível, aumentar o tamanho da amostra.

Ao se analisar o efeito dos poluentes sobre o peso do recém-nascido na cidade de São Paulo, trabalhou-se com o universo e não com amostra, pois foram utilizados alguns critérios de inclusão e não um cálculo para amostra. O número de casos incluídos nesta dissertação foi reduzido de 595.559 nascidos vivos para 311.735 , permanecendo ainda no estudo um grande número de nascidos vivos, não agravando o erro aleatório e nem comprometendo o poder estatístico. 
Duas abordagens podem ser utilizadas para avaliar o papel do acaso (FLETCHER; FLETCHER; WAGNER, 1996). A primeira é o teste de hipótese, verificando se a diferença esta ou não presente, usando testes estatísticos para examinar a hipótese de que não há diferença ("hipótese nula"). As diferenças associadas a p menores que 0,05 são chamadas "estatisticamente significantes", embora esse ponto de corte seja arbitrário. O valor $\mathrm{p}$ é uma estimativa quantitativa da probabilidade de que as diferenças observadas, por exemplo, na exposição aos poluentes do ar, poderiam ter ocorrido somente pelo acaso, pressupondo que não exista de fato diferença entre os grupos (mães expostas nos diferentes trimestres de gestação e ocorrência de menor ganho de peso do $\mathrm{RN}$ ). O poder estatístico é a probabilidade de se encontrar uma diferença estatisticamente significante quando essa diferença realmente existe. A outra abordagem é através de métodos estatísticos para estimar a faixa de valores prováveis de incluírem o valor verdadeiro, o intervalo de confiança. Usualmente esse intervalo é de $95 \%$, ou seja, há uma chance de $95 \%$ de que o intervalo inclua a magnitude real do efeito.

\subsubsection{ERROS SISTEMÁTICOS}

Algumas considerações sobre possíveis erros sistemáticos no desenvolvimento da pesquisa merecem ser apontadas. As três razões principais para estimativas enviesadas são os viéses de informação, de seleção e de confundimento. 


\subsubsection{VIÉS DE INFORMAÇÃO}

Distorções nas estimativas de efeito podem ser obtidas em decorrência de erros de mensuração/aferição da exposição (poluição do ar) e/ou do desfecho (peso ao nascer).

\section{AFERIÇÃO DA EXPOSIÇÃO}

Dentre as limitações que puderam ser encontradas neste trabalho de dissertação está a capacidade de se estimar a exposição materna aos poluentes atmosféricos, a partir das médias de suas concentrações obtidas das estações de monitoramento da qualidade do ar.

Durante o desenvolvimento do estudo questionou-se a utilização de um índice médio da concentração dos poluentes para todo o município, pois nem todas as estações medem as concentrações dos cinco poluentes de interesse, $\mathrm{PM}_{10}, \mathrm{CO}, \mathrm{SO}_{2}$, $\mathrm{NO}_{2}$ e $\mathrm{O}_{3}$. Entretanto, estudo realizado por BRAGA (1998) mostra que, entre as diversas estações de monitoramento, as variações para $\mathrm{PM}_{10}$ apresentam um comportamento semelhante, ou seja, apesar de apresentarem concentrações diferentes, apresentam-se altamente correlacionadas. Como se tem o interesse de avaliar se a variação do evento de interesse (baixo peso ao nascer) está diretamente associada com a variação na exposição aos diversos poluentes, considera-se ser razoável utilizar a concentração média diária das estações como representativa. Além disso, os distritos mais periféricos do município de São Paulo foram excluídos do estudo, priorizando-se 
a região mais central da cidade onde se encontram as estações monitoras da qualidade do ar.

Quanto à mudança de endereço durante o período de gravidez e local do trabalho materno, não puderam ser consideradas pela falta destas informações, já que o instrumento de pesquisa foi de fonte secundária (DN). No entanto, como foram utilizadas as médias das concentrações dos poluentes de todas as estações em conjunto, a presença dessas informações não é necessária. A utilização dessas médias implica ignorar a variabilidade dos níveis da poluição atmosférica existente nas diferentes áreas dentro da cidade. Assim, a exposição das gestantes que moram em diferentes áreas foi homogeneizada e conseqüentemente, o risco estimado da exposição foi possivelmente subestimado. Ao contrário, a delimitação de uma menor área de abrangência, ao redor das estações monitoras, dificultaria a medida da exposição, já que a pessoa teria uma maior chance de se deslocar para fora dessa área. Acredita-se nesse caso em algum grau de classificação incorreta, que são erros inevitáveis em qualquer estudo (HENNEKENS; BURING, 1987). O viés de informação é muitas vezes denominado de erro de classificação. Este erro de classificação pode ser não-diferencial quando existir uma imprecisão na categorização do sujeito independente de ser ou não exposto/doente.

No erro de classificação não-diferencial, o sistema de classificação, seja ele adequado ou não, é o mesmo para os grupos de comparação, ou seja, a sensibilidade e a especificidade não variam segundo o grau de exposição. O resultado usual dos erros não-diferenciais é diminuir as diferenças entre os grupos de comparação e enviesar as 
medidas de associação em direção ao valor nulo (WERNECK; ALMEIDA, 2002). Em outras palavras, as estimativas do odds ratio tendem a se aproximar de 1,0 .

\section{AFERIÇÃO DO DESFECHO E DEMAIS VARIÁVEIS PRESENTES NA} DECLARAÇÃO DE NASCIDO VIVO

As fontes secundárias, em geral, merecem certa cautela ao serem utilizadas devido a fidedignidade de suas informações. A fonte que se teve acesso para o desfecho desta pesquisa (Declaração de Nascido Vivo) não inviabilizou a análise dos dados.

O preenchimento do campo reservado para o peso ao nascer (desfecho) apresenta uma boa concordância entre os dados obtidos da $\mathrm{DN}$ e os de um inquérito realizado no município de São Luís - Ma (SILVA et al, 2001), e também teve boa concordância quando comparado com a informação de prontuário, trabalho realizado em cinco municípios do estado de São Paulo (JORGE et al, 1993).

Conforme já salientado na introdução deste trabalho, apesar da fragilidade do preenchimento de alguns campos, a fidedignidade do preenchimento das DNs é boa para a maioria das variáveis. A Declaração de Nascido Vivo fornece dados importantes que podem ser muito bem aproveitados, empregados e analisados num estudo epidemiológico. Para isso, as pessoas responsáveis pelo seu preenchimento devem ser bem treinadas e capacitadas para tal função. Além disso, algumas variáveis presentes na DN poderiam ser melhor elaboradas, como por exemplo: $\mathrm{n}^{0}$ de filhos mortos, especificando a época da ocorrência, se perinatal, neonatal precoce ou tardia, 
ou então pós-neonatal; idade gestacional em semanas ou a sua substituição pela data da última menstruação. Outras variáveis poderiam ser adicionadas à declaração, como: tabagismo e álcool na gestação, altura materna, ganho de peso na gestação, espaçamento intergestacional, história prévia de filhos com BPN e doenças na gravidez, pois estas são algumas variáveis que contribuem significativamente numa análise mais apurada sobre o recém-nascido. De qualquer forma, dentre os fatores determinantes do BPN, a DN contempla a maior parte destes.

Com relação à condição sócio-econômica, variável de grande importância para qualquer estudo, esta pôde ser investigada na DN, através da variável escolaridade materna. Pode-se considerar que o grau de instrução reflete melhor a classe social do que a ocupação e renda, por ser acessível para ambos os sexos e não dificultar a comparação a nível internacional das diversas estruturas ocupacionais (DUNCAN et al, 1993).

\subsubsection{VIÉS DE SELEÇÃO}

A possibilidade de distorção da estimativa da medida de efeito devido ao modo pelo qual os indivíduos são selecionados para compor a população de estudo, também merece ser comentada. O viés de seleção ocorre quando há diferença sistemática entre as características das pessoas selecionadas para um estudo e as que não foram (HENNEKENS; BURING, 1987). 
Nesta dissertação trabalhou-se primeiro com todos os nascimentos de mães residentes no município de São Paulo e posteriormente foram realizadas as exclusões, mas estas provavelmente não ocasionaram nenhum viés.

Ao se excluir as mães residentes nos distritos mais periféricos, pode-se ter ocasionado um erro sistemático, onde grande parcela das mães com menor nível sócioeconômico não permaneceu no estudo. No entanto, ao se excluir os distritos periféricos, dos 595.559 nascidos vivos com $8,9 \%$ de BPN, restaram 365.792 com $32.212(8,8 \%)$ com BPN, ou seja, o valor não foi tão diferente como o que ocorreu ao se excluir os prematuros, gemelares e pós-termo. Nesse último caso, dos 595.559 nascidos vivos restaram 509.685 nascidos vivos com 24.431 (4,8 \%) com BPN, valor próximo ao encontrado quando todos os critérios de inclusão e exclusão foram considerados juntos, $14.388(4,6 \%)$ com BPN.

\subsubsection{SITUAÇÃO DE CONFUSÃO (CONFUNDIMENTO)}

Para se evitar uma falta de comparabilidade, entre exposição e não-exposição, quanto ao risco de adoecer, tem-se que atentar à situação de confundimento. Para existir validade de comparação, expostos e não-expostos necessitam ser o mais semelhantes em todos os aspectos, com exceção do nível de exposição.

Para isso, variáveis consideradas importantes determinantes do BPN foram consideradas durante a análise, com exceção do tabagismo materno, peso e estatura maternos e paternos, morbidade materna durante a gestação e ganho de peso na gestação (COSTA; GOTLIEB, 1998; MONTEIRO et al, 2000; NASCIMENTO; 
GOTLIEB, 2001). No entanto, torna-se difícil contemplar todas as variáveis que estão relacionadas com o peso ao nascer. Dentre os estudos epidemiológicos que não trabalharam com tais variáveis estão o de WANG et al (1997); BOBAK (2000); GOUVEIA et al (2004) e BOBAK; LEON (1999). MAISONET et al (2001) não incluíram peso e estatura maternos e paternos, bem como morbidade materna durante a gestação.

O hábito de fumar durante a gestação é uma das causas mais importantes de BPN (BARROS et al, 1992). Quanto a informação sobre o tabagismo materno, no Brasil existe evidência desta característica estar associada à educação (BARBIERI et al, 2000), informação esta que se encontra presente na DN. No entanto, como a categorização da variável referente ao grau de instrução materno era diferente entre os anos de estudo, ficou-se impossibilitado trabalhar de forma mais detalhada com a escolaridade (46,8\% das mães com $1^{\circ}$ grau incompleto), mas isso não comprometeu de forma significativa a análise dos dados. Em estudo realizado por HAIDAR et al (2001) utilizou-se desta categorização para analisar a escolaridade materna e indicadores obstétricos, pois a fonte considerada foi a DN. Nesta dissertação, o interesse é a identificação dos riscos associados à qualidade do ar em determinados períodos da gestação. Mesmo não desconsiderando a importância da variável tabagismo materno, pode-se questionar o confundimento desta nesta pesquisa. Uma variável de confusão deve estar associada tanto ao desfecho quanto à exposição, no entanto, o tabagismo está associado com BPN, mas não se altera conforme a variação da poluição atmosférica. 
Com relação à exposição, os aspectos climáticos, como temperatura e umidade, podem influenciar nas variações das concentrações dos poluentes de acordo com os períodos de seca e de chuva que ocorrem durante o ano. A cidade de São Paulo encontra-se a $792 \mathrm{~m}$ do nível do mar, com temperatura média de $19,3^{\circ} \mathrm{C}$ e umidade relativa média de $78 \%$ durante o ano. Por sua localização, o município sofre influências tanto da circulação terra-mar quanto do aquecimento continental e apresenta valores normalmente intermediários com relação às variáveis meteorológicas (CETESB, 2001). Somando-se a isso, o clima de São Paulo pode sofrer alterações devido ao efeito da intensa urbanização.

Na revisão de literatura realizada para esta dissertação, referente à poluição do ar e o baixo peso ao nascer, nenhum estudo considerou os fatores temperatura e umidade na análise dos dados, mas sim estações do ano e meses do ano. No presente trabalho, mês de nascimento seria incluído, mas devido a sua forte correlação com os poluentes, optou-se por não incluir esta variável no modelo de regressão.

\subsection{PLAUSIBILIDADE BIOLÓGICA}

Além de identificar a poluição ambiental urbana como um dos possíveis fatores de risco para o BPN, é importante compreender como tais fatores estão atuando, ou seja, que mecanismos biológicos podem estar envolvidos para que a poluição atmosférica esteja interferindo no crescimento e no desenvolvimento fetal. 
Entre os mecanismos biológicos envolvidos no comprometimento do crescimento fetal estão as alterações que podem ocorrer a nível placentário como diferenças anatomopatológicas e morfométricas, infarto placentário e vilosite crônica.

A placenta humana é o centro funcional da unidade mãe-feto, desempenhando funções respiratória, nutritiva, excretora, endócrina e imunológica. Agressões que incidam sobre a unidade útero-placentária poderão desviar o feto do seu potencial genético de crescimento, determinando retardo de crescimento intra-uterino.

As placentas dos recém-nascidos pequenos para a idade gestacional apresentam diferenças anatomopatológicas e morfométricas, estatisticamente significativas, em relação aos recém-nascidos adequados para a idade gestacional (OLIVEIRA; XAVIER; LANA, 2002). Por exemplo, podem ser encontradas placentas de menor peso e menores diâmetros em recém-nascidos PIG. Embora ambos, placenta e recémnascido PIG, apresentem comprometimento do peso, o comprometimento do peso fetal é relativamente maior que o comprometimento de peso da placenta.

A associação entre infarto placentário e retardo do crescimento intra-uterino é descrita na literatura (BECROFT; THOMPSON; MITCHELL, 2002), bem como a associação encontrada entre vilosite crônica e retardo do crescimento intra-uterino (NORDENVALL; SANDSTEDT, 1990). A vilosite crônica é um processo inflamatório no território viloso, que reduz as trocas materno-ovulares, podendo levar a um processo de desnutrição intra-uterina. A presença de lesões isquêmicas 
correspondentes a distúrbios circulatórios placentários foi destacada em $43 \%$ dos casos de vilosite.

A ocorrência simultânea de infarto placentário e retardo do crescimento intrauterino aponta para a hipóxia intra-útero. Trata-se de necrose de coagulação do tecido viloso, secundária à oclusão de vasos do leito placentário em casos de má adaptação vascular durante o processo de placentação (NORDENVALL; SANDSTEDT, 1990). Estudos realizados com dopplerfluxometria, em casos de retardo do crescimento intrauterino, vêm demonstrando uma diminuição do fluxo sangüíneo útero-placentário associado a um aumento na resistência vascular como causa de hipóxia crônica e crescimento intra-uterino retardado (PARDI; MARCONI; CETIN, 2002). Esse aumento de resistência nos vasos útero-placentários tem sido atribuído a ausência de modificações fisiológicas nas artérias espiraladas miometriais, devido à falha da segunda onda de migração trofoblástica sobre estes vasos e, embora possa ocorrer em outras condições, é freqüentemente associado à doença hipertensiva específica da gestação. A presença de infartos, apesar de não ser primariamente a causa do retardo do crescimento fetal, contribui para o seu agravamento, ao restringir a superfície vilositária de trocas.

Os mecanismos biológicos envolvidos com a poluição atmosférica e o baixo peso ao nascer ainda não estão bem esclarecidos. No entanto, pode-se supor que a poluição do ar esteja interferindo nas diferenças anatomopatológicas e morfométricas da placenta, bem como no infarto placentário e na ocorrência de vilosite, já que os poluentes podem afetar o transporte de oxigênio e também aumentar a viscosidade 
sanguínea devido a uma resposta inflamatória (NETO, 1990; KNOTTNERUS et al, 1990). Acredita-se também num efeito tóxico direto sobre o feto, através da diminuição do suprimento fetal de oxigênio, devido a redução da capacidade do transporte de oxigênio ou pela alteração da viscosidade sanguínea.

O CO facilmente atravessa a barreira placentária entrando em contato com o feto, levando a um rápido acúmulo de carboxihemoglobina, com conseqüente redução do transporte de oxigênio pelo sangue (NETO, 1990). O feto é particularmente vulnerável à toxicidade do CO devido a um acúmulo de $10-15 \%$ maior no sangue fetal do que na circulação materna, pois a hemoglobina do feto tem mais afinidade de se ligar ao CO do que a hemoglobina do adulto (HA et al., 2001).

Outra possibilidade de mecanismo tóxico do CO é a sua capacidade de interferir sobre os leucócitos, plaquetas e endotélio, causando uma resposta inflamatória, contribuindo para o aumento da viscosidade do sangue e facilitando a toxicidade por outros poluentes atmosféricos (PETERS et al, 1997; BOUTHILLIER et al, 1998; HARDY; THOM, 1994). O processo inflamatório que se instala no pulmão em decorrência da poluição atmosférica, aumenta a coagulabilidade do sangue (PETERS et al, 1997). A diminuição do suprimento de oxigênio devido a alteração da viscosidade do sangue, pelo aumento da coagulabilidade, pode causar hipóxia crônica com conseqüentes efeitos adversos ao feto. Essa teoria sustenta a evidência de que o aumento da viscosidade do sangue prejudica o fluxo sanguíneo materno (KNOTTNERUS et al, 1990). Esse comprometimento da perfusão placentária devido a alteração da viscosidade sanguínea pode causar desfechos da gravidez desfavoráveis, incluindo baixo peso ao nascer e a prematuridade (KNOTTNERUS, et al., 1990). 
Estudos epidemiológicos têm evidenciado a toxicidade do $\mathrm{CO}$ ao se examinar a relação do tabagismo e níveis de CO durante a gestação. São encontradas associações entre tabagismo materno e alguns desfechos da gravidez como retardo de crescimento intra-uterino, morte neonatal e parto prematuro (NETO, 1990; SECKER-WALKER, et al., 1997). Dessa forma, ao se analisar o efeito causado pelo CO da poluição atmosférica (produzido por diversas fontes) sobre o peso do recém-nascido e o efeito produzido pelo tabagismo materno, reforça-se a preocupação quanto a exposição ao CO durante a gravidez.

Com relação aos demais poluentes, ressalta-se a resposta inflamatória do organismo materno e o stress fetal frente à exposição. A poluição também pode comprometer o sistema respiratório materno ou o seu estado de saúde geral, que poderá prejudicar o fluxo sangüíneo mãe-feto, glicose transplacentária e o total de insulina, os maiores determinantes do crescimento fetal (VORHERR, 1982).

\subsection{MEDIDAS ADOTADAS PARA O CONTROLE DA POLUIÇÃO DO} AR EM SÃo PAULO.

Constatada a gravidade da poluição gerada pelos veículos, a CETESB, durante a década de 80, desenvolveu as bases técnicas que culminaram com a Resolução $n^{\circ}$ 18/86 do Conselho Nacional do Meio Ambiente (CONAMA), que estabeleceu o Programa de Controle da Poluição do ar por Veículos Automotores (PROCONVE), o qual complementado por outras Resoluções, define os limites de emissão para os veículos (CETESB, 2001). Assim, todos os novos modelos de veículos e motores 
nacionais e importados, são submetidos à homologação quanto à emissão dos poluentes. Os fabricantes de veículos vem cumprindo as exigências legais, favorecendo a redução média de $90 \%$ na emissão de poluentes dos veículos leves novos de 1998, em relação ao início do programa.

A adição do álcool à gasolina também tem contribuído para a redução da poluição ambiental, através da diminuição da emissão de $\mathrm{CO}$, hidrocarbonetos, partículas, óxido de enxofre e chumbo. A porcentagem de $22 \%$ de etanol em volume de gasolina foi adotado pelo CONAMA em 1990 por orientação do setor energético.

Tais medidas foram adotadas na tentativa de se minimizar os efeitos adversos causados pela poluição atmosférica. Apesar da grande redução das emissões dos poluentes atmosféricos na cidade de São Paulo, vários trabalhos têm identificado a poluição do ar como associada à efeitos adversos à saúde neste município (BENÍCIO et al, 2000; MARTINS et al, 2002; GOUVEIA; FLETCHER, 2000; GOUVEIA; MEDEIROS, 2003; GOUVEIA et al, 2004).

A quantidade de resíduos tóxicos lançados pelo tráfego excessivo de veículos na capital paulista, e em menor escala, pela atividade industrial, afeta a qualidade do ar. O monóxido de carbono emitido pelos veículos é o principal poluente nas grandes cidades. Seus níveis ultrapassaram o limite diário em alguns momentos do período estudado nesta dissertação.

Dessa forma, apesar dos níveis da concentração dos poluentes atmosféricos não estarem tão inadequados como estavam há duas décadas, ainda são evidentes os danos causados à saúde da população no município de São Paulo e a necessidade de medidas mais efetivas no controle da qualidade do ar. 


\subsection{IMPLICAÇÕES DA POLUIÇÃO DO AR E DO BPN PARA A SAÚDE PÚBLICA}

Há uma diferença no encaminhamento dado aos problemas ambientais, enquanto nos países "ricos" existe um controle social mais efetivo, onde a participação da população está mais presente, facilitando e agilizando as mudanças para impedir os danos ambientais, nos países "pobres" o mesmo não ocorre.

Na medida em que a urbanização e o desenvolvimento econômico aumentam nos países em desenvolvimento, observa-se um rápido aumento do número de veículos. Esses veículos encontram-se muitas vezes em mau estado de conservação, com uso de um combustível de má qualidade, e ainda somando-se a isto, com motores e mecanismos de filtragem dos gases precários, que trazem como conseqüência o aumento dos níveis de concentração da poluição atmosférica.

Apesar de medidas de controle da poluição atmosférica terem sido implementadas em muitos países, diversos estudos continuam a apontar para a ocorrência de efeitos adversos à saúde da população, principalmente nas mais vulneráveis, entre elas as crianças.

Existe uma importância médico-social do recém-nascido baixo-peso, pois o seu prognóstico pouco favorável poderá levá-lo a ter uma má qualidade de vida, e ainda, uma menor contribuição familiar e social.

Para interromper este círculo vicioso há a necessidade de se prevenir efetivamente os fatores associados ao nascimento dessas crianças, pois a partir da 
redução da prevalência de recém-nascidos com baixo peso, é que poderá se obter uma redução significativa da morbi-mortalidade neonatal e da mortalidade pós-neonatal. Ressalta-se a necessidade de se manter e de se intensificar as medidas de controle da poluição do ar.

Dessa forma, diminuindo-se a morbi-mortalidade e os custos gerados pelo atendimento destas crianças, um número significativo de indivíduos terá uma melhor capacidade intelectiva e física para com a sociedade e família, e gozarão de uma melhor qualidade de vida, contribuindo assim para a redução do BPN na população. 


\section{CONCLUSÃO}

Os resultados desta pesquisa mostram e reforçam que a exposição materna no $1^{\circ}$ trimestre de gestação à poluição do ar no município de São Paulo contribui para um menor ganho de peso da criança ao nascer. Tal desfecho provavelmente se deve aos efeitos da poluição do ar sobre a circulação materno-fetal e conseqüentemente sobre a placenta, comprometendo o crescimento fetal intra-uterino.

Dessa forma, conclui-se que os níveis de concentração dos poluentes atmosféricos da cidade de São Paulo podem produzir efeitos adversos durante a gestação, entre eles, o baixo peso ao nascer, um dos mais importantes preditores da mortalidade infantil.

Outros estudos são necessários para avaliar como vêm se comportando o peso ao nascer e a poluição do ar nessa cidade e para identificar se esse fator pode estar influenciando negativamente os resultados gestacionais. Com medidas de controle dos poluentes sendo efetivamente realizadas poderá haver um maior número de recémnascidos saudáveis, com peso favorável e potencial normal de crescimento e desenvolvimento, conseqüentemente crianças com maior sobrevida. 


\section{REFERÊNCIAS BIBLIOGRÁFICAS}

ABERCROMBIE, G.F. December fog in London and the Emergency Bed Service. Lancet, p. 234-235, 1953.

ALDERMAN, B.W.; BARON, A.E.; SAVITZ, D.A. Maternal exposure to neighbourhood carbon monoxide and risk of low birth weight. Public Health Reports, v.102, n.4, p. 410414, 1987.

ALMANAQUE ABRIL. 20ª ed. São Paulo. Abril, 1994. p. 205.

ALMANAQUE ABRIL 29a ed. São Paulo. Abril, 2003. p. 413-416.

ALMEIDA M.F.; NOVAES, H.M.D.; ALENCAR, G.P.; RODRIGUES, L.C. Mortalidade neonatal no município de São Paulo: influência do peso ao nascer e de fatores sócio-demográficos e assistenciais. Revista Brasileira de Epidemiologia, v. 5, n. 1, p. 93-107, 2002.

ALMEIDA, M.F.; JORGE, M.H.P.M. Pequenos para idade gestacional: fator de risco para mortalidade neonatal. Revista de Saúde Pública, v. 32, n. 3, p. 217-24, 1998.

ARMITAGE, P.; BERRY, G. Multiple measurements. In: . Statistical methods in medical research. $3^{\mathrm{a}}$ ed. London: Blackwell Science, 1994. p. 312-333.

BANCO MUNDIAL. America Latine y el Caribe: diez años después dela crisis de la deuda. Washington D,C.: Banco Mundial, 1993.

BATTAGLIA, F.C.; LUBCHENKO, L.O. A practical classification of newborn infants by weight and gestational age. Journal of Pediatrics, v. 71, n. 2, p. 159-63, 1967.

BARBIERI, M.A.; SILVA, A. A. M.; BETTIOL, H.; GOMES, U.A. Risk factors for the increasing trend in low birth weight among live births Born by vaginal delivery, Brazil. Revista de Saúde Pública, v.34, n. 6, p. 596-602, 2000.

BARROS, F.C.; HUTTLY, S.R.A.; VICTORA, C.G.; KIRKWOOD, B.R.; VAUGHAN, J.P. Comparison of the causes and consequenses of prematurity and intra-uterine growth retardation: a longitudinal study in south Brazil. Pediatrics, v. 90, n. 2, p. 238-244, 1992.

BASCON R. Health effects of outdoor air pollution. American Journal of Respiratory and Critical care Medicine, v. 153, n. 1, p. 3-7, 1996. 
BAILEY, P.; TSUI, A.O.; JANOWITZ, B.; DOMINIK, R.; ARAUJO, L. A study of infant mortality and causes of death in a rural Northeast Brazilian community. Journal of Biosocial Science, v. 22, n. 1, p. 349-363, 1990.

BEAGLEHOLE, R.; BONITA, R.; KJELLSTRÖM, T. Tipos de estudo. In: Epidemiologia básica, $1^{a}$ ed. São Paulo: Livraria Santos, 1996. p. 46-69.

BECROFT, D.M.; THOMPSON, J.M.D.; MITCHELL, E.A. The epidemiology of placental infarction at term. Placenta, v. 23, n. 4, p. 343-351, 2002.

BENÍCIO, M.H.A.; CARDOSO, M.R.A.; GOUVEIA, N.C.; MONTEIRO, C.A. Tendência secular da doença respiratória na infância na cidade de São Paulo (19841996). Revista de Saúde Pública, v. 34, supl. 6, p. 91-101, 2000.

BITTAR, E.R.; RAMOS, J.L.A; LEONE, C.R. Crescimento fetal. In: Marcondes, E., $9^{\mathrm{a} e d . ~ P e d i a t r i a ~ b a ́ s i c a . ~ S a ̃ o ~ P a u l o, ~ S a r v i e r, ~ 2002 . ~ p . ~ 255-265 . ~}$

BOBAK, M.; LEON, D.A. Pregnancy outcomes and outdoor air pollution: an ecological study in districts of the Czech Republic 1986-8. Occupation Environmental Medicine, v.56, n. 1, p. 539-543, 1999.

BOBAK, M. Outdoor air pollution, low birth weight, and prematurity.

Environmental Health Perspective, v.108, n.2, p. 173-176, 2000.

BOUTHILLIER, L. et al. Acute effects of inhaled urban particles and ozone: lung morphology, macrophage activity, and plasma endothelin. American Journal Pathology, v. 153, p. 1873-1884, 1998.

BOY, E.; BRUCE, N.; DELGADO, H. Birth weight and exposure to kitchen wood smoke during pregnancy in rural Guatemala. Environmental Health Perspective, v.110, n.1, p. 109-114, 2002.

BRAGA, A.L.F. Quantificação dos efeitos da poluição do ar sobre a saúde da população pediátrica da cidade de São Paulo e proposta de monitorização. São Paulo, 1998. 225p. Tese (Doutorado) - Faculdade de Medicina, Universidade de São Paulo.

BRAGA, A.L.F. et al. Air pollution and pediatric hospital admissions in São Paulo, Brazil. International Journal of Occupational Environmental Health,v.1, n. 1, p.95-102, 1999.

BRASIL. Ministério da Saúde/UNICEF. A mortalidade perinatal e neonatal no Brasil, 1998. 
BRASIL. Ministério da Saúde. Secretaria de Vigilância em Saúde. Coordenação Geral de Vigilância Ambiental em Saúde. Subsistema de Vigilância Ambiental em Saúde relacionada à qualidade do ar (in press).

BRENELLI, M.A; MARTINS FILHO, J. Curvas de crescimento intra-uterino da população de nascidos vivos na maternidade do CAISM-UNICAMP. Journal Pediatric, v. 68, p. 21-5, 1992.

CETESB - COMPANHIA DE TECNOLOGIA DE SANEAMENTO

AMBIENTAL. Relatório de qualidade no Estado de São Paulo, 1992. São Paulo, 1993.

CETESB - COMPANHIA DE TECNOLOGIA DE SANEAMENTO

AMBIENTAL. Relatório de qualidade no Estado de São Paulo, 1999. São Paulo, 2000.

BELIZÁN, J.M.; VILLAR, J. El crescimiento fetal y su repercusión sobre el desarrollo del niño. In: Cusminsky M, Moreno EM, Suárez-Ojeda, EN, eds. Crescimiento y desarrollo: hechos y tendencias. Washington: Pan American Health Organization; 1988. p. 102-119.

CETESB - COMPANHIA DE TECNOLOGIA DE SANEAMENTO

AMBIENTAL. Relatório de qualidade no Estado de São Paulo, 2000. São Paulo, 2001.

CHIKE-OBI, U.; DAVID, R.J.; COUTINHO, R.; WU, S.Y. Birth weight has increased over a generation. American Journal Epidemiology, v. 144, n. 6, p. 563569, 1996.

CIOCCO, A.; THOMPSON, D.J. A follow-up on Donora ten years after:

methodology and findings. American Journal of Public Health, v. 51, n. 2, p. 155164, 1961.

COSTA, C.E.; GOTLIEB, S.L.D. Estudo epidemiológico do peso ao nascer a partir da declaração de nascido vivo. Revista de Saúde Pública, v. 32, n. 4, p. 328-334, 1998.

DATASUS. Sistema de Informações Hospitalares do SUS (SIH/SUS) 2003.

Disponível em: <http://www.datasus.gov.br> Acesso em: 29 de abr. 2003.

DEJMEK, J.; SELEVAN, S.G.; BENES, I.; SOLANSKY, I.; SRÁM, R.J. Fetal Growth and maternal exposure to particulate matter during pregnancy. Environmental Health Perspective, v.107, n. 1, p. 475-480, 1999.

DIVISION OF NUTRITION, NATIONAL CENTER FOR CHRONIC DISEASE PREVENTION AND HEALTH PROMOTION. Increasing, evidence of low birth 
weight - United States, 1981-91. Morbidity and Mortality Weekly Report, v.43, p. 335-339, 1994.

DOCKERY, D.W.; POPE, C.A.; XU, X.; SPENGLER, J.D.; WARE, J.H.; FAY, M.E.; FERRIS, B.G.; SPEIZER, F.E. An association between air pollution and mortality in six US cities. New England Journal of Medicine, v. 329, n. 24, p. 1753-1759, 1993.

DOCKERY, D.W.; RAIZENNE, M.; NEAS, L.M.; DAMOKOSH, A.L.; SPENGLER, J.D.; KOUTRAKIS, P.; WARE, J.H.; SPEIZER, F.E. Health effects of acid aerosols on north American children: respiratory symptons. Environmental Health Perspectives, v. 104, n. 5, p. 500-505, 1996.

DUNCAN, B.B.; SCHMIDT, M.I.; ACHUTTI, A.C.; POLANCZYK, C.A.; BENIA, L.R.; MAIA, A.A.G. Socioeconomic distribution of noncommunicable disease risk factors in urban Brazil: the case of Porto Alegre. Bulletin Pan American Health Organization, v. 27, n. 4, p. 337-348, 1993.

ELSON, D.M. Atmospheric pollution: causes, effects, and control policies. Basil Blackwell Ltd, Oxford, UK, cap. 1, p. 3-13, 1987.

FIRKET J. Sur les causes des accidents survenus dans la vallée de la Meuse, lors des brouillards de décembre 1930. Bull. Acad. Roy. Med. Belg., v. 11, p. 683-741, 1931.

FLETCHER, R.H.; FLETCHER, S.W.; WAGNER, E.H. Acaso. In: Epidemiologia clínica: elementos essenciais. Porto Alegre: Artes Médicas, 1996. p. 195-216.

FREITAS, C.U. Explorando modelos e indicadores para o estabelecimento de vigilância dos efeitos na saúde decorrentes da poluição atmosférica na cidade de São Paulo. São Paulo, 2000. 150p. Dissertação (Mestrado) - Faculdade de Saúde Pública, Universidade de São Paulo.

GERONIMUS, A.T.; KOREMAN, S. Maternal youth or family back-ground? On the health disadvantages of infants with teenage mothers. American Journal Epidemiology, v. 137, n. 2, p. 213-25, 1993

GOUVEIA, N.C. Air pollution and respiratory diseases in infancy. Is it possible to study this relationship? London, 1993. 73p. Dissertação (Mestrado) - London School of Hygiene and Tropical Medicine.

GOUVEIA, N.C. Air pollution and health effects in São Paulo, Brazil: a time series analysis. London, 1997. 238p. Tese (Doutorado) - London School of Hygiene and Tropical Medicine. 
GOUVEIA, N.; FLETCHER, T. Time series analysis of air pollution and mortality: effects by cause, age and socioeconomic status. Journal Epidemiology Community Health, v. 54, n. 10, p. 750-755, 2000a.

GOUVEIA, N.; FLETCHER, T. Respiratory diseases in children and outdoor air pollution in São Paulo, Brazil: a time series analysis. Occupation Environmental Medicine, v. 57 , n. 1, p. 477-483, 2000b.

GOUVEIA, N.C. Avaliação de políticas ambientais para redução dos níveis urbanos de poluição do ar. In: Global Conference - Building a Sustainable World, 2002.

São Paulo, 2002.

GOUVEIA, N.C.; MENDONÇA, G.A.S.; LEON, A.P.; CORREIA, J.E.M.; JUNGER, W.L.; FREITAS, C.U.; DAUMAS,R.P.; MARTINS, L.C.;GIUSSEPE, L.; CONCEIÇÃO, G.M.S.; MANERICH, A.; CRUZ, J.C. Poluição ambiental e efeitos na saúde nas populações de duas grandes metrópoles brasileiras. Informe Epidemiológico do SUS, v. 12, n.1, p. 29-40, 2003.

GOUVEIA, N.C.; BREMNER, A.S.; NOVAES, H.M.D. The association between ambient air pollution and birth weight in São Paulo, Brazil. Journal of Epidemiology and Community Health, v. 58, n. 1, p. 11-17, 2004.

GOUVEIA, N.C.; MEDEIROS, AP.P. Chronic, more than acute exposure of pregnant women to air pollution seems to be associated with prematurity. Epidemiology, v. 14, n. 5, p. S25, 2003.

GUYER B.; MACDORMAN, M.F.; MARTIN, J.A.; PETERS, K.D.; STROBINO, D.M. Annual summary of vital statistics - 1997. Pediatrics, v. 102, n. 6, p. 13331349, 1998.

HA, E.H.; HONG, Y.C.; LEE, B.E.; WOO, B.H.; SCHWARTZ, J.; CHRISTIANI, D.C. Is air pollution a risk factor for low birth weight in Seoul? Epidemiology, v. 12, n. 6, p. 643-648, 2001.

HAIDAR, F.H.; OLIVEIRA, U.F.; NASCIMENTO, L.F.C. Escolaridade materna: correlação com os indicadores obstétricos. Cadernos de Saúde Pública, v.17, n. 4, p. 1025-1029, 2001.

HARDY, K.R.; THOM, S.R. Pathophysiology and treatment of carbon monoxide poisoning. Clinical Toxicology, v. 32, p. 613-629, 1994.

HENNEKENS, C.H.; BURING, J.E. Case-control studies. In: Epidemiology in Medicine. United States of America: Little Brown, 1987. p.132-152. 
HENNEKENS, C.H.; BURING, J.E. Analysis of epidemiology studies: evaluating the role of bias. In: Brown, 1987. p.272-286. Epidemiology in Medicine. United States of America: Little

HORTA, B.L.; BARROS, F.C.; HALPERN, R.; VICTORA, C.G. Baixo peso ao nascer em duas coortes de base populacional no sul do Brasil. Cadernos de Saúde Pública, v. 12, supl. 1, p.27-31,1996. Disponível em: http://www.bireme.br/scielo.php. Acesso em: 27 de ago. 2003.

IZIQUE C. O mapa da exclusão. Disponível em: $<$ http:revistapesquisa.fapesp.br $>$. Acesso em: 23 de jan. 2003.

JORGE, M.H.P.M.; GOTLIEB, S.L.D.; SOBOLL, M.L.M.S.; ALMEIDA, M.F.; LATORRE, M.R.D.O. Avaliação do Sistema de Informação sobre Nascidos Vivos e o uso de seus dados em epidemiologia e estatísticas de saúde. Revista de Saúde Pública, v. 27, supl. 6, p. 2-39, 1993.

JOSEPH, K.S.; DEMISSIE, K.; KRAMER, M.S. Obstetric intervention, stillbirth and preterm birth. Seminars Perinatology., v. 26, n. 4, p. 250-259, 2002.

KALE, P.L.; COSTA, AJ.L.; LUIZ, R.R. Medidas de efeito e medidas de associação. In: Medronho et al. Epidemiologia. São Paulo: Atheneu, 2002. p. 115-123.

KEIRSE, M.J.N.C. International variations in intrauterine growth. European Journal of Obstetrics \& Gynecology and Reproductive Biology, v. 92, n. 1, p. 21-28, 2000.

KNOTTNERUS, J.A et al. Haematologic parameters and pregnancy outcome: A prospective cohort study in the third trimester. Journal Clinical Epidemiology, v. 43, p. 461-466, 1990.

KRAMER, M.S. The epidemiology of adverse pregnancy outcomes: an overview. Journal Nutrition, v. 133, p. 1592S-1596S, 2003.

LEONE, C.R.; RAMOS, J.L.A.; VAZ F.A.C. O recém-nascido pré-termo. In: Marcondes, E., $8^{a}$ ed. Pediatria básica. São Paulo, Sarvier, 1999. p. 333-344.

LIN, C.A.; PEREIRA, L.A.A.; CONCEIÇÃO, G.M.S.; KISHI, H.S.; MILANI, R.; BRAGA, A.L.F.; SALDIVA, P.H.N. Association between air pollution and ischemic cardiovascular emergency room visits. Environmental Research., v. 92, n. 1, p. 5763, 2003.

LINTON, E.A.; PERKINS, A.V.; WOODS, R.J.; EBEN, F.; WOLFE, C.D.A.; BEHAN, D.P.; POTTER, E.; VALE, W.W.; LOWRY, P.J. Corticotropin releasing hormone-binding protein (CRH-BP): plasma levels decrease during the third trimester of normal human pregnancy. Journal of Clinical Endocrinology and Metabolism, v. 76, n. 1, p. 260-262, 1993. 
LUBCHENCO, L.O.; SEARLS, D.T.; BRAZIE, J.V. Neonatal mortality rate:

Relationship to birth weight and gestational age. Journal of Pediatrics, v. 81, n. 4, p. 814-22, 1972.

LUZ, T.P.; NEVES, L.A.T.; REIS, A.F.F.; SILVA, L.G.P. Baixo peso ao nacer e morbidade. Jornal Brasileiro de Ginecologia, v. 107, n. 8, p. 257-265, 1997.

MAISONET, M.; BUSH, T.J.; CORREA, A.; JAAKKOLA, J.J.K. Relation between ambient air pollution and low birht weight in the northeastern United States. Environmental Health Perspectives, v. 109, supl. 3, p. 351-356, 2001.

MARQUES S.M.B.; CHALEM,E.; ANGELO, L.M.B. Gravidez na adolescência. Pediatria Moderna, v. 28, n. 7, p. 584-590, 1992.

MARGOTTO, P.R. Curvas de crescimento intra-uterino: estudo de 4.413 recémnascidos únicos de gestações normais. Jornal de Pediatria, v. 71, n. 1, p. 11-21, 1995.

MARIOTONI, G.G.B.; BARROS FILHO, A.A. Peso ao nascer e mortalidade hospitalar entre nascidos vivos, 1975-1996. Revista de Saúde Pública, v. 34, n.1, p. 71-76, 2000.

MARTINS, L.C.; LATORRE, M.R.D.O.; CARDOSO, M.R.A.; GONÇALVES, F.L.T.; SALDIVA, P.H.N.;BRAGA, A.L.F. Poluição atmosférica e atendimentos por pneumonia e gripe em São Paulo, Brasil. Revista de Saúde Pública, v. 36, n. 1, p. 8894, 2002.

MEDRONHO, R.A. Estudos ecológicos. In: Medronho, R.A.; Carvalho, D.M.; Bloch, K.V.; Luiz, R.R.; Werneck, G.L, $1^{\text {a }}$ ed. Epidemiologia. São Paulo, Atheneu, 2002. p.191-198.

MENEZES, A.M.B.; VICTORA, C.G. Effects of tobacco on children and adolescents: Brazil and other South American countries. Geneva: WHO Tobacco Free Initiative, 1999. (unpublished report)

MENEZES, A.M.B.; VICTORA, C.G.; BARROS, F.C.; ALBERNAZ, E.; MENEZES, F.S.; JANNKE, H.A.; ALVES, C.; ROCHA, C. Mortalidade infantil em duas coortes de base populacional no sul do Brasil: tendências e diferenciais. Cadernos de Saúde Pública, v. 12, supl. 1, p.73-8, 1996.

MONTEIRO, C.A.; BENICIO, M.H.D.; ORTIZ, L.P. Tendência secular do peso ao nascer na cidade de São Paulo (1976-1998). Revista de Saúde Pública, v. 34 supl. 6, p. 26-40, 2000. 
MURRAY, L.J.; REILLY, D.P.J.; BETTS, N.; PATTERSON, C.C.; SMITH, G.D.; EVANS, A.E. Season and outdoor ambient temperature: effects on birth weight. Obstetrics \& Gynecology, v. 96, n. 5, p. 689-695, 2000.

NASCIMENTO, L.F.C.; GOTLIEB, S.L.D. Fatores de risco para o baixo peso ao nascer, com base em informações da declaração de nascido vivo em Guaratinguetá, SP, no ano de 1998. Informe Epidemiológico do SUS, v.10, n. 3, p. 113- 120, 2001.

NETER, J.; KUTNER, M.H.; NACHTSHEIM, C.J.; WASSERMAN, W. Multicollinearity and its effects. In: Ilinois: Richard D. Irwing, 1996. p. 285-293. Applied linear statistical models. 4.ed.

NETO, A.A. Efeitos do fumo na gravidez. Revista de Saúde Pública, v. 24, n. 5, p. 420-424, 1990.

NETO, O.L.M.; BARROS, M.B.A. Fatores de risco para mortalidade neonatal e pós-neonatal na região centro-oeste do Brasil: linkage entre bancos de dados de nascidos vivos e óbitos infantis. Cadernos de Saúde Pública, v. 16, n. 2, p. 477-485, 2000.

NORDENVALL, M.; SANDSTEDT, B. Placental villitis and intrauterine growth retardation in a Swedish population. Acta Pathológica, Microbiológica, Immunológica Scandinavica, v. 98, n. 1, p. 19-24, 1990.

NOVAES, H.M.D.; ALMEIDA, M.F.; ORTIZ, L.P. O que são nascimentos de baixo peso ao nascer? Disponível em: <http://www.saudepublica.bvs.br> Acesso em: 29 de abr. 2003.

OLIVEIRA, L.H.; XAVIER, C.C.; LANA, A.M.A. Alterações morfológicas placentárias de recém-nascidos pequenos para a idade gestacional. Jornal de Pediatria, 2002, v. 78, n. 5, p. 397-402, 2002.

PARDI, G.; MARCONI, A.M.; CETIN, I. Placental-fetal interrelationship in IUGR fetuses. Placenta, v. 23, supl. A, p. 136-141, 2002.

PENNA, M.L.F.; DULCHIADE, M.P..Air pollution and infant mortality from pneumonia in the Rio de Janeiro metropolitan area. Bulletin Pan American Health Organization, v. 25, p. 47-54.

PEREIRA, L.A.A. Associação entre poluição atmosférica e perdas fetais tardias no município de São Paulo. São Paulo, 1999. 150p. Tese (Doutorado) - Faculdade de Medicina, Universidade de São Paulo.

PERKINS, A.V.; LINTON, E.A.; EBEN, F.; SIMPSON, J.; WOLFE, C.D.A.; REDMAN, C.W.G. British Journal of Obstetrics and Gynaecology, v. 102, n. 2, p.118-122, 1995. 
PETERS, A et al. Increased plasma viscosity during an air pollution episode: a link to mortality. Lancet, v. 349, p. 1582-1587, 1997.

POPE , C.A.; SCHWARTZ, J.; RANSON, M.R. Daily mortality and PM10 pollution in Utah Valley. Archieve Environmental Health, v. 47, n. 3, p. 211-217, 1992.

PRADO, C.J. Evolução política do Brasil e outros estados. 5ªed. Brasiliense, 1966. p.110-136.

RITZ, B.; YU, F. The effect of ambient carbon monoxide on low birth weight among children born in southern Califórnia between 1989-1993. Environmental Health Perspectives, v. 107, n. 1, p. 17-25, 1999.

SALDIVA, P.H.N.; LICHTENFELS, A.J.F.C.; PAIVA, P.S.O.; BARONE, I.A.; MARTINS, M.A.; MASSAD, E.; PEREIRA, J.C.R.; XAVIER, V.P.; SINGER, J.M.; BÖHM, G.M. Association between air pollution and mortality due to respiratory diseases in children in São Paulo, Brasil: A preliminary report. Environmental Research, v. 65, n. 1, p. 218- 225, 1994.

SATANDER, F.M.; NOGUERA, G.I.; VELIZ, M.D. Comparison of three standards for evaluating fetal growth. Bulletin Pan American Health Organization, v. 26, n. 1, p. 37-46, 1992.

SCARLATO, F.C. População e urbanização brasileira. In: Ross, Jurandyr Sanches (org.). Geografia do Brasil. Edusp, 1996.

SCHVARTSMAN, S. Poluição ambiental e sua repercussão sobre o feto. In:

Marcondes, E., $8^{a}$ ed. Pediatria básica. São Paulo, Sarvier, 1999. p. 306-308.

SCHWARTZ, J. Particulate air pollution and daily mortality in Detroit. Environmental Research, v. 56, n. 1, p. 204-213, 1991.

SCHWARTZ, J.; DOCKERY, D.W. Increased mortality in Philadelphia associated with daily air pollution concentrations. American. Review of Respiratory Diseases, v. 145, n. 1, p. 600-604, 1992.

SCHWARTZ, J.; DOCKERY, D.W.; NEAS, L.M. Is daily mortality associated specifically with fine particles? Journal Air Waste Manag. Assoc., v. 46, p. 927-39, 1996.

SECKER-WALKER, R.H. et al. Smoking in pregnancy, exhaled carbon monoxide, and birth weight. Obstetric Gynecology, v. 89, p. 649-652, 1997.

SHEPS, D.S. et al. Production of arrhythmias by elevated carboxyhemoglobin in patients with coronary artery disease. Ann. Intern. Med., v. 113, n. 5, p.343-351, 1990. 
SILVA, A.A.M.; LAMY FILHO, F.; ALVES, MTSSB; COIMBRA, L.C.; BETTIOL, H.; BARBIERE, M.A. Risk factors for low birth weight in north-east Brazil: the role of caesarean section. Paediatric and Perinatal Epidemiology, v. 15, n. 1, p. 257-264, 2001a.

SILVA, A.A.M.; RIBEIRO,V.S.; BORBA JUNIOR, A.F.; COIMBRA, L.C.; SILVA, R.A. Avaliação da qualidade dos dados do Sistema de Informações sobre Nascidos Vivos em 1997-1998. Revista de Saúde Pública, v. 35, n. 6, 2001b. Disponível em:<http:/www.bireme.br/scielo.php.>. Acesso em: 12 jun. 2002.

SOBRAL, H.R. Air pollution and respiratory diseases in São Paulo, Brazil. Society. Science Medicine, v. 29, n. 8, p. 959-964, 1989.

SOBRAL, H.R. A qualidade do ar em São Paulo. In: cidade de São Paulo. 1ª ed. São Paulo: Makron Books, 1996. p. 13-31.

SPEKTOR, D.M. Effects of heavy industrial pollution on respiratory function in the children of Cubatão, Brazil: a preliminary report. Environmental Health Perspective, v. 94, n. 1, p. 51-54, 1991.

SPOSATI , A.O.; KOGA,D.; CÂMARA, G.; NAKANO, K. O que é o mapa de exclusão/inclusão social. In: SPOSATI, A.O. Mapa de exclusão/inclusão social da cidade de São Paulo. São Paulo: EDUC, 2000. p. 7-10. 1 CD-ROM.

SPSS FOR WINDOWS, RELEASE 6.0. SPSS Inc. Chicago, IL. 1993.

SRAM, R.J.; BENES, I.; BINCOVÁ, B.; DEJMEK, J.; HORSTMAN, D.; KOTESOVEC, F.; OTTO, D.; PERREAULT, S.D.; RUBES, J.; SELEVAN, S.G.; SKALIK, I.; STEVENS, R.K.; LEWTAS, J. Teplice Program - the impact of air pollution on human health. Environmental Health Perspectives, v. 104, supl. 4, p. 699-714, 1996.

STATACORP. Statistical software: release 6.0. College station. Tx Stata Corporation, 1999.

VERCELLINI, P. et al. Pregnancy of fourty and over: a case-control study. Europe Journal Obstetric Gynecology Reprodution Biology, v. 48, p. 191-5, 1993.

VICTORA, C.G.; BARROS, F.C.; HUTTLY, S.R.A.; TEIXEIRA, A.M.B.; VAUGHAN, J.P. Early childhood mortality in a Brazilian Cohort: the roles of birth weight and socioeconomic status. International Journal Epidemiology, v. 21, n. 5, p. 911-915, 1992.

VICTORA, C.G. Intervenções para reduzir a mortalidade infantil pré-escolar e materna no Brasil. Revista Brasileira de Epidemiologia, v. 4, n. 1, p. 3-37, 2001. 
VORHERR, H. Factors influencing fetal growth. American Journal of Obstetric Gynecology, v. 142, n. 1, p.577-588, 1982.

WANG, X.; DING, H.; RYAN, L.; XU, X. Association between air pollution and low birth weight: a community- based study. Environmental Health Perspectives, v. 105, n. 5, p. 514-520, 1997.

WERNECK, G.L.; ALMEIDA L.M. Validade em estudos epidemiológicos. In: MEDRONHO, R.A.; CARVALHO, D.M.; BLOCH, K.V.; LUIZ, R.R.; WERNECK, G.L. Epidemiologia. São Paulo: Atheneu, 2002, p. 199-212.

WHO-WORLD HEALTH ORGANIZATION. Air quality guidelines/standards.AMIS Version 1.0., 1997.

WOODRUFF, T.J.; GRILLO, J.; SCHOENDORF, K.C. The relationship between selected causes of postneonatal infant mortality and particulate air pollution in the United States. Environmental Health Perspectives, v. 105, n. 6, p. 608-612, 1997.

YANG, C.Y.; TSENG, Y.T.; CHANG, C.C. Effects of air pollution on birth weight among children born between 1995 and 1997 in Kaohsiung, Taiwan. Journal of Toxicology Environmental Health, v. 66, n.9, p. 807-816, 2003. 


\section{BIBLIOGRAFIA CONSULTADA}

ACKERMAN, M.; STEPHENS, C.; CAMPANARIO, P.; MAIA, P.B. Saúde e meio ambiente: uma análise de diferenciais intra-urbanos enfocando o município de São Paulo, Brasil. Revista de Saúde Pública, v. 28, n. 4, p. 320-325, 1994.

ANDRÉ, P.A.; BRAGA, A.L.F.; LIN, C.A.; CONCEIÇÃO, G.M.S.; PEREIRA, L.A.A.; MIRAGLIA, S.G.E.K.; BÖHM, G.M. Environmental epidemiology applied to urban atmospheric pollution: a contribution from the experimental air pollution laboratory. Cadernos de Saúde Pública, v.16, n. 3, 2000. Disponível em: http://www.bireme.br.scielo.php. Acesso em: 27 ago. 2001.

BENICIO, M.H.D.A.; MONTEIRO, C.A.; SOUZA, J.M.P.; CASTILHO, E.A.;LAMONICA, I.M.R. Análise multivariada de fatores de risco para o baixo peso ao nascer em nascidos vivos do município de São Paulo, SP ( Brasil ). Revista de Saúde Pública, v. 19, n. 1, p. 311-320, 1985.

BOBAK, M.; RICHARDS, M.; WADSWORH. Air pollution and birth weight in Britain in 1946. Epidemiology, v. 16, n. 3, p. 358-359, 2001.

CARRARA, W.; ZUGAIB, M. Parto prematuro: fatores predisponentes e prevenção. In: Marcondes, E., 8 a ed. Pediatria básica. São Paulo, Sarvier, 1999. p. 329-331.

CECATTI, J.G.; MACHADO, M.R.M.; SANTOS, F.F.A.; MARUSSI, E.F. Curva dos valores normais de peso fetal estimado por ultra-sonografia segundo a idade gestacional. Cadernos de Saúde Pública, v. 16, n. 4, p. 1083-1090, 2000.

DESHMUKH, J.S.; MOTGHARE, D.D.; ZODPEY, S.P.; WADHVA, S.K. Low birth weight and associated maternal factors in an urban area. Indian Pediatrics, v.35., n. 1, p. 33-36, 1998.

DOLK, H.; PATTEDEN, S.; VRIJHEID, M.; THAKRAR, B.; ARMSTRONG, B. Perinatal and infant mortality and low birth weight among residents near cokeworks in Great Britain. Archives of Environmental Health, v. 55, n. 1, p. 1-8, 2000.

DUARTE MCR. Qualidade de vida e indicadores de saúde: aspectos da mortalidade infantil no Estado do Rio de Janeiro e suas regiões. Cadernos de Saúde Pública, v. 8, n. 4, p. 414-427, 1992.

DUCHIADE, M.P. Poluição do ar e doenças respiratórias: uma revisão.Cadernos de Saúde Pública, v. 8, n. 3, p. 311-330, 1992. 
*************ERICSON, A.; ERIKSSON, M.; KÄLLÉN, B.; MEIRIK, O. Birth weight distribution as an indicator of environmental effects on fetal development. Scand J Soc Med, v.15, n. 1, p. 11-17, 1987.

FERRAZ, E.M.; GRAY, R.H.; CUNHA, T.M. Determinants of preterm delivery and intrauterine growth retardation in north-east Brazil. International Journal of Epidemiology, v. 19, n. 1,p. 101-108, 1990.

GOUVEIA, N.C. Air pollution and health effects in São Paulo, Brazil: a time series analysis. London, 1997. 238p. Tese (Doutorado) - London School of Hygiene and Tropical Medicine.

HICKEY, R.J.; CLELLAND, R.C.; HARNER, E. B. Smoking, birth-weight, development, and pollution [Letter]. The Lancet, 1973.

JORGE, M.H.P.M.; GOTLIEB, S.L.D.; OLIVEIRA, H. O Sistema de Informações sobre Nascidos Vivos: primeira avaliação dos dados brasileiros. Informe Epidemiológico do SUS, v. 2, n. 1, p. 15-48, 1996.

JURETIC, A.A.; FRKOVIC, A.; SIMIC, D. The effect of air pollution on the outcome of pregnancies. International Journal of Gynecology \& Obstetrics, v.75, n. 1, p. 315- 316, 2001.

KALLAN, J.E. Race, intervening variables, and two components of low birth weight. Demography, v. 30, n. 3, p. 489-506, 1993.

MONGELLI, M.; BISWAS, A. A fetal growth Standard derived from multiple modalities. Early Human Development, v. 60, p. 171-177, 2001.

PEITER, P.; TOBAR, C. Poluição do ar e condições de vida: uma análise geográfica de riscos à saúde em Volta Redonda, Rio de Janeiro, Brasil. Cadernos de Saúde Pública, v.14, n. 3, p. 473-485, 1998.

PERERA, F.P.; JEDRYCHOWSKI, W.; RAUH, V.; WHYATT, R.M. Molecular epidemiologic research on the effects of environmental pollutants on the fetus. Environmental Health Perspectives, v. 107, supl. 3, p. 451-460, 1999.

RAMOS, J.L.A.; CALIL, V.M.T.; QUINTAL, V.S. O recém-nascido pequeno para idade gestacional. In: Marcondes, E., $8^{a}$ ed. Pediatria básica. São Paulo, Sarvier, 1999. p.339-344.

RAMOS, J.L.A.; CORRADINI, H.B.;VAZ, F.A.C. Classificação do recém-nascido diagnóstico da idade gestacional e da qualidade do crescimento. In: Marcondes E., 8ª ed. Pediatria básica. São Paulo, Sarvier, 1999. p. 321-328. 
RAMOS, J.L.A.; CORRADINI, H.B.; NEME, B.; CALIL, V.M.T. Malformações. In: Marcondes E., 8ª ed. Pediatria básica. São Paulo, Sarvier, 1999. p. 329-331.

RAMOS, J.L.A. Pediatria neonatal: âmbito e finalidades. In: Marcondes E., $8^{\mathrm{a}}$ ed. Pediatria básica. São Paulo, Sarvier, 1999. p. 253.

RAMOS, J.L.A.; BITTAR, R.E.; LEONE, C.R. Crescimento fetal. In: Marcondes, E., $8^{a}$ ed. Pediatria básica. São Paulo, Sarvier, 1999. p. 262-267.

RITZ, B.; YU, F.; CHAPA, G.; FRUIN, S. Effect of air on preterm birth among children born in southern California between 1989 and 1993. Epidemiology, v. 11, n. 5, p. 502-511, 2000.

RITZ, B.; YU, FEI; FRUIN, S.; CHAPA, G.; SHAW, G.M.; HARRIS, J.A. Ambient air pollution and risk of birth defects in southern California. American Journal of Epidemiology, v. 155, n. 1, p. 17-25, 2002.

ROGERS, J.F.; THOMPSON, S.J.; ADDY, C.L.; MCKEOWN, R.E.; COWEN, D.J.; DECOUFLÉ, P. Association of very low birth weight with exposures to environmental sulfur dioxide and total suspended particulates. American Journal of Epidemiology, v. 151, n. 6, p. 602-613, 2000.

RUMMEL, D. et al. Infarto do miocárdio e acidente vascular cerebral associados à alta temperatura e monóxido de carbono em área metropolitana do sudeste do Brasil. Revista de Saúde Pública, v.27, n.1, p.15-22, 1993.

SADECK, L.S.R; BARROS, J.C.R.; RAMOS, J.L. Variação secular do peso de recém-nascidos do hospital das clínicas de São Paulo em quatro períodos nos últimos 50 anos. Pediatria (São Paulo), v. 22, n. 1, p. 14-20, 2000.

SPINILLO, A.; CAPUZZO, E.; IASCI, A.; INCOLA, S.; PIAZZI, G.; BALTARO, F. Sociodemographic and clinical variables modifying the smoking-related risk of low birth weight. International Journal of Gynecology \& Obstetrics, v. 51, n. 1, p. 1523, 1995.

VICTORA, C.G.; HUTTLY, S.R.; FUCHS, S.C.; OLINTO, M.T.A. The role of conceptual frameworks in epidemiological analysis: a hierarchical approach. International Journal of Epidemiology, v. 26, n. 1, p. 224-227, 1997.

WILCOX, A.J. On the importance-and the unimportance-of birthweight. International Journal of Epidemiology, v. 30, n. 1, p. 1233-1241, 2001. 
WILLIAMS, R.L.; CREASY, R.K.; CUNNINGHAM, G.C.; HAWES, W.E.; NORRIS, F.D.; TASHIRO, M. Fetal growth and perinatal viability in California. Obstetrics \& Gynecology, v. 59, n. 5, p. 624-632, 1982. 